Institut sur la retraite et l'épargne HEC MONTRËAL

\title{
The Impact of Social Security on Pension Claiming and Retirement: \\ Active vs. Passive Decisions
}

\section{CAHER DE RECHERCHE No 4 WORKING PAPER No. 4}

Rafael Lalive, Arvind Magesan and Stefan Staubli

Août / August 2020

Retirement and Savings Institute 
Les opinions et analyses contenues dans les cahiers de recherche de l'Institut ne peuvent en aucun cas être attribuées aux partenaires ni à l'Institut lui-même et elles n'engagent que leurs auteurs.

Opinions and analyses contained in the Institute's working papers cannot be attributed to the Institute or its partners and are the sole responsibility of the authors.

(C2020 Rafael Lalive. Arvind Magesan and Stefan Staubli. Tous droits réservés. All rights reserved.

Reproduction partielle permise avec citation du document source, incluant la notice $\odot$. Short sections may be quoted without explicit permission, if full credit, including $\odot$ notice, is given to the source. 


\title{
The Impact of Social Security on Pension Claiming and Retirement: Active vs. Passive Decisions*
}

\author{
Rafael Lalive, University of Lausanne \\ Arvind Magesan, University of Calgary \\ Stefan Staubli, University of Calgary
}

August 2020

\begin{abstract}
We exploit a unique Swiss reform to identify the importance of passivity, claiming social security benefits at the Full Retirement Age (FRA). Sharp discontinuities generated by the reform reveal that raising the FRA while imposing small early claiming penalties significantly delays pension claiming and retirement, but imposing large penalties and holding the FRA fixed does not. The nature of the reform allows us to identify that between 47 and $69 \%$ of individuals are passive, while imposing additional structure point identifies the fraction at $67 \%$. An original survey of Swiss pensioners reveals that reference-dependent preferences is the main source of passivity.
\end{abstract}

Keywords: Full retirement age, social security, regression discontinuity design, reference dependence. JEL Classification: H55, J21, J26

${ }^{*}$ Rafael Lalive, University of Lausanne, CH-1015 Lausanne-Dorigny, Rafael.Lalive@unil.ch. Lalive is also affiliated with CEPR, CESifo, IFAU, and IZA. Arvind Magesan, University of Calgary, Calgary, AB, T2N 1N4, arvindmagesan@gmail.com. Stefan Staubli, University of Calgary, Calgary, AB, T2N 1N4, sstaubli@ucalgary.ca. Staubli is also affiliated with CEPR, IZA, NBER, and Retirement and Savings Institute at HEC Montréal. We thank Paul Beaudry, Mark Bils, Pierre Cahuc, David Card, Jonathan Cribb, Eric French, Alex Gelber, Nathaniel Hendren, Sacha Kapoor, Lawrence Katz, Mashfiqur Khan, Henrik Kleven, Patrick Kline, Alan Manning, Nicole Maestas, Lucija Muehlenbachs, Emmanuel Saez, Gustavo Ventura, Kent Weaver, Basit Zafar, Josef Zweimüller, and seminar and conference audiences at London School of Economics, Institute for Fiscal Studies, UC Berkeley, University of Michigan, UQAM, University of Zurich, University of Lugano, Erasmus University, Vanderbilt University, VATT, Arizona State University, American Economic Association, European Economic Association, the SOLE/EALE joint meeting, the Paris-London Public Economics Conference, and the Economic Day at Rennes for helpful comments and suggestions. This research was supported in part by funding from the Social Sciences and Humanities Research Council in Canada and the U.S. Social Security Administration through grant \#RRC08098400-09 to the National Bureau of Economic Research as part of the SSA Retirement Research Consortium. The findings and conclusions expressed are solely those of the authors and do not represent the views of SSA, any agency of the Federal Government, or the NBER. We thank the Swiss Federal Social Insurance Office for supporting data access. Rafael Lalive thanks the UC Berkeley Center for Labor Economics for its hospitality while writing substantial parts of this paper. All remaining errors are our own. 


\section{Introduction}

Financial incentives, while potentially powerful, are often limited in their ability to shape behavior in important policy environments. Individual behavior is often guided by one of a number of possible behavioral biases that prevent individuals from behaving in the way that standard models of economic behavior would predict ${ }^{1}$ While the presence of behavioral bias has been documented in settings ranging from saving for retirement to buying health insurance, quantifying and characterizing the nature of the bias is a more difficult task. And yet, without this knowledge, policymakers can not be expected to choose the appropriate policy.

In this paper, we identify, quantify, and study the source of behavioral bias in the decision to claim social security benefits and to exit the labor market. Social security is an urgent policy issue in most advanced economies. Between 1970 and 2020 the average life expectancy at age 65 increased by about six years in OECD countries, while the average retirement age declined by about three years ( OECD, 2019). These trends put enormous financial pressure on social security systems, as individuals contribute to pensions for fewer years and receive pension benefits for more years than they ever have. A common policy response has been to increase the Full Retirement Age (FRA) - the earliest age at which an individual can draw a full pension - while penalizing early claiming. The logic is simple. Individuals who comply with the new FRA will contribute for more years and draw benefits for fewer years, while those who claim early receive lower benefits than they would have before the policy change.

Evidence is mounting that people do not claim a pension when a standard life cycle model would predict. In the U.S., people claim their pension at the FRA and this "spike" in pension claiming moves in lock-step with increases in the FRA (Behaghel and Blau, 2012). In Germany, people retire from working much more often at statutory retirement ages, e.g. the FRA, than what financial incentives would predict (Seibold, 2019). But pension claiming and retirement are often linked through institutional rules, e.g. the earnings test (for all claiming decisions in Germany, and claiming before the FRA in the US), so it remains a challenge to identify which decision, to claim a pension, or to retire from work, or both, is driven by behavioral biases. While the empirical spike in pension claiming at the FRA is well documented and appears to be a general phenomenon, the reasons for the spike, and whether it is a behavioral feature of older workers in general, or only of a fraction thereof, remains poorly understood.

Our venue is a unique and major reform to the female old age survivor's insurance (OASI) in Switzerland. The reform first increased the FRA in two steps, from 62 to 63 years for women born on or after January 1, 1939, and from 63 to 64 years for women born on or after January 1, 1942. Initially, the penalty for early claiming was $3.4 \%$ of benefits per year of claiming prior to the FRA. Under this regime, early claiming is actuarially attractive for the average woman; the discounted expected social security wealth when claiming early is larger than that when claiming at the FRA, while the reduction in social security wealth due to the FRA increase creates an incentive to work longer. The final step of the reform increased the penalty for early claiming to $6.8 \%$ for women born on or after January 1, 1948, which is a more than actuarially fair increase.

Several features of our setting are useful from a research design standpoint. First, the reform generates

\footnotetext{
${ }^{1}$ Beginning with Madrian and Shea (2001), a large literature has found empirical evidence of behavioral responses to policy changes that do not conform to the standard model of economic behavior in a wide range of settings. See Bernheim and Taubinsky (2018) for a detailed discussion.
} 
sharp discontinuities in the FRA and in the penalties for early claiming, allowing for the application of a credible Regression Discontinuity (RD) research design. Second, the first two stages of the reform increased the FRA and made early claiming economically attractive, while the final stage held the FRA fixed and made early claiming economically unattractive. Contrasting the various stages of the reform affords us an opportunity to study the degree to which financial incentives shape behavior relative to behavioral bias. Third, in the Swiss setting, pension claiming and retirement are not mechanically linked, as there is no universal mandatory retirement from work, and there is no earnings test, so that individuals are able to claim and continue working or retire early and not claim benefits 2 Generally, changes to social security benefits affect wealth but do not change the incentive to work over and above the disincentive effects through the tax system. As such, we can cleanly disentangle the effect of the reform on pension claiming and retirement behavior.

Using comprehensive administrative data and exploiting the sharp cutoffs generated by the reform, we find that increasing the FRA and offering early claiming at a low penalty of $3.4 \%$ delays pension claiming by 7-8 months, even though the average individual would receive higher lifetime social security wealth by claiming early. The mechanical reduction in social security wealth generated by these reform stages delays labor market exit by 5-7 months. In contrast, we find that increasing the penalty for early claiming to $6.8 \%$ and holding the FRA fixed delays pension claiming by about 4 months and has no effects on labor market exit.

Since benefit claiming and retirement are not mechanically linked in Switzerland, we can use our RD strategy to identify the income effect of social security benefits on lifetime employment earnings; a critical estimate when evaluating many public policies including changes to social security. The identification of the income effect from pension wealth shocks has been challenging, because in other countries pension benefit claiming is tied to retirement, limiting individuals' ability to respond to pension wealth shocks by continuing to work after claiming or delaying claiming after retirement 3 We find that individuals replace a substantial amount of lost pension wealth through labor supply: a 1 Swiss Franc decrease in pension wealth increases lifetime earnings by 39 to 57 cents. This estimate is significantly larger than the estimates reported in Cesarini et al. (2017) and Imbens et al. (2001) who study the impact of wealth on labor supply among lottery winners, and similar to results in Gelber et al. (2016) who study the effects of pension wealth shocks.

The effect of the reform on retirement can be rationalized in a standard life-cycle model of labor supply. Increases in the FRA reduce lifetime wealth; women adapt to this negative wealth shock by working longer. We find extensions of labor supply for all groups of women including women who are self-employed, suggesting that labor supply considerations dominate labor demand considerations. In contrast, the effect of the reform on pension claiming is difficult to rationalize with any standard model of behavior. The standard assumptions on economic behavior - fully rational forward-looking expected utility maximization - would dictate that individuals simply claim benefits at the age that maximizes discounted expected pension wealth. Yet, we observe large spikes in claiming at the FRA, which shift as the FRA is increased, even though early claiming is the wealth-maximizing choice for the average woman.

\footnotetext{
${ }^{2}$ Some sectors are covered by collective agreements that specify that contracts end at the FRA leading to unusually high rates of labor market exit. We explore labor market exit decisions of self-employed women, who are not covered by collective agreements, and find their labor market exit patterns are similar to other women's exit patters.

${ }^{3}$ For example, Gelber et al. (2016) study the effect of shocks to pension income on elderly earnings in the US, but in the US in the period of their study there is an earnings test which would disincentivize working after claiming benefits.
} 
These empirical patterns suggest that a substantial fraction of the population simply claims their pension at the nominal age prescribed by the government. Following Chetty et al. (2014), we label these individuals as passive decision makers, and set out to quantify the fraction of the population that is passive using two complementary strategies. The first strategy places no additional structure on the problem and simply assumes that passive decision makers always claim at the FRA, while active decision makers respond to economic incentives. We exploit the different stages of the reform to identify and estimate bounds on the fraction of the population that is passive. Our strategy is simple. Compliance with a stage of the reform is informative about the individual's type. For example, an individual who claims early in response to an increase in the FRA with a small penalty for early claiming cannot be "passive," because being passive means claiming at the FRA regardless of the financial implications. Similarly, an individual who delays claiming in response to an increase in the financial penalty for early claiming without changing the FRA also cannot be passive. The compliance rates with a stage of the reform are identified under mild assumptions and we estimate the bounds on the fraction of passive individuals as $[0.463,0.691]^{4}$

The second strategy imposes structure on the problem and assumes that active decision makers choose their claiming age in a way that maximizes lifetime discounted expected wealth 5 With this assumption we can point identify the fraction of passive individuals, because all determinants of pension benefits associated with each possible claiming age are observable in the data. The maximum likelihood estimate of the fraction of passive decision makers is 0.67 , which lies inside the estimate of our non-parametric bounds, so that we cannot reject the possibility that our simple structural model generates the data we observe. We simulate claiming hazards using this point estimate and show that we can nearly perfectly replicate the empirical claiming hazards, while a model with only active decision makers cannot.

While knowing the fraction of population that is passive is useful for policymakers, governments that maximize social welfare would also want to know the reason why individuals are passive. Clearly passive decision makers leave money on the table by not claiming at the wealth maximizing age. To the extent that governments wish to correct this behavior, knowing the source of bias is of first-order importance. If, for example, the reason is that passive individuals lack knowledge or understanding about their options, then information campaigns, as in Liebman and Luttmer (2015) may be the solution 6 Alternatively, the hassle cost to claim the pension at an age other the nominal FRA may be too large, or individuals could have reference-dependent preferences with loss aversion, because early claiming is framed as a benefit loss (Behaghel and Blau, 2012, Seibold, 2019), 7

To uncover the source of bias, we conducted an original survey of 1,223 Swiss women between ages 60-65 using a representative internet panel of the Swiss population 8 Individuals were asked what they knew about their options, how they gathered information for the decision, and how they made the decision about when to claim. Few women cited a lack of information or knowledge about their options as an

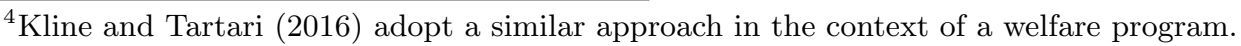

${ }^{5}$ As long as there is no bequest motive and individuals are not liquidity constrained, maximizing lifetime wealth and maximizing lifetime utility lead to the same decision rule.

Chan and Stevens (1994) also study the role of misinformation and misunderstanding in generating non-response to pension incentives in the context of employer-provided pensions rather than social security.

${ }^{7}$ In Switzerland, individuals who want to claim pensions before the FRA must submit an application to the local OASI office before reaching the early claiming age. Individuals who want to claim after the FRA must submit a deferral declaration to their local OASI agency within a year after reaching the FRA.

${ }^{8}$ OASI claims cannot be made before 62 and most women in the population have claimed by 65 . Our survey respondents will thus be a mix of those who have claimed and those who have not, but all are in the age range where they would be thinking about the claiming decision.
} 
important factor. In fact, most women do seek information, whether from a financial advisor or from friends and family. The hassle associated with claiming at an age other than the FRA was not cited as an important factor either. Rather, the most important reasons were that it "seems natural to start my OASI pension" at the individual's claiming age and "I wanted to avoid getting a reduced OASI pension" by claiming early. These answers point to reference dependence together with loss aversion as the dominant reason that many individuals do not claim at the age that maximizes lifetime wealth. This finding implies that the way the benefit schedule is framed is a key dimension of choice for governments.

Finally, we study how much money is being left on the table by passive decision-makers as well as the consequences for the government budget. We tackle these questions by separating the direct, mechanical effect from the behavioral effect of each stage of the reform on individual pension wealth and income. The mechanical effect captures the change in pension wealth from lowering pension benefits, holding the claiming age fixed. The behavioral effect captures the change in pension wealth and income from adjusting behavior to mitigate the mechanical pension wealth loss. We find that the behavioral effect for the increases the FRA with low early claiming penalties is negative, exacerbating the loss in pension wealth, consistent with mostly passive decision makers responding to these stages of the reform. Individuals do mitigate some of the lost income by working longer and earning more labor income. The stages of the reform that increased the FRA also generate most of the fiscal savings: A one Swiss franc cut in OASI benefits increases public funds by 1.6-2.16 Swiss Francs. On the other hand, the increase in public funds from the stage of the reform that increased the price of early claiming is about 2-3 times smaller. Passive behavior is the source of much government savings and individual wealth loss. Our results illustrate, that with a sizeable share of passive decision makers, FRA increases can generate substantial savings without steep penalties for early claiming, but they are extra costly for passive decision makers.

Our paper builds on a large literature on the effects of social security programs on labor supply and benefit claiming (for reviews, see Lumsdaine and Mitchell, 1999, Feldstein and Liebman, 2002, Coile, 2015, Blundell et al., 2016, and Böersch-Supan et al., 2016). Our paper is related to the branch of the literature estimating the effect of changes in the early or full retirement age (Baker and Benjamin, 1999 Mastrobuoni, 2009 Staubli and Zweimüller, 2013 Cribb et al., 2016; and Deshpande et al., 2020). In this literature, Hanel and Riphahn (2012) study the first two steps of the Swiss 1997 reform using survey data and find that an increase in the FRA by one year delayed labor force exit by half as much. Our paper is also related to a branch of the literature that studies the retirement effects of financial incentives associated with changes in old age benefits (Krueger and Pischke, 1992; Gruber and Wise, 1999, French, 2005, Coile and Gruber, 2007; Liebman et al., 2009; Manoli and Weber, 2016; Gelber et al., 2016; and Fetter and Lockwood, 2018). Most closely related are recent studies that have attempted to rationalize the retirement and claiming effects using non-standard models of economic behavior. In the case of retirement, Seibold (2019) shows that bunching of job exits at statutory retirement ages in Germany is in excess of what can be explained by financial incentives. In the case of benefit claiming, Behaghel and Blau (2012) find that in the US the spike in the claiming hazard at the FRA moves with an increase in the FRA in a way that is hard to explain with a standard model of behavior. Gruber et al. (2020) find that simply "relabeling" a statutory retirement age affects claiming behavior in Finland, and those who claim at relabeled ages display "regret", they are more likely to return to work.

This paper makes three important contributions relative to the earlier literature. A first key contribu- 
tion is that in our setting benefit claiming and retirement are not tied together institutionally. This feature allows us to separately identify the effects of social security programs on benefit claiming and retirement using the sharp discontinuities generated by the reform. It also offers an opportunity to estimate the income effect of social security benefits on labor supply, an important parameter for policy and understanding work patterns among the elderly. The existing literature has studied settings in which claiming and retirement are tied together through an earnings test, making it difficult to disentangle the effect on pension claiming from the effect on retirement.

A second key contribution of this paper is to quantify the subpopulation of passive decisions makers by using a variety of empirical designs and transparent and independent variation in the FRA and financial incentives. Chetty et al. (2014) estimate how many individuals are passive when saving for retirement by studying two policies to raise saving: price subsidies and automatic contributions. Because interior optima with respect to a continuous choice variable (retirement savings, portfolio allocation) should move in response to a price change, they are able to estimate the fraction of passive decision makers by counting the number of non-responders. The choice variable in our setting (to claim early or not) is discrete, which requires us to develop a new approach that delivers bounds around the share of the population that is passive. We also show that with minimal structure we can point identify and estimate the fraction of passive decision makers.

A third key contribution is that we provide evidence that the underlying reason for passivity is about preferences and not a lack of knowledge or understanding of social security. Behaghel and Blau (2012) and Seibold (2019) posit that reference dependence with loss aversion is the reason for why some people are not optimizing and they provide indirect evidence consistent with this explanation. Our original survey allows us to rule alternative explanations and confirm that the most important reason for passivity in benefit claiming is reference-dependent preferences with loss aversion.

The outline of the paper is as follows. We next discuss the institutional background and data. Section 3 provides a conceptual framework for claiming and retirement. Section 4 discusses the RD strategy and presents the main results. Section 5 describes our strategy for identifying bounds around the proportion of the population that is passive, presents estimates of the bounds, and then point identifies the fraction of passives using a simple dynamic discrete choice model of benefits claiming. Section 6 presents the results of our survey of Swiss pensioners and discusses policy implications. Section 7 concludes.

\section{Institutional Background and Data}

\subsection{Pension Wealth and Work}

The Swiss OASI pays a full pension to anyone claiming at the full retirement age (FRA); 62 years of age for women (before 2001) and 65 years of age for men. Men and women contribute to OASI by paying payroll taxes of $8.4 \%$ on their wage or unemployment benefits. Full contribution to OASI means paying into the system for each year between age 20 and the FRA. Pensions are reduced by $2.3 \%$ per missing contribution year 9

\footnotetext{
${ }^{9}$ Students, individuals receiving disability benefits, and other non-employed individuals pay means-tested non-employment contributions to maintain a continuous contribution history. These contributions range from less than 500 Swiss Francs or CHF (CHF $1=$ USD $1.07=0.83$ EUR) for individuals with wealth below 300,000 CHF to 24,000 CHF for individuals with wealth at 8,4 Million $\mathrm{CHF}$ or higher.
} 
Individuals with a full contribution history receive a pension whose level depends on average indexed (annual) earnings (AIE) ${ }^{10}$ Individuals with AIE of 14,100 CHF, or lower, receive the minimum pension of $14,100 \mathrm{CHF}$, so the replacement rate for these individuals is $100 \%$ or higher. Individuals with AIE of $84,600 \mathrm{CHF}$, or higher, receive an annual pension of $28,200 \mathrm{CHF}$, so the replacement rate is $34 \%$ at the maximum pension. On average, OASI benefits replace about $30 \%$ of pre-retirement earnings and are indexed to the average of price and wage inflation, with adjustments taking place every other year.

Individuals who claim the OASI pension later than the FRA earn an actuarially fair increase in their pension. For instance, a woman who delays claiming benefits by one year receives a $5.2 \%$ higher pension than at the FRA, not capped at the regular maximum of 28,200 CHF. Delaying and claiming after the FRA is an active decision: Individuals must submit a deferral declaration to their local OASI agency within a year after reaching the FRA. Individuals who do not submit a deferral declaration receive the same benefits as they would have if they had claimed at the FRA. Individuals who work beyond the FRA, independent of whether they have claimed a pension or not, continue to pay payroll taxes on any job with income that exceeds 1,400 CHF per month. These additional contributions do not increase their pension level. Prior to 2001 there was no early retirement age, so claiming before the FRA was not an option.

Married spouses are assessed as individuals until both spouses claim benefits. Couples are eligible for a joint pension that is equal to $150 \%$ of the husband's pension. A claiming husband whose wife is 55 years or older but has not started claiming yet, receives a supplementary pension of $30 \%$ of his individual OASI pension.

Individuals have access to two additional sources of pension wealth. The first is an employer provided occupational benefit plan to guarantee the accustomed (pre-retirement) standards of living. Occupational benefits can differ enormously, as the government only regulates minimum contributions and payouts. Contributions are mandatory for annual earnings that exceed about CHF 20,000. Occupational pension plans specify a full retirement age that need not be the same as the FRA associated with OASI. Individuals who reach the occupational pension FRA can either receive an annuity, withdraw a lump-sum amount, or receive a mix of these two. The majority of retired individuals choose the annuity, even though the first pillar already provides an annuity in old age (Bütler and Teppa, 2007). Occupational pensions can be withdrawn as early as age 58 years, with actuarially fair adjustment. Late claiming is also possible if the pension plan allows it. The net replacement rate of the occupational pension is about $40 \%$ for the average earner, but less than that for women 11 Occupational pension plans are highly fragmented: 2,543 pension funds operated in 2007, offering different plans with respect to claiming and payout options. The second additional source of pension wealth consists of tax deferred savings accounts, or life insurance policies, to supplement the state pension with sufficient means to ensure comfortable retirement. The contribution rate is decided individually. Contributions to the third pillar are deducted from taxable income. Wealth in tax deferred savings accounts is taxed, albeit at a reduced rate.

OASI programs in other countries often embed strong disincentives from working an extra year, through small or no adjustments of benefits for delays in claiming. At the extreme, in some systems, retiring from work and claiming are mechanically joint decisions. In Switzerland claiming and retiring from work are

\footnotetext{
${ }^{10}$ Average earnings are supplemented for parents who have taken care of children below age 16, or individuals who provide for relatives in need of care. Supplements are equivalent to three times the minimal pension.

${ }^{11}$ About $83 \%$ of working women are covered by an occupational pension scheme, but since they often work part-time, their occupational pension is much lower than men's. Occupational pensions accounted for $41 \%$ of men's retirement income, but only $19 \%$ of women's, and women's occupational pensions were $63 \%$ lower than men's (Fluder and Salzgeber (2016)).
} 
separate decisions, and the Swiss OASI offers actuarial adjustment for delays in claiming. Switzerland also has no mandatory retirement at the FRA (Senti, 2011). Workers who wish to leave the labor force upon reaching the FRA have to quit their job by formally informing the employer of their decision. Workers covered by collective agreements or public sector employees may have contracts that terminate automatically upon reaching the FRA, but these contracts can be renewed. Continuing work beyond the FRA is often financially attractive as contributions to company pension plans are no longer mandatory ${ }^{12}$ However, many employment relationships are implicitly understood to end at the FRA, and employment protection legislation weakens at the FRA. Considering that workers have access to a pension after the FRA, the Swiss Supreme Court has ruled that dismissal was just in situations that would have been deemed unjust for a worker younger than the FRA.

Unemployment insurance (UI) and disability insurance (DI) are income support programs that can serve to finance hidden forms of early retirement. Though UI is more generous to individuals who are two years from the FRA, it is no easier to qualify for older workers than it is for younger ones. DI pays higher benefits than UI, though the requirements for receiving DI benefits are more stringent. Time on both UI and DI counts towards the contribution requirement for receiving a full OASI pension.

\subsection{The 1997 FRA Reform}

The Swiss government enacted a major reform of OASI to take effect as of January 1, 1997. The most important element of this reform was an increase in the FRA for women from age 62 to age 64, affecting all women born on January 1, 1939 or after (first row of Table 1). The increase occurred in two main stages. The FRA was increased to age 63 for women born between 1939 and 1941 and to age 64 for women born in 1942 or later.

Table 1

The second major element of the reform was the introduction of early claiming (second row of Table 1 ). Women born January 1, 1939 or after could still claim benefits as early as age 62 subject to an adjustment of $3.4 \%$ of full benefits for each year of claiming prior to the FRA. The price per year of early claiming doubled, from $3.4 \%$ to $6.8 \%$, for women born on January 1, 1948 or after. Women who wanted to claim pensions early had to submit an application to the local OASI office in advance, at least one day ahead of their early retirement birthday. Early claimers continue to contribute to the system until the FRA, either through the OASI tax, if working, or through a tax on their pension income, if not working.

Figure 1(a) shows the pension adjustment factor (PAF) for early and late claiming, while Figure 1 (b) shows the corresponding social security wealth (SSW) for a woman with average life expectancy and a discount rate of $2 \%$ (implying a discount factor of 0.98) ${ }^{13}$ The blue circles show the PAF and SSW for women born in 1938, the last cohort unaffected by the reform, who we label as the FRA62 cohort. Women in this cohort could not claim an old age pension before age 62 . Women who started claiming an old age

\footnotetext{
${ }^{12}$ Workers who continue to work beyond the FRA pay contributions to OASI on all income above 1,400 CHF. Pension levels are not adjusted for work after the FRA - there is no accrual beyond the FRA - so the OASI contributions become taxes.

${ }^{13}$ In our data, we observe empirical survival rates until age 76 . Between age 77 and age 86, we predict survival rates using a Gompertz extrapolation, based on a regression of log mortality on a linear trend in age (Chetty et al., 2016). Beyond age 87, we predict survival rates using mortality rates from the Swiss Federal Statistical Office. Appendix A.1 shows that our survival rates closely align with official survival rates from the Federal Statistical Office.
} 
pension at age 62 received the full pension amount; their PAF was at 100\%. Women who delayed claiming by one year to age 63 were entitled to a pension that was $5.2 \%$ higher than the full pension. The PAF increased further for every year of delay beyond age 63. The SSW is roughly constant for the FRA62 cohort, reflecting the actuarial fairness of the pension adjustments associated with each claiming age.

\section{Figure 1}

The reform affected the PAF and SSW in three stages. The blue diamonds show the PAF and SSW for women born 1939 to 1941. We label this cohort the FRA63 cohort. For this cohort, age 62 became an early retirement age. Women could claim benefits at 62 , but their pension would be cut by $3.4 \%$. Delaying to the new FRA of 63 would mean eligibility for a full pension, with actuarially fair adjustments to pensions for those claiming later than the FRA. We see that cohort FRA63 experiences a negative SSW shock relative to FRA62, and it is actuarially advantages for women in cohort FRA63 to claim early, as the SSW is higher for those who do so.

The red triangles show the PAF and SSW for women born between 1942 and 1947, who we label as the FRA64 cohort. As in the case of the FRA63 cohort, women in FRA63 could claim a year early (at age 63 ) at the price of a $3.4 \%$ cut to benefits. Additionally, women in the FRA64 cohort could claim benefits as early as 62 (2 years before their FRA), at the price of a $6.8 \%$ cut to benefits. Women in the FRA64 cohort who waited until age 64, the FRA, received a full pension. If maximizing SSW is the objective, the average woman in this cohort should claim before age 64 . Given the low price of early claiming, women in this cohort (and the FRA63 cohort) can partially mitigate the implied wealth shocks by claiming early.

The red squares apply to women born in 1948 or later, who also have an FRA of 64 . The adjustment for these women is such that they could claim at age 63 years and face a $6.8 \%$ cut to their pension, or at age 62 years at a cut of $13.6 \%$. The early claiming adjustment for this cohort of women is double the adjustment of the FRA63 and FRA64 cohorts, making the system more than actuarially fair (MAF) so that for the average woman, delaying claiming to the FRA offers the highest value of SSW. As such, we label this cohort the MAF cohort.

We also explore alternative ways of calculating the SSW. First, we consider that delaying claiming affects the SSW also through the AIE if women continue to work (the pension accrual). Second, we consider that the tax system may affect actuarial fairness, because OASI benefits are subject to regular income taxes. Appendix Figure A.3 and Appendix Table A.1 show that these considerations are not significant enough to change the SSW patterns. Claiming early is financially attractive for FRA63 and FRA64 cohorts and financially unattractive for MAF cohorts, independent of when women retire and whether OASI benefits are gross or net of taxes.

Three other elements of the reform are important in our context. First, the 1997 reform changed pensions for couples. Prior to the reform, retired couples earned 150\% of the husband's pension. The 1997 reform introduced splitting. Once both husband and wife claimed benefits, the earnings accumulated by husband and wife during the marriage were split equally between the two. These split earnings trajectories were used to determine the pension benefit separately for husband and wife. All new pensions were calculated according to the new rules immediately, and on-going pensions were re-calculated from January 1, 2001 onwards. Splitting came into effect in 1997, whereas the FRA increase affected new pensions from 2001 onwards, so that splitting does not affect our analysis of the effects of the FRA on women's decisions. 
Second, the 1997 reform abolished the supplementary pensions for retired husbands whose wives were born in 1942 or after. This change could in principle affect our analysis of the FRA64 reform, because the change also occurs sharply around the January 1, 1942 cutoff. We show below that our results are robust to considering the subsample of single women, or women with a young husband (couples where the husband is no more than two years older than the wife).

Third, the reform introduced early claiming for men. From January 1, 1997 onwards, men could claim OASI pensions at age 64, one year prior to men's FRA at 65. The first cohort affected is the cohort born in 1933. Pension benefits were reduced by $6.8 \%$ for those men who decided to claim early, i.e. the early claiming adjustment was twice as large for men than for women. Starting January 1, 2001, men could claim old age pensions at age 63, up to two years prior to the FRA, at a penalty of $6.8 \%$ per year of early claiming. The first cohort affected is born in 1938. In appendix We assess this element of the reform by comparing male cohorts who were and were not affected by the reform and find no significant change in claiming or retirement behavior.

The OASI reform did not affect rules for occupational pensions. We assess occupational pensions for cohorts that are affected by the reform and those that are not and find no differences in the occupational pension claiming age and the occupational pension benefit level (Figure C.11 and Table C.7 in the appendix.)

\subsection{Data and Descriptive Statistics}

Our empirical analysis uses Swiss Social Security data (SSSD) from two sources that are linked using unique person-level identifiers. The first data source covers all women born between 1935 and 1948. We observe their labor market histories, beginning in 1982 and terminating at the end of 2015. Employed or self-employed individuals generate one record per employment spell per year that details the starting and ending month of an employment relationship along with the total earnings over that time period, without information on full- or part-time status. Unemployment benefit recipients also generate one record per year that contains information on unemployment benefits and the starting and ending months of an unemployment spell. Individual accounts also contain information on week of birth, marital status, canton of residence, and nationality.

The second data source contains information on all OASI pension and disability claims, beginning in 1992 and terminating at the end of 2016. For both pensions, we observe the start date of the pension, its benefit level along with the contribution years and average indexed earnings used to calculate the pension level. The pension claims data also contains information on mortality as both disability and old age pension claims terminate when its claimant dies. We match spouses to married women and observe information on the spouses' labor supply and pension claiming.

We extract a series of samples of women with labor force attachment who were just affected or not affected by the changes implemented with the reform. Specifically, we focus on women born between 1938 and 1939, between 1941 and 1942, and between 1947 and 1948, around the sharp cutoffs generated by the reform. We exclude women who are never employed after age 50 and those who claim a disability pension before age 50 .

Our empirical analysis focuses on the following key outcome variables. Claiming Age is the age an individual first starts claiming a disability or old-age pension (daily precision). Retirement Age is the last 
age an individual has positive earnings (monthly precision). OASI pension is the old age pension amount (in CHF per year). Social Security Wealth $(S S W)$ is the expected discounted value of future benefits. Specifically, $\mathrm{SSW}=\sum_{\tau=61}^{T} \beta^{(\tau-61)} s_{\tau} b_{\tau}(C) \mathbf{1}\{\tau \geq C\}$ where $C$ is the claiming age, $b_{\tau}(C)$ are the annual benefits associated with claiming at age $C, \mathbf{1}\{\tau \geq C\}$ indicates that age $\tau$ is at least as old as the age of claiming, $T$ is the maximum age an individual can live to (110 years), $\beta$ is the discount factor (set at 0.98 ), and $s_{\tau}$ is the probability of being alive at age $\tau$ conditional on being alive at age 61 .

Table 3 reports summary statistics for the three samples we use to measure the effects of increasing the FRA from 62 to 63 years (FRA63) and from 63 to 64 years (FRA64), and adjusting benefits to be more than actuarially fair (MAF). Panel A provides statistics on the key outcome variables. Women leave the labor force about two to three years before the FRA. The average claiming age is between 0.4 to 1.7 years below the FRA. The average OASI pension is around 19,000 CHF for one year. SSW is about 19 times larger than the annual OASI pension.

\section{Table 3}

Panel B of Table 3 shows summary statistics on key background variables. About one in five or six women has a non-Swiss nationality. About $63 \%$ of women are married.About $30 \%$ of women in the FRA63 sample get a supplementary pension. Supplementary pensions are less frequent in the FRA64 and MAF samples; only about 20\% in the FRA64 sample and 8\% in the MAF sample receive one because the 1997 reform abolished the supplemental pension for women born in 1942 or after. Average indexed earnings (AIE) - the base for setting the benefit amount - are 50,592 CHF per year for the women affected by the FRA increase from 62 to 63 , about 2,600 CHF larger for women affected by the change in the FRA from 63 to 64 years, and about 4,300 CHF larger for women affected by the MAF change. OASI benefits replace about $38 \%(=19,076 / 50,592 * 100)$ of indexed earnings in the 62 to 63 years sample, and the replacement rate is similar for the FRA64 and MAF samples. Annual earnings at age 55 are between 14,000 and 16,000 CHF lower than average indexed earnings. The reason for this difference is twofold. First, annual earnings look at the entire year regardless of whether a woman worked or not; periods of non-employment contribute zero to annual earnings. Second, indexed earnings also reflect care supplements. OASI pensions replace about $50 \%$ of annual earnings at age 55 .

\section{Conceptual Framework}

The Swiss reform provides a unique opportunity to study how behavior responds to pension wealth shocks. First, because the Swiss pension system allows individuals to claim a pension and work at the same time, retiring from work and claiming benefits are two separate decisions 14 A second key advantage is that the Swiss reform generates independent variation in the price of early claiming and the level of the FRA, which allows us to disentangle active and passive pension claimers.

Claiming Decision. With respect to the claiming decision, there are two types of decision makers in the population, passive and active. Passive claimers are not responsive to financial incentives and claim

\footnotetext{
${ }^{14}$ Women who claim a pension early, and continue to work until the FRA, will potentially enter a higher income tax bracket. Appendix Table A.1 shows that the additional tax burden on OASI benefits when continuing to work has a small impact on the actuarial fairness of the pension system. For example, claiming early under FRA63 increase SSW by CHF 6,250 (or 1.73\%) when not working and by $\mathrm{CHF} 4,680$ (or $1.30 \%$ ) when working.
} 
the OASI pension at the FRA regardless of the pension adjustment factor schedule they are faced with 15 There are a number of possible sources of passivity, including lack of information about claiming options, avoiding hassle costs associated with deviating from the FRA, peer effects, reference-dependent preferences with loss aversion, because early claiming is framed as a benefit loss. As section 6 discusses, we find that reference-dependent preferences together with loss aversion is the dominant reason for passivity.

Active claimers, by contrast, time claiming to maximize lifetime discounted value of future benefits, taking into account the pension adjustments for early and late claiming. The logic is that the timing of claiming offers an arbitrage opportunity (Davidoff et al., 2005). Early claimers could have sold risk-free assets and bought more retirement benefits by delaying claiming. Substituting retirement benefits for riskfree assets yields an arbitrage-like gain if the pension adjustment exceeds the return on risk-free assets. Such a gain improves welfare independent of the underlying utility function as long as individuals are not liquidity constrained and do not value bequests.

In choosing the age to claim, active decision makers trade off receiving a lower benefit today and every period in the future against no benefit today and a higher benefit for every period in the future. Sufficiently patient or long-lived individuals would optimally delay, while impatient or short-lived individuals claim today. We illustrate this in a slightly more formal way, as it will be useful in subsequent discussion.

Suppose an individual expects to live for $T$ periods and decides whether to claim early at age $t$ or delay claiming one year to the FRA $t+1$. If the individual discounts the future at rate $\beta$, the lifetime discounted value of benefits when claiming early is $V_{t}(b)=\sum_{\tau=t}^{T} \beta^{\tau-t} \alpha b$, where $b$ is the value of the full pension at the FRA and $\alpha<1$ is the pension adjustment factor. If the individual instead delays claiming one year to the FRA, she receives $V_{t+1}(b)=\sum_{\tau=t+1}^{T} \beta^{\tau-t-1} b$. Maximizing pension wealth at period $t$ means comparing $V_{t}(b)$ with the discounted value of claiming next period, $\beta V_{t+1}(b)$. Comparing the two values, we get that the individual claims early if and only if $\alpha \sum_{\tau=t}^{T} \beta^{\tau-t} \geq \sum_{\tau=t+1}^{T} \beta^{\tau-t}$ or:

$$
\alpha \geq 1-\frac{1}{\sum_{\tau=t}^{T} \beta^{\tau-t}} .
$$

A pension system is actuarially fair if equation (1) holds with equality: the lifetime discounted value of future benefits is the same across claiming ages. A pension system is actuarially unfair if in equation (1), $\alpha>$ RHS (delaying reduces pension wealth) and actuarially more than fair if $\alpha<$ RHS (delaying increases pension wealth).

Equation (1) shows that actuarial fairness depends on the life expectancy $T$. As $T$ gets larger, the RHS gets smaller and the pension system is more likely to be actuarially more than fair for a given $\alpha$. This is intuitive. The longer a person expects to live, the more costly is a penalty on benefits for every period into the future. In the limit as $T \rightarrow \infty$, the RHS approaches $\beta$. Hence, an individual that expects to live forever will delay claiming if $\alpha<\beta$ and claim early if $\alpha>\beta$ 16 $\beta$ is the cutoff point where an individual is indifferent between claiming early and delaying - it is the actuarially fair adjustment for an

\footnotetext{
${ }^{15}$ Our definition of active and passive follows Chetty et al. (2014). In the context of saving for retirement, they label individuals who make decisions optimally given preferences and constraints as active and individuals that do not as passive. They find that the existence of passive decision makers is important for explaining observed patterns in retirement savings behavior.

${ }^{16}$ The condition $\alpha>\beta$ is the same as saying that the return from delaying claiming is lower than the return on the risk-free asset. We can write $\alpha=\frac{1}{1+q}$ where $q$ is the return that the pension system offers for delaying claiming to $t+1$. Similarly, we can write $\beta=\frac{1}{1+r}$ where $r$ is the return on a risk-free asset. The condition $\alpha>\beta$ implies that $q<r$.
} 
infinitely lived individual. Reducing benefits associated with claiming early by a factor of $\beta$ would result in a lifetime payoff exactly equal to receiving full benefits starting from next period. Equation (1) also shows that actuarial fairness does not depend on the benefit level. All that matters is the relative comparison from claiming at $t$ versus delaying to $t+1$.

Preliminary evidence for passivity. We can characterize a break-even life expectancy $T^{*}(\alpha, \beta)$ such that equation 1 holds with equality for candidate values of $\alpha, \beta$. Individuals who expect to die before $T^{*}$ should claim early if their goal is maximizing pension wealth. In Table 2, we compare rates of early claiming in the data (first column) with simulated rates assuming pension wealth maximizing individuals. For the simulation, we find $T^{*}$ for a given discount factor and value of $\alpha$ implied by the policy and calculate the fraction of individuals who die before $T^{*}$, and should therefore claim early. We perform the simulations for average life expectancies (columns 2-4) as well as for heterogenous life expectancies that vary by AIE-quintile and marital status (columns 5-7) 17

In the first row, we consider the FRA63 reform stage where $\alpha=0.96$ and early claiming means claiming at age 62 , while delaying means not claiming until 63 . In the data, $22.3 \%$ claim at age 62 , while pension wealth maximization would dictate that $70.9 \%$ claim early if $\beta=0.98,47.7 \%$ claim early if $\beta=0.99$ and $35.6 \%$ claim early if $\beta=1$. The percentages are very similar if we allow for heterogenous survival rates. The story is similar for the FRA64 reform stage. There is thus no reasonable value of the discount factor that can rationalize the low rates of early claiming we observe in the data. This evidence strongly rejects a population comprised by only active decision makers; to be able to replicate the distribution of claiming ages in the data, we would need to allow for a substantial fraction of individuals who delay to the FRA when it is not in their financial interest to do so.

Finally, for the MAF reform stage, which changed the price of early claiming but not the FRA, we find that the optimal early claiming percentages closely align with the data for a large enough discount factor, as simulations now predict that most active individuals also delay to the FRA.

Table 2

Retirement Decision. A standard model of the lifetime budget constraint, as illustrated in Figure 2 , helps to illustrate how changes to the pension system might affect the retirement decision. The lifetime income of an individual is total lifetime labor earnings $R w$, where $R$ is the retirement age and $w$ is the annual wage. The individual's lifetime pension benefits are $\alpha b(T-C)$, where $T$ is the age at death, $C$ is the claiming age, and $\alpha b$ is the annual pension, with $\alpha$ denoting the adjustment factor and $b$ the full pension at the FRA (for simplicity, the discount factor is set to one).

Since there is no earnings test, lifetime pension benefits do not depend on the retirement age: The budget constraints are simply straight lines with slope $w$ (solid lines in Figure 2). A reduction in benefits to $b^{\prime}$ (for example because of an increase in the FRA) and/or a reduction in the adjustment factor to $\alpha^{\prime}$ introduce parallel downward shifts of the budget constraint, creating an income effect that tends to delay retirement (if leisure is a normal good). In the empirical analysis, we estimate the size of the income effect of lifetime pension benefits on lifetime labor supply by exploiting the reform-induced variation in pension benefits.

\footnotetext{
${ }^{17}$ We divide the sample into ten groups, defined by AIE-quintile and marital status, and then use the method described in footnote 13 to calculate group-specific survival rates. Figure A.2 in Appendix A.1 shows the group-specific survival curves.
} 
In contrast, a pension system with an earnings test introduces a kink in the lifetime budget constraint at the claiming age, by reducing the private return of work after the claiming age (dashed lines in Figure 2). A change in benefits and/or the adjustment factor shifts the budget constraint but also changes its slope, creating an income and a substitution effect. Decomposing the retirement response into an income and substitution effect is challenging and requires additional assumptions (Gelber et al. (2016), Fetter and Lockwood (2018)).

One potential concern in our setting is that the FRA could terminate labor market careers, because contracts may automatically end or because of mandatory retirement in some sectors. Appendix Table shows the importance of different reasons for why women retire using data for Switzerland from the Survey of Health, Ageing and Retirement in Europe. The most important reason for retirement by far is becoming eligible for an OASI pension. Over $60 \%$ of women list OASI eligibility as the reason for retirement. In contrast, layoffs and firm early retirement programs account for less than $5 \%$ of retirements. We further explore the relevance of these demand side constraints by comparing workers in the public sector, which has mandatory retirement at the FRA, to workers in the private sector; and self-employed to salaried workers.

Another question is how liquidity constraints change the retirement response to the reforms we study. Since liquidity constrained individuals lack the means to finance an early labor market exit, they work until reaching the eligibility age for a pension. Increasing the FRA, while offering early claiming, leaves labor supply of liquidity constrained individuals unchanged, even if the price for early claiming is more expensive than would be actuarially fair. We explore the role of liquidity constraints by contrasting women with low and high lifetime earnings.

Figure 2

\section{Main Results}

In this section we present our empirical strategy for identifying the causal effect of the different stages of the reform on claiming decisions, labor supply and pension wealth, and then present and discuss the results.

\subsection{Empirical Strategy}

The 1997 OASI reform generates sharp cutoffs with respect to an individual's birthdate. While women born on December 31, 1938 can claim and receive full benefits at age 62, women born the next day, on January 1, 1939, have an FRA of 63 with the option to claim early at age 62 at the price of $3.4 \%$ of benefits. The same new rules hold for women born up to December 31, 1941, but a woman born on January 1, 1942 has an FRA of 64 and can again claim early at the price of $3.4 \%$ per year early. These rules again apply to women born up to December 31, 1947, but a woman born on January 1, 1948 now pays 6.8\% per year of claiming early. We can thus identify three different treatment affects, one associated with each stage of the reform, as long as the distribution of observable and unobservable characteristics is similar to the left and right of each birthdate threshold.

We estimate regressions of the following type:

$$
y_{i}=\alpha+\beta D_{i}+f_{0}\left(Z_{i}-z\right)+D_{i} f_{1}\left(Z_{i}-z\right)+\varepsilon_{i}
$$


where $i$ indexes the individual. $Z(i)$ is the birthdate of individual $i$ and $z$ is the cutoff date associated with a given stage of the reform. The variable $D_{i}$ is the treatment indicator, which takes the value 1 if the woman is born to the right of the cutoff and takes the value 0 otherwise:

$$
D_{i}= \begin{cases}1, & \text { if } Z_{i} \geq z \\ 0, & \text { otherwise }\end{cases}
$$

$f_{0}()$ and $f_{1}()$ are unknown functions, allowed to differ flexibly across the threshold, included to control for trends in $Z_{i}$. The coefficient of interest is $\beta$ which measures the impact of the increase in the FRA on the outcome variable $y_{i}$.

We adopt a local linear regression approach in estimating treatment effects. We present results for a bandwidth of 12 weeks, but we also present estimates for larger bandwidths. We probe sensitivity of our results to adopting a linear or quadratic specification for $f_{0}()$, and $f_{1}()$. Our baseline results adopt a linear specification.

Validity of the RD design requires that women cannot manipulate the assignment variable (Lee and Lemieux, 2010). In our context, the assignment variable is the date of birth of women born just before and after the cutoff dates. Clearly, is impossible that women or their parents manipulated the date of birth in anticipation of the policy change. But seasonality in births or other policy changes or anticipation of WWII could still have been driving dates of birth. We are not aware of any change in the incentive to give birth in 1939 as opposed to 1938, for example. Appendix Figure B.4 shows that the number of women born per weeks is smooth around the cutoff dates and Appendix Table B.2 shows that the point estimates are insignificant locally around the cutoff.

We also carefully examine the distribution of covariates and see no evidence of a significant change in the means of background variables around the cutoff dates (Appendix Table B.3). These checks do not indicate concerns with the validity of the RD design.

The RD design identifies the effects of an increase in the FRA only if there is no other policy change at the same age cutoff. The 1997 reform also introduced a new algorithm to separately calculate OASI pensions for husbands and wives. This splitting algorithm does not affect our estimates of the effects of increasing the FRA since it applies to all women regardless of their date of birth. The reform also abolished the supplementary pension for women born after 1942. This aspect of the reform could confound our estimate of an increase in the FRA from 63 to 64 years. We explore sensitivity of our results for FRA64 in a sub-sample of women that were not affected by abolishment of the supplementary pension.

\subsection{Estimating Discontinuities in Key Outcomes}

Figure 3 shows discontinuities in key outcomes at the cohort cutoffs and Table 4 presents the corresponding $\mathrm{RD}$ estimates. We present estimates for two different bandwidths, a "local" one (12 weeks) and a "global" one (30 weeks), and include a linear trend on either side of the cohort cutoff. We find qualitatively and quantitatively similar estimates when we include a quadratic trend on either side of the cutoff (Appendix Table B.4.)

Figure 3

Figures $3(\mathrm{a})-(\mathrm{c})$ show the effect of the reform on the claiming age. We observe sharp and large increases 
in the claiming age at the cohort cutoff for FRA63 and FRA64 and a sharp, but smaller increase in the claiming age for MAF. Panel A of Table 4 documents the RD estimates for the claiming age. The FRA63 and FRA64 stages of the reform increase the age of claiming by 7-8 months. The MAF stage of the reform has a much more modest effect on claiming age, increasing it by just over 4 months. The estimates depend only slightly on the bandwidth.

Appendix Figure shows the claiming hazards before and after each reform step, providing evidence on how the changes in the average claiming age came about. We find that the hazard probability peaks at close to one at a cohort's FRA, so women almost perfectly comply with the full retirement age. The claiming hazard moves in lockstep with an increase in the FRA. Few women take advantage of early claiming, the early claiming hazard is about $20 \%$ for FRA63 and FRA64, even though claiming before the FRA maximizes pension wealth. For the MAF reform we again find that the claiming hazard is close to one at the FRA, but the early claiming hazard after the reform step is about half of the early claiming hazard before the reform step, suggesting that the increased penalties for early claiming were effective.

Recall that the reform abolished supplementary pensions for couples with a retired husband, and a non-retired wife older than 55 years and born after 1942. Supplementary pensions were abolished at the same time as the FRA was increased from 63 to 64 for wives whose husbands were older. We assess sensitivity of our results for FRA64 by considering single women, or women living with a husband who is at most two years older. Indeed, supplementary pensions are much less frequent among women born 1942 or later, compared to women born at the end of 1941, but single women and age balanced couples were not affected by the reform, since these couples had no access to a supplementary pension (Appendix Figure B.5). Results for this sample (second row of Panel A) are virtually identical to main results. Abolishing the supplementary pension does not appear to affect labor supply and claiming decisions.

As the claiming estimates may be driven in part by the additional tax levied on women who work and claim a pension, we restrict the sample to include only women who have left the labor market before reaching the age of early retirement and find that the effects are not statistically different from the full sample (third row of Panel A). The interaction of retirement and claiming through the tax system appears to be negligible.

Figures 3(d)-(f) show the effect of each stage of the reform on social security wealth. We observe large drops in social security wealth at the cohort cutoff for FRA63 and FRA64 and only a small drop for MAF. Consistent with these patterns, Panel B of Table 4 shows that FRA63 decreases social security wealth by about 18,500-21,000 CHF, but has no effect on annual OASI benefits. FRA64 decreases not only social security wealth, but also the size of annual pension benefits, while MAF decreases pension wealth by about one sixth of the amount in FRA63 and FRA64. These findings are also consistent with Panel B of Figure 3. where

Figures 3(g)-(i) show how the retirement age changes at the cohort cutoffs. There is a clear increase in the retirement age at the cohort cutoff for FRA63 and FRA64 but no visible discontinuity at the cohort cutoff for MAF. Panel $\mathrm{C}$ of Table 4 shows that the retirement age increases by 5-8 months at the cohort cutoff for FRA63 and FRA64, but the MAF stage of the reform has no effect on the retirement age. The estimates depend only slightly on the bandwidth and are robust when we restrict the sample to single women and age balanced couples.

Appendix Figure decomposes the retirement age effect by showing the retirement hazards before and 
after each reform step. We find that the retirement hazard peaks at about 0.8 at a cohort's FRA. This peak moves in lockstep with the FRA increases, expanding labor supply around the pre- and post-reform FRA. The retirement hazard is unchanged with the doubling of the price for early claiming. Most women already postpone retirement to the FRA, leaving little room for MAF to increase labor supply around the early claiming ages.

\section{Table 4}

\subsection{Robustness and Heterogeneity}

We explore estimates with larger and smaller bandwidths to assess the sensitivity of our results to bandwidth choice. Our estimates are robust to these alternative specifications. Figure 4 reports estimates of the effects on labor market exit, and claiming age, varying bandwidth between 4 and 38 weeks. Effects are broadly robust to varying the bandwidth. We also compare Placebo and real RD estimates (Figure 5). Reform effects are orders of magnitude larger than effects of Placebo reforms.

Figure 4

Figure 5

We also assess to what extent spouses react to their partner's wealth shock (Figure C.5 and Table C.5 in the appendix.) Partners do not work longer to help accommodate the pension wealth shock, nor do they adapt pension claiming in response to the FRA increases 18

We also explore heterogeneity of the reform effects by health, self-employment, sector, and prior earnings. Figure 6 displays the effects of the reform steps, FRA63, FRA64, and MAF, and for claiming (a) and retirement (b). We proxy for poor health by whether a woman dies in the period we observe, before the end of 2013, and for good health with whether she is still alive. Women in poor health delay claiming by about 2 months less than women in good health, but the difference is very imprecisely measured. Women in poor health delay retirement by about as much as healthy women in the FRA63, and somewhat in the FRA64.

Self-employed women and salaried women inform on the role of firms and employers (Figure 6). Claiming responses by the self-employed and salaried are very similar in terms of magnitude suggesting that claiming results are unlikely to be driven by labor demand considerations. The self-employed delay labor market exit very strongly, by somewhat more than 1 year, in FRA63 whereas the salaried delay retirement by less, about 7 months, but this difference is imprecisely measured. Also, in FRA64 the responses by self-employed and salaried women are very similar. Firms and other labor demand considerations do not appear to be driving results.

Figure 6

We contrast women employed in the public sector and the private sector (Figure 6). The public sector has mandatory retirement at the FRA while the private sector is covered by collective agreements. Sector

\footnotetext{
${ }^{18}$ Cribb et al. (2016) show that increasing the U.K. state pension age for wives by one year increases their husband's employment rate by 4-5 percentage points, a result we do not find for the Swiss reform, perhaps because wealth shocks were smaller for Swiss women, compared to U.K. women.
} 
is not important for the claiming response. Regardless of the sector of an employer, women delay claiming by about 7-8 months. Public sector employees delay retirement more strongly for FRA63, but much less strongly for FRA64, than private sector employees. This evidence suggests that, perhaps, the timing of the increase in the work life was somewhat different between the public and the private sectors, but its overall impact appears relatively similar.

We assess whether women's responses differ by average indexed earnings (AIE) (Figure 6). AIE do not matter for claiming responses, women with low AIE and women with high AIE delay claiming of pension benefits by about the same amount. Low AIE women delay labor market exit more strongly in FRA64 than high AIE women, but the difference is not precisely estimated, and the effects of FRA63 on retirement are very similar for low and high AIE women.

Claiming responses differ somewhat with respect to health, but not much by self-employment, sector, or earnings. Retirement responses differ somewhat by health, self-employment, sector, and earnings, but the differences are not systematic across FRA63, and FRA64 (MAF does not trigger a retirement response).

\subsection{Lifetime Marginal Propensities to Earn}

Pension reforms generate shocks to lifetime pension wealth, which in turn cause labor market responses that can have important implications for lifetime employment earnings. While understanding the consequences of pension reform for lifetime earnings is clearly a first-order policy issue, it is difficult to quantify the effect in most cases, because labor market exit and benefits claiming are institutionally tied together. This limits the ability of individuals to respond to negative pension wealth shocks by, for example, working longer and earning more labor income. The Swiss system, however, where retirement and claiming are not linked institutionally, provides us with a unique opportunity to estimate the effect of pension wealth shocks on lifetime earnings. Our lifetime earnings measure is the sum of earnings after payroll taxes between ages 62 and the last age of observation (age 77 for FRA63, age 74 for FRA64, and age 68 for MAF.) ${ }^{19}$ Our measure of pension wealth is the sum of old age pensions. We discount future earnings and old age pensions using a discount factor of 0.98 and mortality rates that vary by income and martial status. Lifetime earnings and pension wealth are winsorized at the 1 th and 99 th percentile.

Table 5 shows RD-estimates of lifetime marginal propensities to earn out of unearned income. We obtain these estimates by dividing the change in lifetime earnings at the cohort cutoff by the corresponding change in pension wealth (both estimated using the RD). For the full sample, we find that women who are affected by the FRA63 increase lifetime earnings by 57 cents for a 1 Swiss Franc drop in pension wealth. The estimate is smaller for FRA64 (39 cents), but we fail to reject the null hypothesis that the two estimates are equal (see Figure C.12 in the appendix). For the MAF stage, we find an increase in lifetime earnings of 34 cents per one Swiss Franc drop in pension wealth, but the estimate is less precise, because the MAF stage of the reform barley changes pension wealth (Table 4). We also explore whether the effects of wealth on lifetime earnings are heterogeneous by citizenship, marital status, self employment, sector, and prior earnings. Table 5 shows little evidence for heterogenous effects across these subgroups of the population. Figure C.12 in the appendix shows that we cannot reject the null hypothesis that the estimates are equal among subgroups within a reform step as well as across reform steps.

\footnotetext{
${ }^{19}$ The estimates are similar if we censor lifetime earnings at age 68 for all reform steps, since few women work beyond this age.
} 
Our estimates of the marginal propensities to earn are substantially larger than the estimates in Imbens et al. (2001) and Cesarini et al. (2017) who study lottery players. They find marginal propensities to earn of around -0.1 and, similar to us, limited heterogeneity across demographic subgroups. Our estimates are similar to Gelber et al. (2016) who study a population comparable to ours. They study a U.S. policy that cut lifetime OASI benefits by $\$ 6,100$, about three to four times less than in our setting, and find that a $\$ 1$ increase in OASI benefits reduces earnings among the elderly by 46 to 61 cents.

\section{Table 5}

\section{$5 \quad$ Quantifying Passive Claiming}

The RD evidence points to a large fraction of individuals making decisions that do not maximize pension wealth. In the context of saving for retirement, Chetty et al. (2014) find that the existence of passive decision makers is important for explaining observed patterns in retirement savings behavior 20 Because interior optima with respect to a continuous choice variable (retirement savings, portfolio allocation) should move in response to a price change, they are able to conclude that the non-responders to these policy reforms are passive.

In our setting, passivity would mean claiming benefits at the reference age - the FRA - regardless of the financial incentives associated with claiming earlier. The large increase in claiming age in response to the increase in the FRA when financial incentives would dictate that optimizing individuals should not delay, suggests that passive individuals might comprise an important fraction of the population in our setting as well. However, because benefit claiming is a discrete choice, we cannot take the approach of Chetty et al. (2014) and label non responders to a change in incentives as passive. To see why, consider the MAF stage of the reform, where the government increased the price of early claiming while holding the FRA fixed at 64 . Individuals who change the age they claim in response are surely active decision makers, but individuals who do not may be passive or they may be active and found it optimal to claim at 64 under both incentive regimes given their life expectancy and the rate at which they discount the future.

In this section, we quantify the fraction of passive individuals in the population using two alternative but complementary approaches. First, we exploit the variation in incentives generated by the policy reform to identify bounds on the fraction of the population that is passive ${ }^{21}$ This approach is attractive because it relies only on the identification of the fraction of compliers with each stage of the reform-those who claim at the FRA in response to the reform but would not otherwise, and thus relies on minimal assumptions. Second, we show that if we are willing to make a behavioral assumption about active decision makers, that they maximize lifetime discounted pension wealth, then the fraction of passive decision makers $\pi$ is in fact point-identified. We then estimate $\pi$ using a dynamic discrete choice model of benefits claiming with a finite mixture of types, where $\pi$ is the mixing probability over the two types of individual. Our point estimate of $\pi$ lies inside our estimated bounds so that we cannot reject that the simple two type model

\footnotetext{
${ }^{20}$ Chetty et al. (2014) study responses to two types of reform to the Danish pension system. In the first, they find that $85 \%$ of individuals do not reduce retirement savings in response to an increase in compensation through higher employer provided automatic contribution. In the second, they find that $81 \%$ of individuals do not reallocate voluntary contributions from capital pension accounts to annuity pension accounts when the relative price of contributing to the former increases.

${ }^{21}$ Kline and Tartari 2016) adopt a bounding approach to recover labor supply strategies in a welfare program setting, an approach that inspired our analysis.
} 
generates the data that we observe. We finally show that the simple two type model provides an excellent fit of the data, as it nearly perfectly replicates the empirical hazard function.

\subsection{Bounds on Passive Claiming}

The 1997 reform can be seen as having induced three different experiments. Individuals born in the neighborhood of Jan 1, 1939 are assigned to the first experiment, FRA63, individuals born in the neighborhood of Jan 1, 1942 are assigned to the second experiment, FRA64, and individuals born in the neighborhood of Jan 1, 1948 are assigned to the third experiment, MAF. Index experiments by $q$, and as above, denote individual $i$ 's birthdate by $Z_{i}^{q}$ where we now use the superscript $q$ to make explicit the experiment that individual $i$ is assigned to. Denote the birthdate cutoff associated with experiment $q$ by $z_{q}$. Also, as above the variable $D_{i}$ indicates whether individual $i$ falls to the left or right of the cutoff in the experiment she is assigned to. Formally:

$$
D_{i}= \begin{cases}1, & \text { if } Z_{i}^{q} \geq z_{q} \\ 0, & \text { otherwise }\end{cases}
$$

Finally, let $F_{i} \in\{0,1\}$ indicate that individual $i$ delays claiming to the FRA associated with the experiment she has been assigned to. That is, delay in experiment FRA63 means claiming at or after 63, while delay in experiments FRA64 and MAF means claiming at or after 64. Compliance with experiment $q$ means delaying if and only if $Z_{i}^{q} \geq z_{q}$.

In our setting, compliance is informative about passivity, as Table 6 shows. For example, individuals that are compliant with the FRA63 experiment delay claiming to age 63 if and only if they have $D=1$. All passive individuals in this experiment behave this way, as they switch their claiming age with the FRA. But some active individuals also behave this way. Active individuals choose when to claim optimally as a function of their preferences and constraints. This could mean that they delay when faced with the incentives of FRA63 and claim early otherwise, in which case they are compliant. This would be the case if, for example, the individual has a long-life expectancy, so that even a small penalty for early claiming induces delay for an active decision maker. Or it may mean they find it optimal to delay claiming for either set of incentives, or they always find it optimal to claim early, either of which would make them non-compliant. By contrast, a complier in the MAF experiment cannot be passive, because the FRA does not change, and passive individuals do not respond in such a case.

The first and second columns have similar composition in each group (row), because both experiments raise the FRA with a change in price for early claiming. The third column is different, because it does not shift the FRA. We now show how we can exploit rates of compliance across the three stages of the reform, which are directly observable from the data, to identify bounds around the fraction of the population that is passive (denoted as $\pi$ ). A key assumption of our approach is that the share of passive decision makers does not change across the three reform steps.

\section{Table 6}

Upper Bound. The upper bound on the fraction of passives is simple to obtain given experiments FRA63 and FRA64. Let $\mathcal{C}$ and $\mathcal{N}$ denote the events " $i$ is compliant" and " $i$ is non-compliant" respectively. 
For experiments $q \in\{F R A 63, F R A 64\}$, we have:

$$
\begin{aligned}
& \operatorname{Prob}_{q}\left(\operatorname{Passive}=\operatorname{Prob}_{q}\left(\operatorname{Passive}_{\mid} \mathcal{C}\right) \operatorname{Prob}_{q}(\mathcal{C})+\operatorname{Prob}_{q}(\operatorname{Passive} \mid \mathcal{N}) \operatorname{Prob}_{q}(\mathcal{N})\right. \\
& =\operatorname{Prob}_{q}(\operatorname{Passive} \mid \mathcal{C}) \operatorname{Prob}_{q}(\mathcal{C}) \\
& \leq \operatorname{Prob}_{q}(\mathcal{C})
\end{aligned}
$$

where the first equality is by the law of total probability and the second is because there are no passive non-compliers to either FRA63 or FRA64. Note as well that for the MAF reform we have that $\operatorname{Prob}_{M A F}($ Passive $\mid \mathcal{C})=0$ so that:

$$
\begin{aligned}
\operatorname{Prob}_{M A F}(\text { Passive }) & =\operatorname{Prob}_{M A F}(\operatorname{Passive} \mid \mathcal{N}) \operatorname{Prob}_{M A F}(\mathcal{N}) \\
& \leq \operatorname{Prob}_{M A F}(\mathcal{N})
\end{aligned}
$$

At the cutoff of the reform, individuals are randomly assigned to experiments with respect to their rationality so that $P_{q}($ passive $)=P($ passive $) \quad$ for any $q$, and we have the upper bound:

$$
\pi \leq \min \left\{\operatorname{Prob}_{63}(\mathcal{C}), \operatorname{Prob}_{64}(\mathcal{C}), \operatorname{Prob}_{M A F}(\mathcal{N})\right\}
$$

$\operatorname{Prob}_{63}(\mathcal{C}), \operatorname{Prob}_{64}(\mathcal{C})$ and $\operatorname{Prob}_{M A F}(\mathcal{N})$ are identified under the assumption that individuals are randomly assigned around the cutoffs associated with the reform. Since their assignment is a function of their birthdate alone, this assumption is satisfied. The objects $\operatorname{Prob}_{63}(\mathcal{C}), \operatorname{Prob}_{64}(\mathcal{C})$ and $\operatorname{Prob}_{M A F}(\mathcal{N})$ are only bounds on the set of passives because there are potentially some actives in these groups.

Lower Bound. We are able to identify an upper bound on $\pi$ because all passives are either compliers or non-compliers at each stage of the reform. However, there is no stage of the reform where all actives are either compliers or non-compliers, so we need to make one further assumption to identify a lower bound.

\section{Assumption A1:}

$$
\operatorname{Prob}_{M A F}(\text { active, } \mathcal{C}) \geq \operatorname{Prob}_{64}(\text { active }, \mathcal{C})
$$

Consider what it means to be an active complier in experiment FRA64. Delayed claiming in this experiment is not actuarially fair for the average individual-maximizing lifetime discounted expected benefits would dictate claiming early. As such, we should expect a small number of active compliers. Experiment MAF makes delayed claiming more than actuarially fair relative to early claiming for the average individual. We should then expect the group of active compliers in experiment MAF to be larger than in experiment FRA64.

This intuition is supported by Table 2. Each simulation entry here represents the probability of delaying to the FRA given that the individual is active. For simplicity, consider the third column where $\beta=1$ and there is no heterogeneity in survival rates. In the FRA64 cohort, 39.4\% of individuals optimally claim early, meaning that $60.6 \%$ optimally delay to the FRA, or that $\operatorname{Prob}_{64}(\mathcal{C} \mid$ active $)=0.606$. Similarly, the next row down tells us that $\operatorname{Prob}_{M A F}(\mathcal{C} \mid$ active $)=0.875$, which implies $\operatorname{Prob}_{M A F}(\mathcal{C} \mid$ active $) \geq \operatorname{Prob}_{64}(\mathcal{C} \mid$ active $)$. This is close to, but not quite, Assumption A1. However, note that $\operatorname{Prob}_{64}(\mathcal{C} \mid$ active $) \operatorname{Prob}_{64}($ active $)=$ 
$\operatorname{Prob}_{64}(\mathcal{C}$, active $)$ and $\operatorname{Prob}_{M A F}(\mathcal{C} \mid$ active $) \operatorname{Prob}_{M A F}($ active $)=\operatorname{Prob}_{M A F}(\mathcal{C}$, active $)$. Moreover, random assignment in our experimental design implies that $\operatorname{Prob}_{64}($ active $)=\operatorname{Prob}_{M A F}($ active $)$, so that:

$$
\operatorname{Prob}_{M A F}(\mathcal{C} \mid \text { active }) \geq \operatorname{Prob}_{64}(\mathcal{C} \mid \text { active }) \Leftrightarrow \operatorname{Prob}_{M A F}(\mathcal{C}, \text { active }) \geq \operatorname{Prob}_{64}(\mathcal{C}, \text { active })
$$

In other words, the simulations in Table 2 support Assumption A1. Notice that the same patterns hold in each column, and is thus independent of the discount factor as well as whether we allow for heterogeneous mortality or not.

With this assumption in hand, we begin as we did in the case of the lower bound, but now consider experiment FRA64 specifically. The fraction of the population that is active satisfies:

$$
\begin{aligned}
& \operatorname{Prob}_{64}(\text { Active })=\operatorname{Prob}_{64}(\text { Active } \mid \mathcal{C}) \operatorname{Prob}_{64}(\mathcal{C})+\operatorname{Prob}_{64}(\operatorname{Active} \mid \mathcal{N}) \operatorname{Prob}_{64}(\mathcal{N}) \\
& =\operatorname{Prob}_{64}(\text { Active, } \mathcal{C})+\operatorname{Prob}_{64}(\mathcal{N}) \\
& \leq \operatorname{Prob}_{M A F}(\text { Active, } \mathcal{C})+\operatorname{Prob}_{64}(\mathcal{N}) \\
& =\operatorname{Prob}_{M A F}(\text { Active } \mid \mathcal{C}) \operatorname{Prob}_{M A F}(\mathcal{C})+\operatorname{Prob}_{64}(\mathcal{N}) \\
& =\operatorname{Prob}_{M A F}(\mathcal{C})+\operatorname{Prob}_{64}(\mathcal{N})
\end{aligned}
$$

The first line is by the Law of Total Probability, the second line is because all non-compliers in experiment FRA64 are active decision makers, the third line is by Assumption A1, the fourth line is by definition and the final line is because all compliers in the MAF stage are active decision makers. This gives an upper bound on the fraction on actives, so that the complement of this probability is a lower bound on the fraction of passives. Our two-sided bounds are:

$$
1-\operatorname{Prob}_{M A F}(\mathcal{C})-\operatorname{Prob}_{64}(\mathcal{N}) \leq \pi \leq \min \left\{\operatorname{Prob}_{63}(\mathcal{C}), \operatorname{Prob}_{64}(\mathcal{C}), \operatorname{Prob}_{M A F}(\mathcal{N})\right\}
$$

Estimates. To estimate bounds on $\pi$, we need estimates of the 4 probabilities $\left\{P_{63}(\mathcal{C}), P_{64}(\mathcal{C}), P_{M A F}(\mathcal{C}), P_{64}(\mathcal{N})\right\}$. They are non-parametrically identified with no further assumption. For example, $P_{q}(\mathcal{C})=E_{q}\left[D_{i} \mid T_{i}=1\right]-E_{q}\left[D_{i} \mid T_{i}=0\right]$, meaning we can consistently estimate $P_{q}(\mathcal{C})$ using sample counterparts.

Alternatively, we can estimate these probabilities using the following regression:

$$
F_{i}=\alpha_{0}+\alpha_{1} D_{i}+f_{0}\left(Z_{i}-z_{i}(q)\right)+D_{i} f_{1}\left(Z_{i}-z_{i}(q)\right)+\varepsilon_{i}
$$

The sample estimators (evaluated at $\left.Z_{i}-z_{i}(q)=0\right)$ are then given by $\hat{P}_{q}(\mathcal{C})=\hat{\alpha}_{1}$, and $\hat{P}_{q}(\mathcal{N})=1-\hat{\alpha}_{1}$.

Table 7 presents estimates of the component objects required to construct the bounds derived above, as well as the bounds themselves. We estimate that $\pi \in[0.465,0.686]$, so that between $46.5 \%$ and $68.6 \%$ of the population passively claims at the FRA. Bounds on the proportion passive decision makers in our setting are somewhat, but not much, lower than in the $80 \%$ in retirement savings setting of Chetty et al. (2014). Observe that $\hat{P r o b}_{63}(\mathcal{C}) \leq \operatorname{Prob}_{M A F}(\mathcal{N})$ and $\hat{P r o b}_{64}(\mathcal{C}) \leq \operatorname{Prob}_{M A F}(\mathcal{N})$. The stages FRA63 and FRA64 made delayed claiming less attractive for the average woman, so we expect relatively few active compliers in these stages. Further note that $\operatorname{Pr}_{\hat{r} o b_{64}}(\mathcal{C}) \leq \hat{P r o b}_{63}(\mathcal{C})$. By increasing the Full Retirement Age to 64, the FRA64 stage introduced two ages of early claiming, age 62 and 63 . An active individual who 
found it optimal to claim at 63 in the FRA63 experiment cannot be distinguished from a passive individual, however an active individual that found it optimal to claim at age 63 in the FRA64 experiment can be distinguished from a passive individual because 63 is an active claiming age in the FRA64 experiment. So it is not surprising that $\operatorname{Prob}_{64}(\mathcal{C})=\min \left\{\operatorname{Prob}_{63}(\mathcal{C}), \hat{P r o b}_{64}(\mathcal{C}), \hat{P r o b}_{M A F}(\mathcal{N})\right\}$.

Table 7

\subsection{Structural Model with Passive Decision Makers}

The bounds on $\pi$ derived above rely on minimal assumptions. In particular, we made no assumption about the objective function of active decision makers. We now show that with an assumption about the behavior of active decision makers - that they choose their claiming age to maximize discounted expected pension wealth - the fraction of passive decision makers $\pi$ is in fact point-identified. Conditional on making an assumption about active decision makers' objectives, this is perhaps the weakest assumption we could make, as a large class of utility functions would imply the same decision rule as the one that maximizes lifetime pension wealth 22

We then estimate $\pi$ using a dynamic discrete choice model of benefits claiming with a finite mixture of types, where $\pi$ is the mixing probability over the two types of individual.

Point Identification of $\pi \quad$ Let the observed claiming age of individual $i$ be given by $a_{i}$ and the individual's full retirement age be given by $F R A_{i}$. Let $\mathbf{1}_{i}^{\pi}$ indicate that individual $i$ is a passive decision maker. Lastly, let $a_{i}^{*}$ represent the claiming age that would maximize individual $i$ 's discounted expected pension wealth. Then the following holds for any individual $i$ :

$$
\mathbf{1}\left\{a_{i}=F R A_{i}\right\}=\mathbf{1}_{i}^{\pi}+\left(1-\mathbf{1}_{i}^{\pi}\right) \mathbf{1}\left\{a_{i}^{*}=F R A_{i}\right\}
$$

In words, observing that an individual claimed at her FRA can be explained by either the individual being passive, or by the FRA being the age that maximizes pension wealth. Under the assumption that $a_{i}^{*}$ is independent of $\mathbf{1}_{i}^{\pi}$ (the claiming age that would maximize pension wealth is independent of passivity), taking expectations of both sides of equation 7 gives:

$$
P_{F R A}=\pi+(1-\pi) P_{F R A}^{*}
$$

where $P_{F R A}$ is the probability of claiming at the FRA and $P_{F R A}^{*}$ is the probability that claiming at the FRA maximizes the agent's lifetime pension wealth. Re-arranging:

$$
\pi=\frac{P_{F R A}-P_{F R A}^{*}}{1-P_{F R A}^{*}}
$$

Since $P_{F R A} \leq 1$ and $P_{F R A} \geq P_{F R A}^{*},{ }^{23}$ we have that $0 \leq \pi \leq 1$. Moreover, the quantity $P_{F R A}$ is identified from the raw data under random sampling and $P_{F R A}^{*}$ is identified once we make the assumption that

\footnotetext{
${ }^{22}$ In particular, since claiming and retirement are formally untied in our setting, individuals without a bequest motive or liquidity constraints who maximize consumption would follow the same decision rule.

${ }^{23}$ Because if $a_{i}^{*}=F R A_{i}$ so that the claiming age of individual $i$ that maximizes lifetime pension wealth is equal to the FRA, then the claiming age of individual $i$ is certainly the FRA of individual $i, a_{i}=F R A_{i}$.
} 
individuals maximize expected pension wealth, because we observe all determinants of pension wealth, and given mortality estimates and an assumption on discounting, we can calculate the expected discounted pension wealth associated with each possible claiming age. So, the right-hand side of 9 is a probability and is observable, and $\pi$ is identified.

Estimation of $\pi \quad$ To calculate $P_{F R A}^{*}$ and then estimate $\pi$, we posit a simple dynamic binary choice model of benefits claiming. Let $b_{t}(c, m)$ represent the annual benefit payment to an individual who belongs to cohort $c$ and has average indexed annual earnings $(A I E)$ of $m$ if she claims at age $t$. The variables $c, m$ and the claiming age $t$ fully determine the stream of lifetime benefits.

Denote the decision of individual $i$ to claim at $t$ by $d_{i t}$. Then the flow payoff to claiming $\left(d_{i t}=1\right)$ is:

$$
u_{i t}(1, c, m)=b_{t}(c, m)+\varepsilon_{i t}(1)
$$

while the flow payoff to not claiming at $t$ is:

$$
u_{i t}(0, c, m)=\varepsilon_{i t}(0)
$$

where $\varepsilon_{i t}(d)$ is a choice-specific shock, observable to the agent but not to the econometrician, independent and identically distributed over $i$ and $t$. $\varepsilon_{i t}$ can be interpreted to be a shock to the cost/benefit of claiming that is idiosyncratic across individuals, and could include, for example, optimization error.

Claiming is irreversible, and individuals who don't claim retain the option value to claim in the future. Individuals take into account that they have survival rate $s_{i t}$, which depends on individual-level observables $\mathbf{x}, s_{i t}=s_{t}(\mathbf{x})$. Then the choice specific values associated with each choice are:

$$
\begin{aligned}
& v_{t}(1, \mathbf{x})=b_{t}(c, m)+\sum_{\tau=1}^{T-t} \beta^{\tau} s_{\tau}(\mathbf{x}) b_{\tau}(c, m) \\
& v_{t}(0, \mathbf{x})=\beta s_{t}(\mathbf{x}) E V_{t+1}(\mathbf{x})
\end{aligned}
$$

where $\beta$ is the discount factor and $E V_{t}(\mathbf{x})$ is the expected value of having the option to claim at age $t$, given the incentives associated with delaying to that point and anticipated future mortality.

It is standard in the dynamic discrete choice literature to assume $\varepsilon_{i t}(d)$ is type 1 extreme value distributed for each $d \in\{0,1\}$, as this yields a closed form expression for the choice probabilities:

$$
P_{t}(\mathbf{x})=\frac{\exp \left\{v_{t}(1, \mathbf{x})\right\}}{\exp \left\{v_{t}(1, \mathbf{x})\right\}+\exp \left\{v_{t}(0, \mathbf{x})\right\}}
$$

Note as well, given the vector of probabilities $\mathbf{P}(\mathbf{x})$ over the possible claiming ages $t=\underline{t}, \ldots, \bar{t}$ we can calculate the probability $P_{f}^{*}(\mathbf{x})$ as:

$$
P_{F R A}^{*}(\mathbf{x})=\prod_{t=\underline{t}}^{F R A-1}\left(1-P_{t}(\mathbf{x})\right) P_{F R A}(\mathbf{x})
$$

which then yields identification in equation 7 above. 
The dynamic binary choice model presented here implies a simple finite mixture likelihood model, where the type probabilities are $\pi$ and $(1-\pi)$. In the Appendix section $\mathrm{D}$ we describe in detail how we estimate $\pi$ using an Expectation Maximization (EM) algorithm. We estimate $\pi$ to be 0.673 (significant at the $1 \%$ leve 24 , which falls just inside the estimated upper bound of 0.686 .

Comparing Empirical and Simulated Claiming Hazards. We use the estimated $\pi$ to simulate claiming behavior. Figures 7 a)-c) display the empirical hazards (in blue) against model-simulated hazards (in red) when we fix $\pi=0$ (no passives), while figures 7 d)-f) display empirical hazards against modelsimulated hazards when $\pi=0.673$ as we estimated. Clearly the model with no passives does a poor job of replicating the data. When $\pi=0$, under FRA63 and FRA64, the average individual should claim before the FRA - in panel (a) the model predicted hazard is almost 0.6 at the ERA of 62 , while in panel (b) the model predicted hazard is about 0.6 at the first ERA of 62 and bigger than 0.6 at the second ERA of 63 . Yet in the data the empirical hazard at the ERA's is about 0.2. Moreover, the model cannot replicate the defining feature of the empirical hazards, the spike at the FRA. In panel (c) the story is similar except that the model predicts the hazard should increase significantly at the FRA. This is not surprising given the financial incentives associated with MAF, which strongly discourage early claiming.

Figure 7

By contrast, when we set $\pi=0.673$, the model does a good job of predicting spikes in the claiming hazards at exactly the right points. In panel $(\mathrm{d})$ both the empirical and model hazards are about 0.2 at the ERA of 62 , and spike at the FRA of 63 and then drop down again afterwards. In panel (e) both hazards lie below 0.2 at the ERAs of 62 and 63 and then spike at the FRA of age 64, again dropping down afterwards. Finally, in panel (f), although the model slightly overpredicts early claiming and under predicts late claiming, it predicts a shape that is very similar to what is observed in the data.

\section{Sources of Passivity and Policy Implications}

Our results so far indicate that passive decision makers are a substantial fraction of the population, and policymakers should take this into account when setting social security policy. However, nothing in our results so far tell us why individuals are passive. Without knowing the source of passivity, the appropriate policy will remain elusive.

In this section, we examine the sources of passivity using an original survey and then study the policy implications of pension reforms with passive individuals.

\subsection{Original Survey to Study Passivity}

Spikes in benefits claiming at the FRA have been observed in several countries (Mastrobuoni, 2009, Cribb et al., 2016, Seibold, 2019). Some of the existing explanations for the spikes can be ruled out in the Swiss case, for example the availability of health insurance (Rust and Phelan, 1997) or a sharp nonlinearity

\footnotetext{
${ }^{24}$ To obtain standard errors for our estimates of $\pi$ and $\sigma_{\varepsilon}$, we perform one iteration in the full likelihood Rust (1994). Not surprisingly, given the size of the model estimation sample (274875 individuals) and the parsimonious specification of the model, the estimates are precisely estimated - the standard error estimates are 0.0010 for $\pi$ and 0.0012 for $\sigma_{\varepsilon}$, so that our estimates are significant at the $1 \%$ level.
} 
in financial incentives induced by earnings tests or employer pension plans (Mastrobuoni, 2009). However, several other leading explanations cannot be ruled out a priori in our setting, including lack of information about claiming options (Liebman and Luttmer, 2015), peer effects (Brown and Laschever, 2012), and perceiving the FRA as a reference point coupled with loss aversion, because early claiming involves a penalty (Behaghel and Blau, 2012; Seibold, 2019). Default behavior ((Chetty et al., 2014), (Madrian and Shea, 2001) - avoiding the costs associated with deviating from a default choice - is also a possibility, as claiming before the FRA requires filing paperwork and delaying claiming requires filing additional paperwork.

To sort through the long list of possibilities, we fielded an original survey as part of the LINK Internet Panel, a representative internet panel of the Swiss population with 115,000 respondents. The survey was sent to 5,000 women aged 60 to $65 ; 2,916$ women opened the survey and 1,223 women completed it, resulting in a response rate of $25 \% 25$ We also asked women at what age they claimed their OASI pension, or at what age they plan to claim it in case they have not claimed it already. All women in the survey were born after January 1, 1948, and thus face the same incentives as the women in the MAF cohort of our study. Appendix Figure E.14 shows the claiming age distribution resembles closely the one observed in the administrative data: about $85 \%$ of women claim (or plan to claim) at the MAF FRA of age 64 and few claim early or delay claiming.

Using a field experiment to randomly provide information about important aspects of Social Security, Liebman and Luttmer (2015) show that simply sending an informational brochure and an invitation to a web-tutorial can significantly affect the retirement decisions of older workers. In our setting, it could be that older workers end up claiming benefits at the FRA because they are not fully informed about the possible options. We approached this possibility in two ways. First, we allowed respondents to say "I didn't know I could start my OASI pension at another age" in response to a list of possible reasons why they claimed at the age they did (the other possible reasons are studied below). Second, we asked women how they gathered information to make their claiming decision. Here, respondents had to chose at least one and up to three of the following options: sought advice from a financial advisor, sought advice from an employee at the OASI office, sought advice from friends or family, searched online or attended a workshop (for example at the workplace), thought about it themselves, or did not think about it.

In Figure 8(a) we see that a relatively small fraction $(<20 \%)$ of women responded that they "did not think" about the claiming decision beforehand. Importantly, the proportion of women who claimed at or after the FRA that say they did not think about it is significantly larger than the set of women who claimed early and said they did not think about it. This points to rational inattention as a potential partial explanation for the passivity displayed by some women in the claiming decision, but it cannot be a major explanation.

The vast majority of women do gather information; about 25-30\% of women selected each of these options, independent of the claiming age. Early claimers, late claimers and women who claimed at the FRA were all (roughly) equally likely to get their information from a financial advisor, from family and friends and online or at a workshop. A very small fraction $(<10 \%)$ thought through it themselves. The one information source that systematically differed between women who claim at the FRA and women who

\footnotetext{
${ }^{25}$ Appendix Table E.8 shows that women from the French-speaking region and women with missing or low wealth were less likely to complete the survey, while women renting a house, women with high education, and older women were more likely to complete the survey.
} 
don't is the OASI office: Women who claim before the FRA, compared to women who claim at the FRA, are significantly more likely to seek advice from the OASI office.

As we see in figure 8(b), a relatively small fraction $(<20 \%)$ of women say they simply didn't know that there was another option besides the one they chose. Perhaps more importantly, there is no statistical difference between the fraction of women who claimed at the FRA from those who either claimed early or late. So, a lack of knowledge about claiming age options cannot drive the spike in claiming at the FRA that we observe.

In sum, the takeaway so far is that a lack of information or knowledge about options cannot explain the spike in claiming at the FRA. Few women claim that they didn't know about the possibility of claiming at an age other than the one they did or intend to, and there is no difference between those who claimed at the FRA and those who didn't. The vast majority of women spend time gathering information and thinking about the decision, and for the most part the source of information doesn't vary significantly as a function of claiming age.

We then explore alternative sources of passivity. Adjustment costs associated with opting out of a default have been identified as important for explaining passive decision making (Madrian and Shea, 2001) in saving for retirement 26 The FRA is the default claiming age in the sense that individuals must file paperwork ahead of time when claiming before the FRA or file additional paperwork when claiming after the FRA. We asked women whether "the process to start my OASI pension at another age is too burdensome" was an important reason that they claimed at the age they did. Again, looking at the column labelled Hassle in Figure 8(b) we see that about 20\% said this was an important consideration, but there is no difference between FRA claimers and other claimers. Adjustment costs do not explain the spike either.

The remaining reasons offered, "I wanted to start my OASI pension at the same age I retire" (Claim/Retire Together in Figure 8b), "My family and friends started their OASI pension at the same age" (Family/Friends in Figure 8b), "I wanted to avoid getting a reduced OASI pension" (Avoid Penalty in Figure 8b), and it seems natural to start my OASI pension at that age (Reference Point in Figure 8b) were all listed as important by more than half the women who answered this question. ${ }^{27}$ They also were substantially more important for women who delayed claiming than for women who claimed before the FRA. We discuss each in turn.

Claim/Retire Together: Although retirement and benefits claiming are institutionally untied in Switzerland, individuals appear to still view the decisions as linked. There are multiple reasons this could be the case. Liquidity constraints might dictate that individuals cannot delay claiming past their retirement age. Also, as we noted above, the increase in the FRA represents a negative shock to lifetime wealth for an individual, and one response is to work longer. Thus, a person who intended to claim after retirement might shift their retirement age later to compensate for the wealth shock, reducing the distance between retirement and claiming ages.

\footnotetext{
${ }^{26}$ While (Chetty et al. 2014 ) do not take a stand on the source of passivity in their setting, the hassle associated with deviating from the status quo is a primary candidate explanation.

${ }^{27}$ The exact wording of the question is "you will now see different reasons why some people started collecting the OASI pension at age X (where X would be the person's claiming age). Please indicate whether, for your claiming decision, this reason was important or not important." For women who have not claimed yet, we replaced the verbs in past tense with verbs in present tense.
} 
Family/Friends: Brown and Laschever (2012) exploit reforms that differentially impacted financial incentives for teacher retirement within and across schools to study whether peer effects matter in the decision of when to retire. They find that a teacher's own likelihood of retirement is significantly affected by the retirement of other teachers at the same school in the previous year. Similarly, we find that the decisions of an individual's family and friends (presumably including co-workers) are influential, though not quite to the same degree as the other three significant factors.

We do note however that the decisions of family and friends themselves may be affected by the other factors given here and then transmitted through peer effects, meaning we underestimate the overall impact of other factors.

Avoid Penalty and Reference Point: Behaghel and Blau (2012) and Seibold (2019) posit that reference dependence with loss aversion is important for explaining spikes in retirement decisions. In Switzerland, the FRA is called Normales Pensionsalter, or, "normal pension age," and the benefits associated with claiming early are framed as a loss relative to the "full benefits" one would receive by claiming at the FRA ${ }^{28}$ These reasons were both most important factors cited in our survey, and also represent the reasons that had the biggest gap in affirmative response between FRA (or later) claimers and early claimers. More than $80 \%$ of women who claim at the FRA say that "avoiding the penalty" and "claiming at the FRA seems natural" are important determinants for their claiming decision. Women who delay claiming may also do so because of loss aversion. Indeed, we find that avoiding the penalty is equally important for women who claim after the FRA as for women who claim early. In contrast, "claiming at the FRA seems natural" is less important for women who claim after instead of at the FRA, consistent with only the FRA being a reference point. For women who claim early neither loss aversion nor the reference point should matter and as such we see that these two reasons are significantly less important than for women who claim at or after the FRA.

\section{Figure 8}

In sum, a lack of information and knowledge about the options is not an important reason for spikes in claiming ages. The most important reason is that individual preferences exhibit reference dependence with an aversion to losses associated with early claim penalties. This has important implications for how the government frames the schedule of pension adjustment factors. Moreover, policy makers would not help reduce passivity by providing more information to individuals.

\subsection{Policy Implications}

The total effect of pension reforms on social security wealth has two components. First, there is a direct mechanical component because, holding fixed the claiming age, individuals simply have lower benefits. Consider the FRA63 stage of the reform, for example. An individual in the FRA63 cohort who claims at 62 takes a $3.4 \%$ cut in benefits relative to an individual who is in the FRA62 cohort and claims at 62 . Similarly, an individual in the FRA63 cohort who claims at 63 does not receive the $5.2 \%$ gain that an individual in the FRA62 cohort does, and so on. Individuals are able to adjust their claiming age to

\footnotetext{
${ }^{28}$ An alternative would be to label the benefits associated with early claiming as "full benefits" and the benefits associated with claiming at the FRA as a gain or reward.
} 
at least partly compensate for these mechanical wealth shocks. The individual who would have claimed at 62 under FRA62 may no longer do so to avoid the 3.4\% cut in benefits (although such a response would in fact exacerbate the negative impact of the reform on SSW, given the actuarial unfairness of this stage of the reform). These adjustments in the claiming are the behavioral component of the total effect.

In Table 8, we study the mechanical and behavioral implications of the reform for women's lifetime income (the discounted sum of OASI pensions, earnings, and UI benefits) and on government's fiscal costs (the discounted sum of spending on OASI pensions and UI benefits minus payroll tax revenue). We use a discount factor of 0.98 and survival rates that vary by income and marital status. To separate out the behavioral and mechanical effects on SSW, we do the following exercise. For individuals in a control cohort, we apply to the observed claiming ages the pension adjustment factors associated with the treatment cohort and calculate the resulting hypothetical SSW. The difference between the actual SSW for individuals in the treatment cohort and the hypothetical SSW in the control cohort represents the behavioral effect; pension adjustment factors are the same for both cohorts and the calculated difference is a consequence purely of changes in behavior. To calculate the mechanical effect, we then subtract from the total effect the calculated behavioral effect.

The behavioral component of the effect of the reform on SSW reveals how much money women leave on average on the table by being passive. Since the reform reduces benefits at all claiming ages (except for MAF cohorts who claim after age 63), the total SSW change will be negative - there is no way for individuals to adjust behavior in a way that increases total SSW. Panel A of Table 8 shows that the total SSW declines by 24,228 CHF and 27,632 CHF for FRA63 and FRA64 cohorts and by 4,261 CHF for the MAF cohort, although the effect for the MAF cohort is not statistically significant. Women can mitigate part of this loss by adjusting their claiming age. For example, given the actuarial unfairness inherent to the FRA63 and FRA64 stages of the reform, women in these cohorts can mitigate the negative effects on SSW by claiming early. If women were to adjust in this way, we would observe a positive behavioral effect on SSW. However, Table 8 shows that the behavioral SSW change is negative and large for women in FRA63 and FRA64 cohorts. Women do not adjust their claiming ages to mitigate the negative shock to pension wealth, providing evidence consistent with mainly passive women responding to the FRA63 and FRA64 reform steps. The behavioral SSW change is positive (but not statistically significant) for women in the MAF cohort, providing evidence consistent with active women responding to the MAF reform step. Women offset part of the loss in SSW by working longer and receiving unemployment benefits. Consequently, for FRA63 and FRA64 total lifetime income declines only half as much as SSW, while for MAF total lifetime stays the same.

Panel B of Table 8 present estimates of total fiscal costs - the sum of SSW and UI benefits minus payroll taxes-and the fiscal multiplier. The fiscal multiplier measures total fiscal costs relative to mechanical fiscal costs, which correspond to the mechanical change in SSW. As Haller (2020) shows, the fiscal multiplier is key for welfare analysis: all else equal pension reforms with a higher fiscal multiplier are more likely to be welfare-enhancing. We find that the fiscal multiplier for FRA63 and FRA64 varies between 1.6 to 2.16, implying that a one Swiss Franc cut in OASI benefits increases public funds by 1.6 to 2.16 Swiss Francs. In contrast, the fiscal multiplier for MAF is about two to three times smaller (0.7-0.9).

The large difference in fiscal multipliers is explained by passivity. An increase in the FRA with actuarially unfair pension adjustments is extra costly for passive individuals: They lose more pension wealth 
than the mechanical effect would imply. However, the same type of reform generates extra savings for the government: Spending on the OASI program drops by more than the mechanical effect would imply. Our results illustrate that changing the FRA is a highly effective instrument to curb government spending, but it disproportionably hurts passive decision makers if coupled with actuarially unfair benefit adjustments.

Table 8

\section{Conclusion}

Using a combination of administrative and survey data, we study responses to a major reform to social security in Switzerland. Exploiting sharp cutoffs generated by the reform in a Regression Discontinuity design, we find that an increase in the Full Retirement Age (FRA) with an actuarially less than fair penalty for early claiming causes a 7 to 8 month delay in pension claiming and a 5 to 7 month delay in labor market exit. By contrast, a large increase in the penalty for claiming early with no change in the FRA delays pension claiming by only 4 months and has no effect on labor market exit.

The evidence suggests that a significant fraction of the population is not responding to incentives in the way standard economics models would predict. There is a growing belief that this type of behavioral bias is a key determinant of individuals' responses to social security reforms. Knowing the extent of the bias in the population as well as the nature of the bias can help to set the appropriate policy. We propose a novel method that relies on minimal assumptions to bound the fraction of the population that does not respond to incentives, who we label as passive decision makers. Our estimate of the bounds is $[0.46,0.69]$. Imposing weak additional structure in the context of a dynamic discrete choice model of benefit claiming, we point identify and estimate the fraction of passive decision makers to be 0.67 . The simple estimated model closely replicates the empirical claiming hazards. To uncover the source of bias, we conducted an original survey of pensioners in Switzerland. The survey responses indicate that individual behavior is guided by a tendency to view the nominal FRA as the "normal" age to claim benefits as well as an aversion to the penalty associated with claiming before the FRA, even though lifetime wealth can be increased by claiming early.

The results suggest that nominal pension claiming ages are an effective tool for governments who wish to improve the solvency of their social security systems. As we show, much of the government savings from the reform are a consequence of nominal FRA increases and not the financial penalties themselves, a result of the substantial passivity in the population. This finding introduces an interesting dilemma for governments. On the one hand, governments can exploit passivity by nominally increasing the FRA, and significantly improve the pension budget. But we show that the increases in the FRA are extremely costly for passive decision makers, who do not adjust their claiming age to maximize pension wealth. Policy changes that increase the FRA while providing weak financial incentives to delay, such as the first two stages of the Swiss reform that we study, redistribute wealth from passive decision makers to active ones. If society places equal or higher welfare weights on passive individuals, then the system should be actuarially fair. We leave the study of optimal social security systems in the presence of passive decision makers for future work. 


\section{References}

Arcidiacono, P. and Jones, J. (2003). Finite Mixture Distributions, Sequential Likelihood and the EM Algorithm. Econometrica, 71(3), 933-946.

Baker, M. and Benjamin, D. (1999). Early Retirement Provisions and the Labor Force Behavior of Older Men: Evidence from Canada. Journal of Labor Economics, 17(4), 724-756.

Behaghel, L. and Blau, D. M. (2012). Framing Social Security Reform: Behavioral Responses to Changes in the Full Retirement Age. American Economic Journal: Economic Policy, 4(4), 41-67.

Bernheim, B. and Taubinsky, D. (2018). Behvioral Public Economics. In B. D. Bernheim, S. DellaVigna, and D. Laibson, editors, Handbook of Behavioral Economics: Applications and Foundations. NorthHolland, Amsterdam.

Blundell, R., French, E., and Tetlow, G. (2016). Retirement Incentives and Labor Supply. In J. Piggott and A. Woodland, editors, Handbook of the Economics of Population Aging, volume 1B, pages 457-566. Elsevier.

Böersch-Supan, A., Härtl, K., and Leite, D. (2016). Social Security and Public Insurance. In J. Piggott and A. Woodland, editors, Handbook of the Economics of Population Aging, volume 1B, pages 781-863. Elsevier.

Brown, K. M. and Laschever, R. A. (2012). When They're Sixty-Four: Peer Effects and the Timing of Retirement. American Economic Journal: Applied Economics.

Bütler, M. and Teppa, F. (2007). The Choice Between an Annuity and a Lump-Sum: Results from Swiss Pension Funds. Journal of Public Economics, 91, 1944-1966.

Calonico, S., Cattaneo, M. D., and Titinuik, R. (2014). Robust Nonparametric Confidence Intervals for Regression Discontinuity Designs. Econometrica, 82(6), 2295-2326.

Cesarini, D., Lindqvist, E., Notowidigdo, M. J., and Östling, R. (2017). The Effect of Wealth on Individual and Household Labor Supply: Evidence from Swedish Lotteries. American Econmic Review, 107(12), $3917-3946$.

Chan, S. and Stevens, A. (1994). What You Don't Know Can't Help You: Pension Knowledge and Retirement Decision-Making. The Review of Economics and Statistics, 62(2), 467-475.

Chetty, R., Friedman, J. N., Leth-Petersen, S., Nielsen, T. H., and Olsen, T. (2014). Active vs. Passive Decisions and Crowd-Out in Retirement Savings Accounts: Evidence from Denmark. The Quarterly Journal of Economics, 129(3), 1141-1219.

Chetty, R., Stepner, M., Abraham, S., Lin, S., Scuderi, B., Turner, N., Bergeron, A., and Culter, D. (2016). The Association Between Income and Life Expectancy in the United States, 2001-2014. The Journal of the American Medical Association, 315(16), 1750-1766.

Coile, C. (2015). Economic Determinants of Workers' Retirement Decisions. Journal of Economic Surveys, $\mathbf{2 9}(4), 830-53$.

Coile, C. C. and Gruber, J. (2007). Future Social Security Entitlements and the Retirement Decision. The Review of Economics and Statistics, 89(2), 234-246.

Cribb, J., Emmerson, C., and Tetlow, G. (2016). Signals Matter? Large Retirement Responses to Limited Financial Incentives. Labour Economics, 42, 2013-212. 
Davidoff, T., Brown, J. R., and Diamond, P. A. (2005). Annuities and Individual Welfare. The American Economic Review, 95(5), 1573-1590.

Deshpande, M., Fadlon, I., and Gray, C. (2020). How Sticky is Retirement Behavior in the U.S.? Responses to Changes in the Full Retirement Age. NBER Working Paper No. 27190.

Feldstein, M. and Liebman, J. B. (2002). Social Security. In A. J. Auerbach and M. Feldstein, editors, Handbook of Public Economics, volume 4, pages 2245-2324. Elsevier.

Fetter, D. K. and Lockwood, L. M. (2018). Government Old-Age Support and Labor Supply: Evidence from the Old Age Assistance Program. American Economic Review, 108(8), 2174-2211.

Fitzpatrick, M. D. and Moore, T. J. (2018). The Mortality Effects of Retirement: Evidence from Social Security Eligibility at Age 62. Journal of Public Economics, 157, 121-137.

Fluder, R. and Salzgeber, R. (2016). Das Rentengefälle zwischen Frauen und Männern. Soziale Sicherheit/CHSS.

French, E. (2005). The Effect of Health, Wealth, and Wages on Labour Supply and Retirement Behaviour. The Review of Economic Studies, 72(2), 395-427.

Gelber, A., Isen, A., and Song, J. (2016). The Effect of Pension Income on Elderly Earnings: Evidence from Social Security and Full Population Data. Working paper, UC Berkeley.

Gruber, J. and Wise, D. A., editors (1999). Social Security and Retirement around the World. University of Chicago Press.

Gruber, J., Kanninen, O., and Ravaska, T. (2020). Relabeling, retirement and regret. Working Paper 27534, National Bureau of Economic Research.

Haller, A. (2020). Welfare Effects of Pension Reforms. Working Paper.

Hanel, B. and Riphahn, R. T. (2012). The Timing of Retirement - New Evidence from Swiss Female Workers. Labour Economics, 19(5), 718-728.

Imbens, G. W., Rubin, D. B., and Sacerdote, B. I. (2001). Estimating the Effect of Unearned Income on Labor Earnings, Savings, and Consumption: Evidence from a Survey of Lottery Players. American Economic Review, 91(4), 778-794.

Kline, P. and Tartari, M. (2016). Bounding the Labor Supply Responses to a Randomized Welfare Experiment: A Revealed Preference Approach. American Economic Review, 106(4), 972-1014.

Krueger, A. B. and Pischke, J.-S. (1992). The Effect of Social Security on Labor Supply: A Cohort Analysis of the Notch Generation. Journal of Labor Economics, 10, 412-437.

Kuhn, A., Staubli, S., Wuellrich, J.-P., and Zweimüller, J. (2020). Fatal Attraction? Extended Unemployment Benefits, Labor Force Exits, and Mortality. Journal of Public Economics.

Lee, D. S. and Lemieux, T. (2010). Regression Discontinuity Designs in Economics. Journal of Economic Literature, 48(2), 281-355.

Liebman, J. and Luttmer, E. F. P. (2015). Would People Behave Differently If They Better Understood Social Security? Evidence from a Field Experiment. American Economic Journal: Economic Policy, $7(1), 275-299$.

Liebman, J., Luttmer, E. F. P., and Seif, D. G. (2009). Labor Supply Responses to Marginal Social Security Benefits: Evidence from Discontinuities. Journal of Public Economics, 93(11-12), 1208-23. 
Lumsdaine, R. L. and Mitchell, O. S. (1999). New Developments in the Economic Analysis of Retirement. In O. Ashenfelter and D. Card, editors, Handbook of Labor Economics, volume 3, pages 3261-3307. Elsevier.

Madrian, B. C. and Shea, D. F. (2001). The Power of Suggestion: Inertia in 401(k) Participation and Savings Behavior. The Quarterly journal of economics, 116(4), 1149-1187.

Manoli, D. and Weber, A. (2016). Nonparametric Evidence on the Effects of Financial Incentives on Retirement Decisions. American Economic Journal: Economic Policy, 8(4), 160-182.

Mastrobuoni, G. (2009). Labor Supply Effects of the Recent Social Security Benefit Cuts: Empirical Estimates using Cohort Discontinuities. Journal of Public Economics, 93, 1224-1233.

McCrary, J. (2008). Manipulation of the Running Variable in the Regression Discontinuity Design: A Density Test. Journal of Economic Literature, 142(2), 698-714.

OECD (2019). Pensions at a Glance 2019. Organisation for Economic Cooperation and Development.

Rust, J. (1994). Structural Estimation of Markov Decision Processes. Handbook of Econometrics, 4, 3081-3143.

Rust, J. and Phelan, C. (1997). How Social Security and Medicare Affect Retirement Behavior in a World of Incomplete Markets. Econometrica, 65(4), 781-831.

Seibold, A. (2019). Reference Points for Retirement Behavior: Evidence from German Pension Discontinuities. CESifo Working Papers No. 7799.

Senti, C. (2011). Pensionierte als Arbeitnehmende: Ein arbeits- und sozialversicherungsrechtlicher Sonderfall mit Stolperstricken. Presentation, University of St. Gallen.

Staubli, S. and Zweimüller, J. (2013). Does Raising the Early Retirement Age Increase Employment of Older Workers? Journal of Public Economics, 108(C), 17-32. 
Figure 1: Pension Adjustment Factor (PAF) and Social Security Wealth (SSW)

(a) PAF

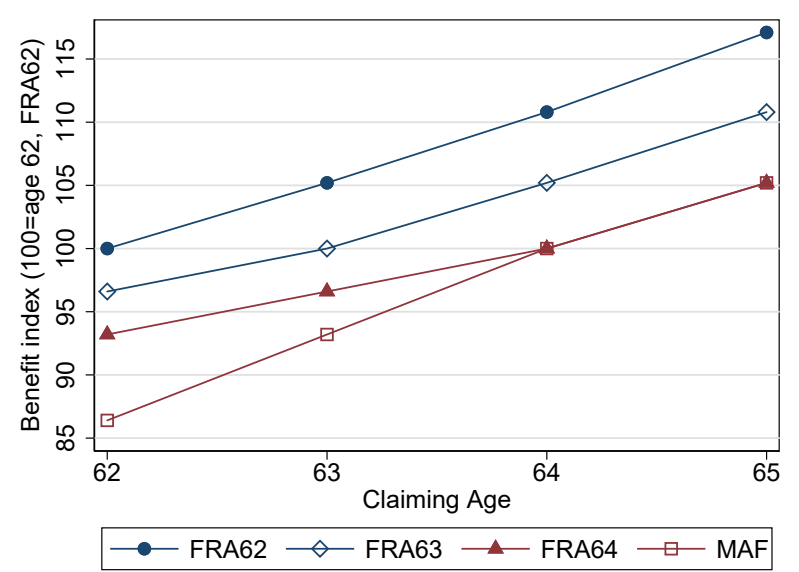

(b) SSW

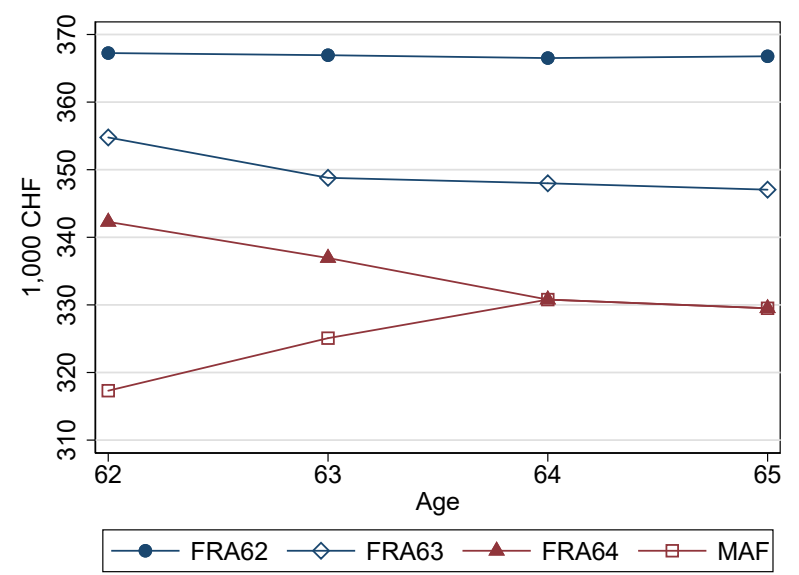

Notes: Graph (a) shows how the Swiss social security system adjusts women's old age pensions as a function of the claiming age for different pension regimes. Base pension amount, 100, is the pension for a woman with FRA 62 (born in 1938 or before), claiming a pension at age 62. Graph (b) shows the discounted social security wealth as a function of the claiming age. We assume a discount factor $\beta=0.98$ and average survival rates (see Appendix A.1 for details how we estimate survival rates).

Figure 2: Lifetime Budget Constraint with OASI Reform

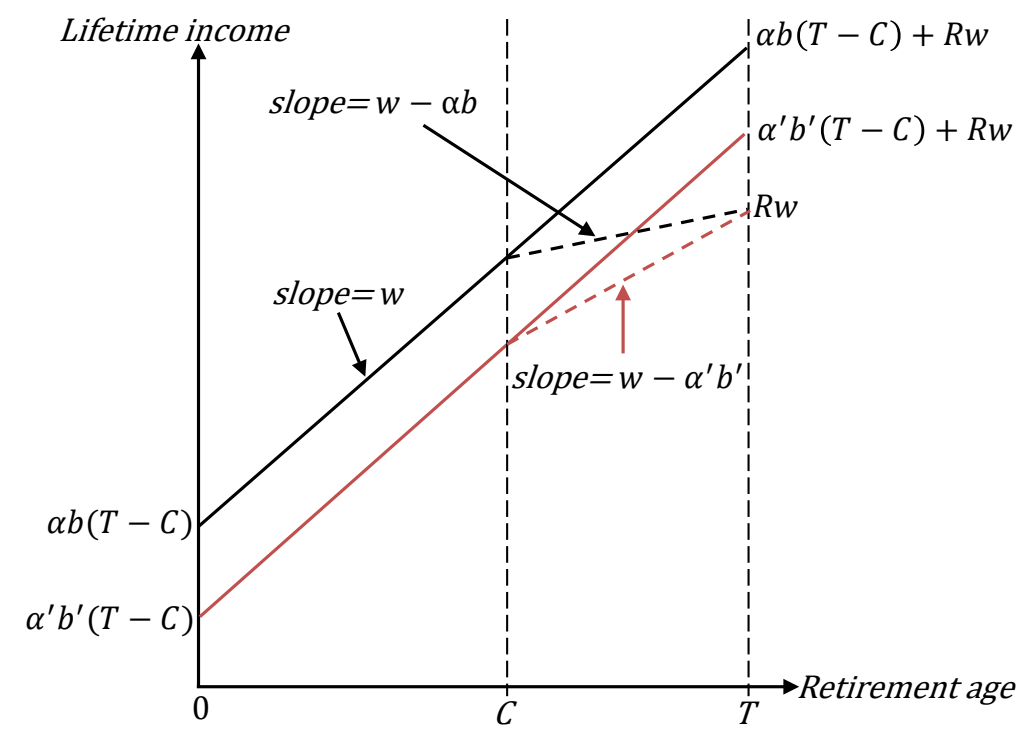

Notes: The figure shows the lifetime budget constraint linking the present value of lifetime income to the retirement age $R$, with and without an OASI reform that lowers OASI benefits from $b$ to $b^{\prime}$ and the adjustment factor from $\alpha$ to $\alpha^{\prime}$. Lifetime labor earnings are $R w$ where $w$ is the annual wage, $T$ is the age at death, and $C$ is the claiming age. Without an earnings test an OASI reform introduces a parallel downward shift of the budget constraint, creating an income effect (solid lines). An earnings test introduces a kink in the budget constraint at $C$ and an OASI reform creates an income and a substitution effect (dashed lines). For simplicity, we set the discount factor $\beta=1$. 
Figure 3: Key Outcomes

(a) FRA63

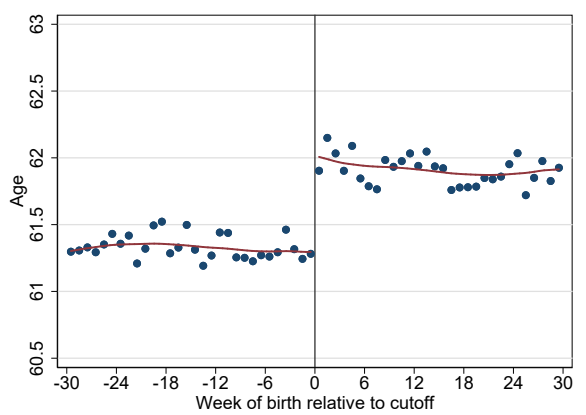

(d) FRA63

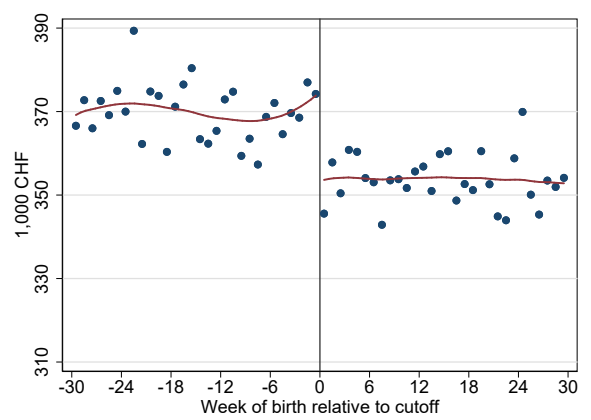

(g) FRA63

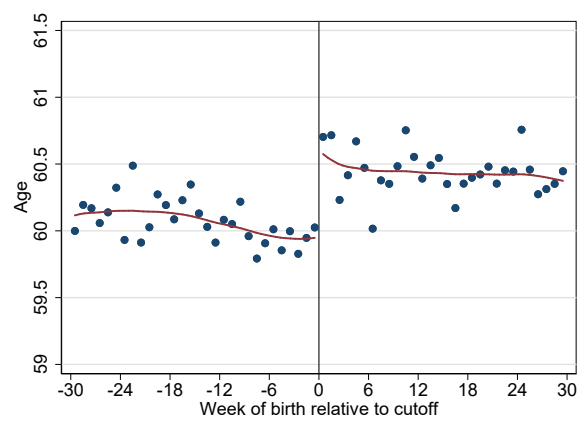

A. Claiming Age

(b) FRA64

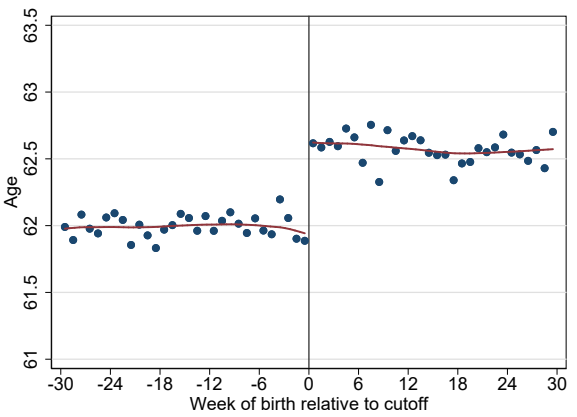

B. Social Security Wealth

(e) FRA64

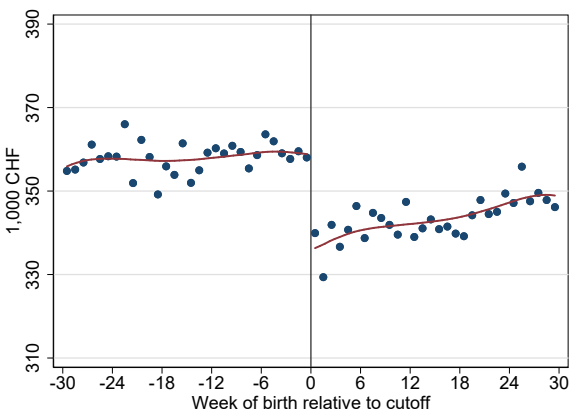

C. Retirement Age

(h) FRA64

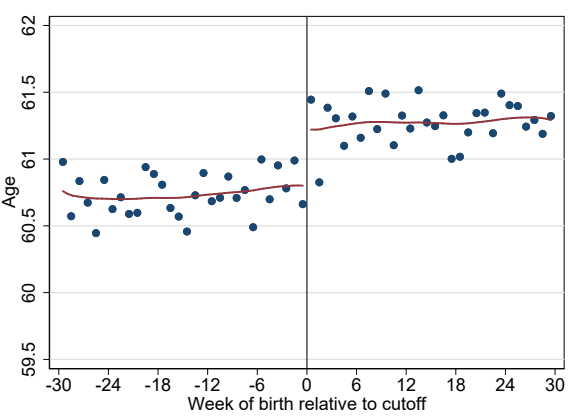

(c) MAF

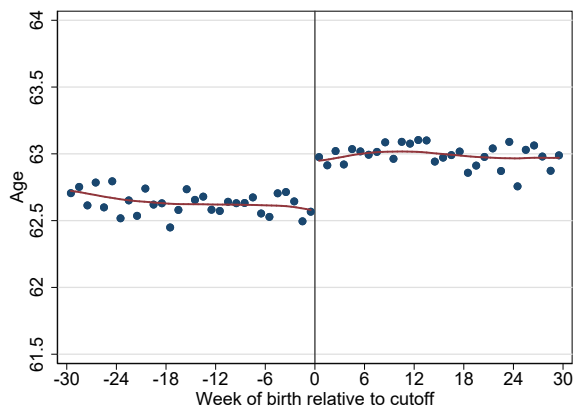

(f) MAF

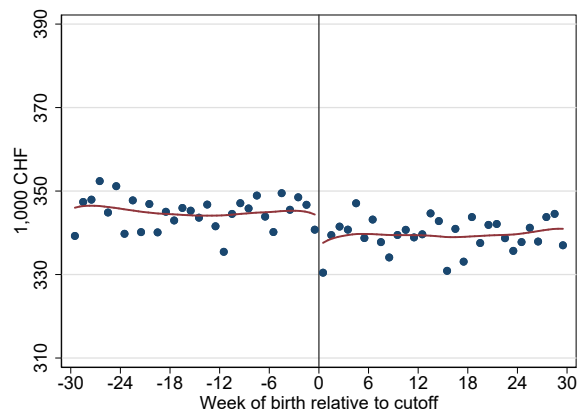

(i) $\mathrm{MAF}$

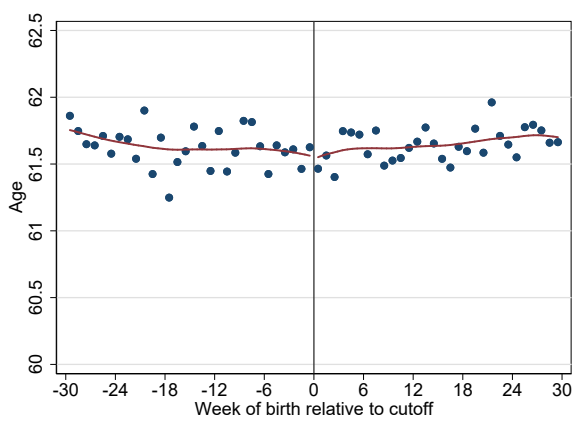

Notes: The figures show the claiming age (panel A), the social security wealth (panel B), and the retirement age (panel C) around the cutoff separating the 1939 and 1938 birth cohorts (FRA63), the 1941 and 1942 birth cohorts (FRA64), and the 1947 and 1948 birth cohorts (MAF). The solid red line plots the best local linear fit to the actual data above and below the reform cutoff. 
Figure 4: Sensitivity to Changes in Bandwidth

(a) FRA63

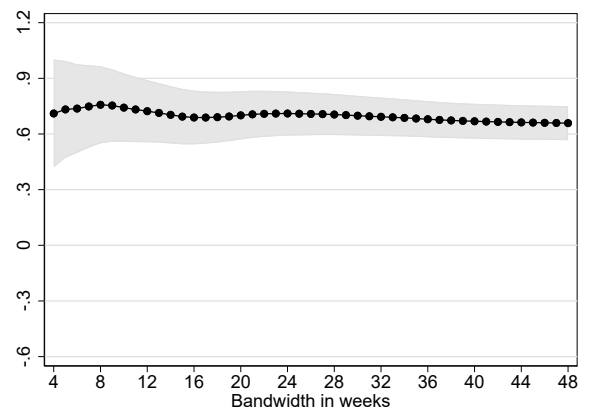

(d) FRA63

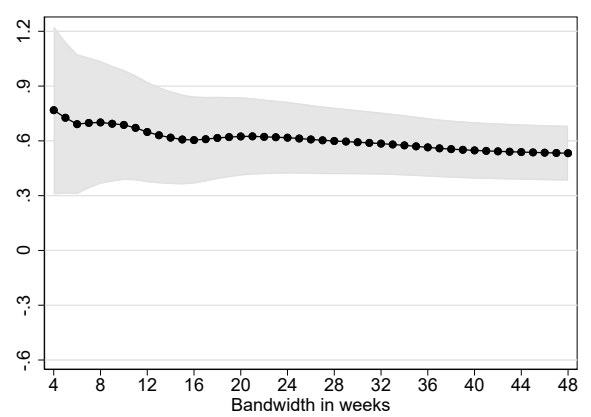

A. Claiming Age

(b) FRA64

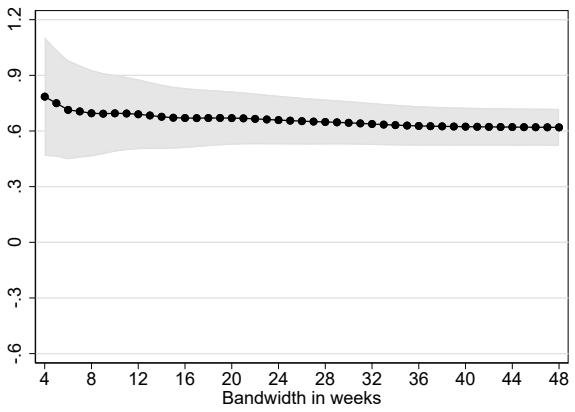

B. Retirement Age

(e) FRA64

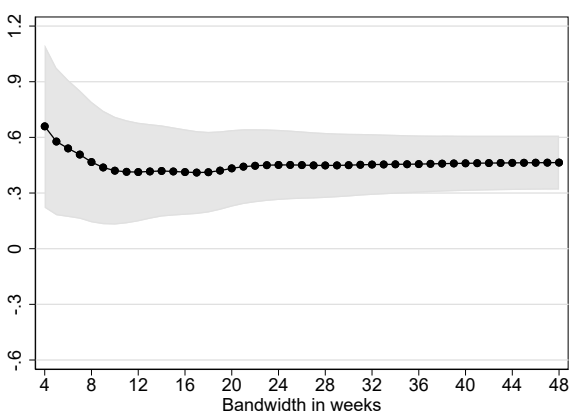

(c) MAF

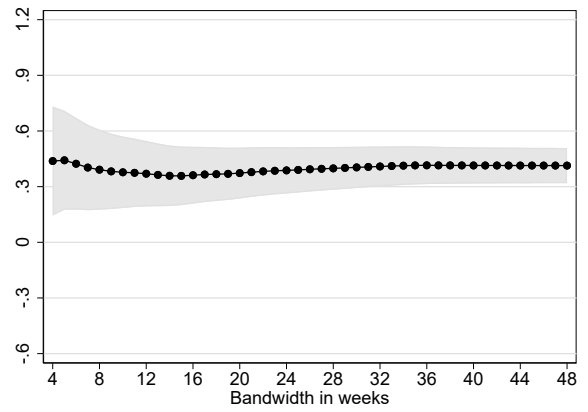

(f) MAF

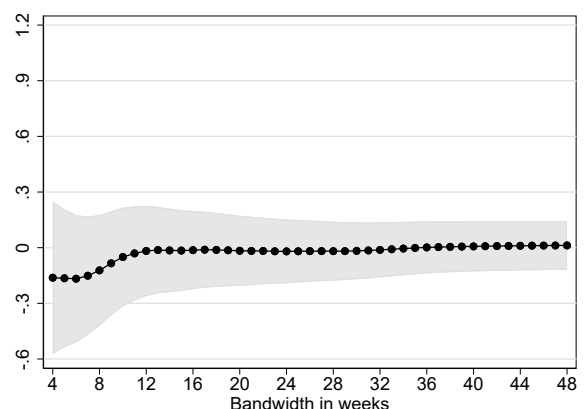

Notes: The figure shows RD-estimates of the impacts of different reform steps on the claiming age (panel A) and the retirement age (panel B) when varying the bandwidth from 4 to 48 weeks. The shaded area denotes the $95 \%$ confidence interval. The specification includes a linear trend on either side of the cutoff and observations are weighted using a triangular kernel. 
Figure 5: Placebo Regression Discontinuity Estimates

(a) Claiming Age

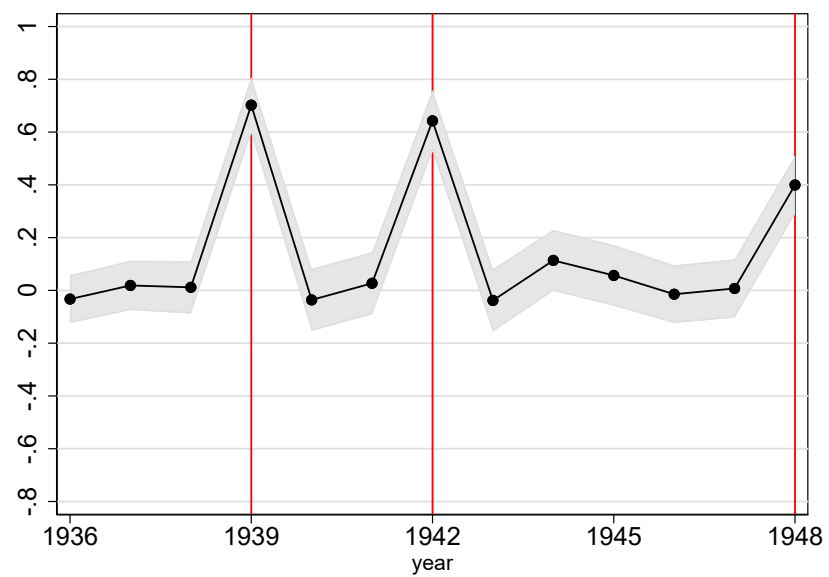

(b) Retirement Age

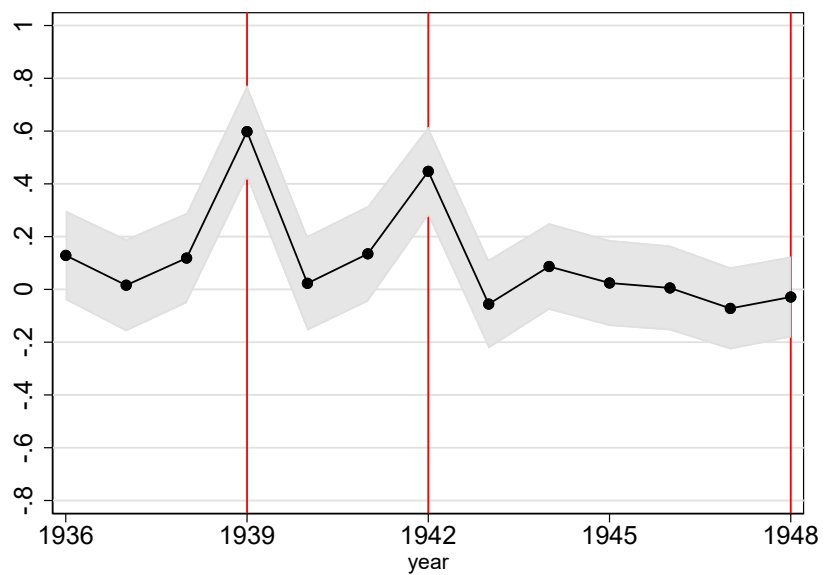

Notes: The figure shows RD-estimates for the claiming age (panel a) and the retirement age (panel b) at the true cohort cutoffs (1939, 1942, and 1942) along with placebo cutoffs (before 1939, 1940-1941, and 1943-1947). The bandwidth is 30 weeks. The shaded area denotes the $95 \%$ confidence interval. The specification includes a linear trend on either side of the cutoff and observations are weighted using a triangular kernel.

Figure 6: Heterogeneity in Claiming and Retirement

(a) Claiming Age

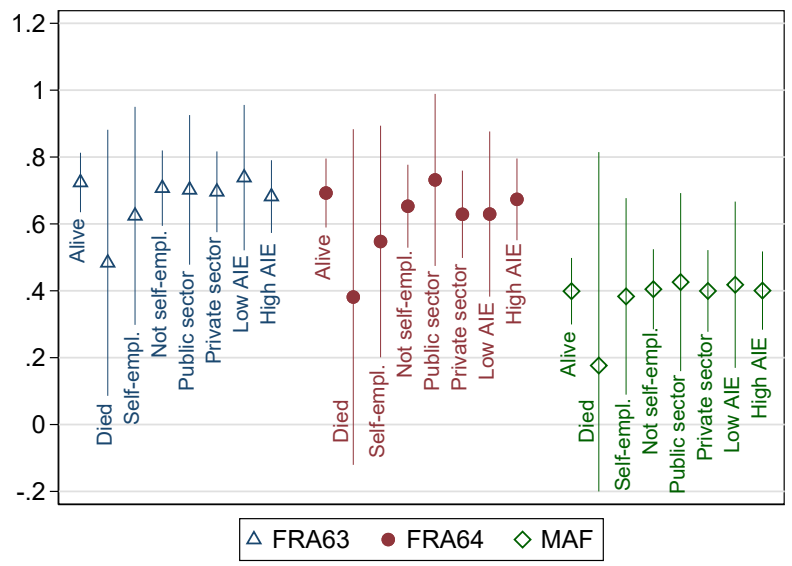

(b) Retirement Age

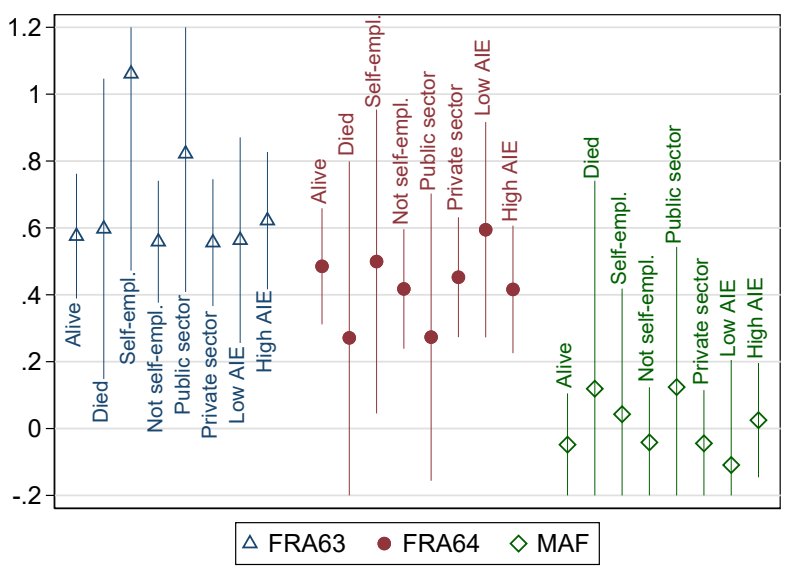

Notes: The figure shows RD-estimates for the claiming age (panel a) and the retirement age (panel b) for different subgroups. The length of the vertical lines around the point estimate denotes the $95 \%$ confidence interval (capped below at -2 and above at 1.2). The bandwidth is 30 weeks. The specification includes a linear trend on either side of the cutoff and observations are weighted using a triangular kernel. 
Figure 7: Fit of the Estimated Models

(a) FRA63

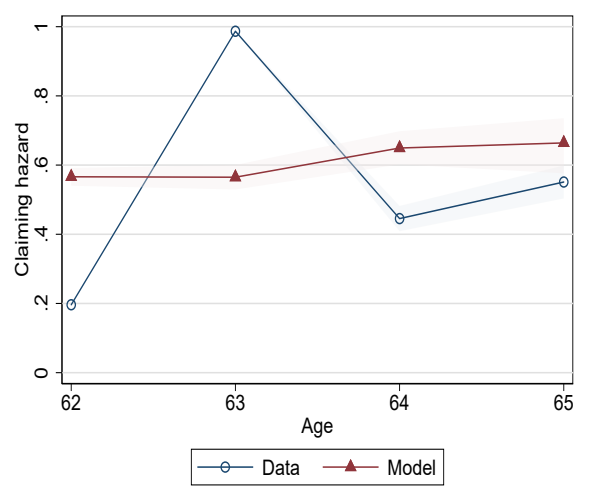

(d) FRA63

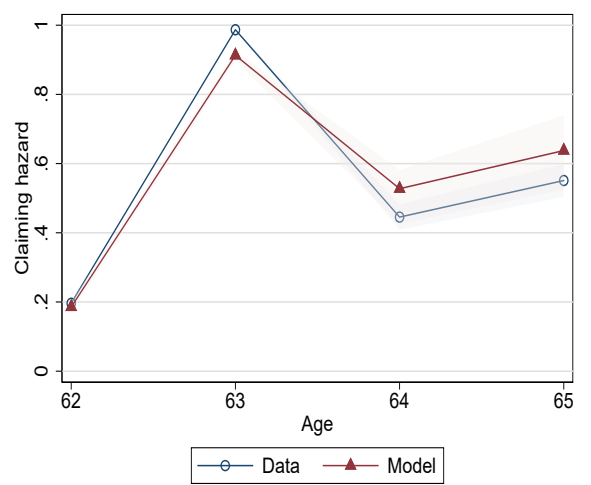

\section{A. Only Active Decision Makers}

(b) FRA64

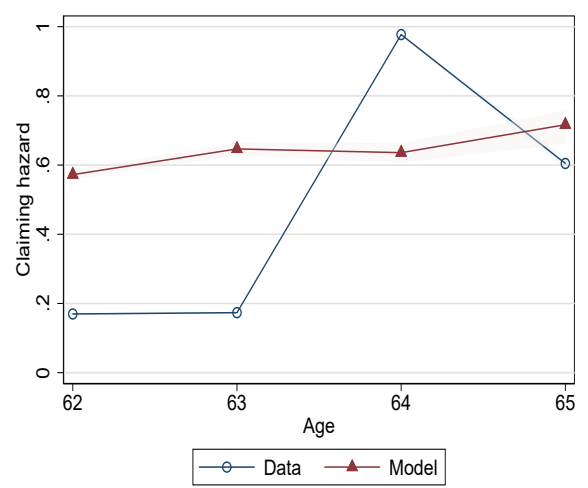

B. With Passive Decision Makers

(e) FRA64

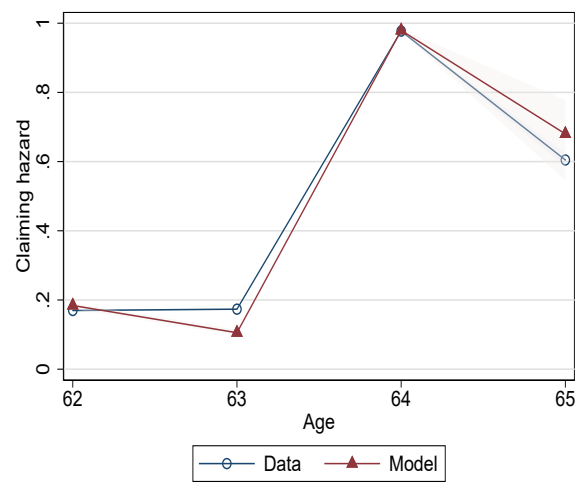

(c) MAF

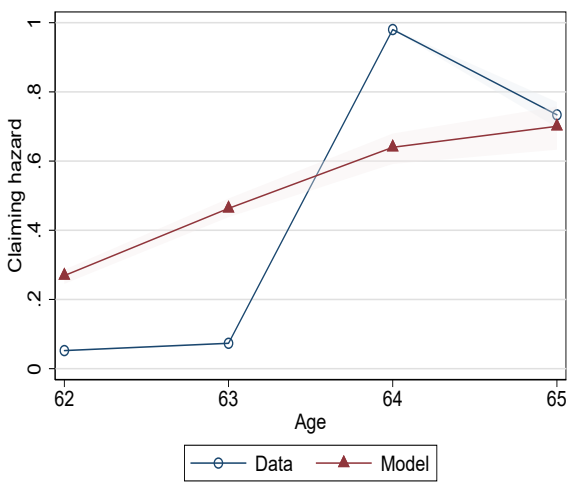

(f) MAF

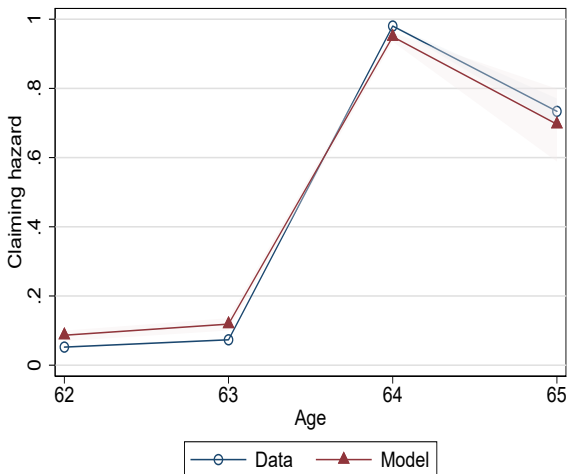

Notes: The figure shows the empirical claiming hazard (blue circles) and the simulated claiming hazards (red triangles) from a structural model with only active decision makers (panel A) and a structural model with active and passive decision makers (panel B). The share of passive decision makers is $\pi=0.67$. The shaded area denotes the $95 \%$ confidence interval. 
Figure 8: Survey Evidence on Gathering Information and Reasons for Passivity

(a) Gathering Information

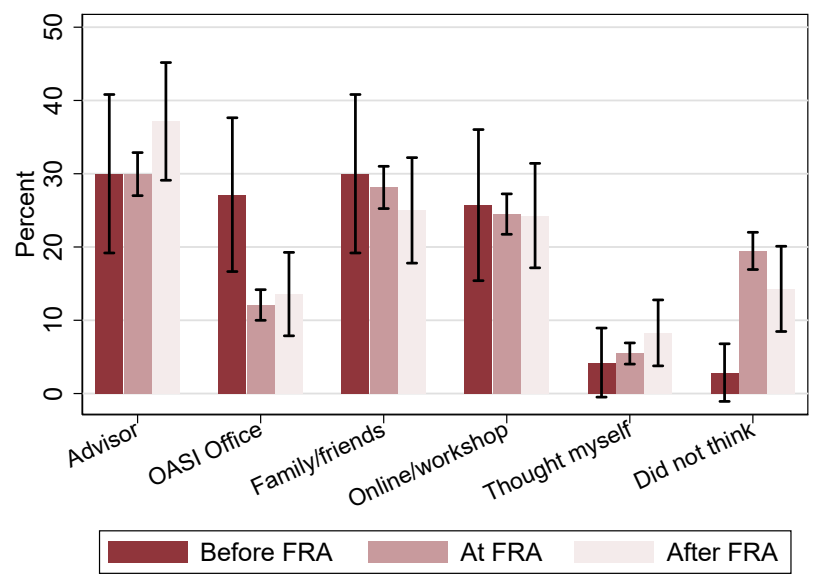

(b) Reasons for Passivity

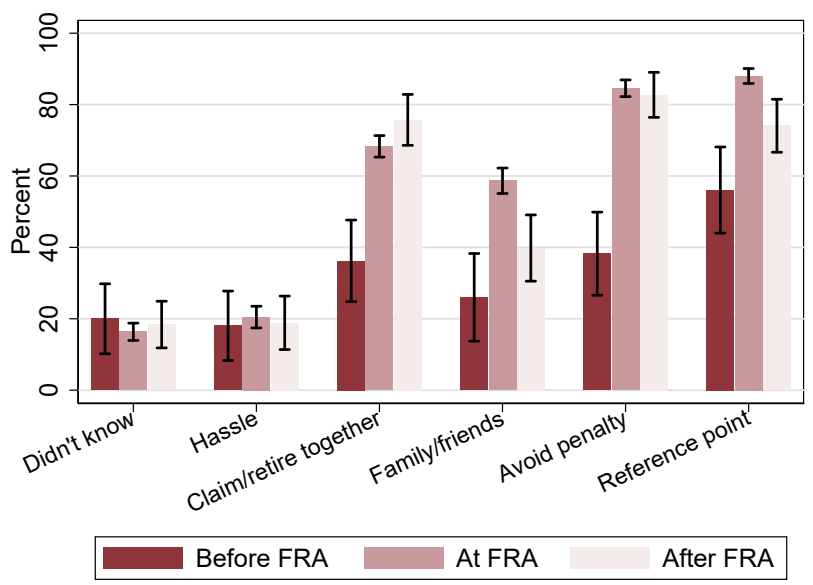

Notes: The figure shows how women gathered information to make their claiming decision (panel a) and the importance of different reasons for passivity (panel b), distinguishing between women who claim before the FRA, at the FRA, or after the FRA. The height of the bar is the percent of women who choose an option (panel a) or a reason (panel b). See text for a description of the different options and reasons. The length of the vertical lines at the end of the bar denotes the $95 \%$ confidence interval. 
Table 1: 1997 OASI Reform

\begin{tabular}{lcccc}
\hline $\begin{array}{l}\text { Reform step } \\
\text { Cohort }\end{array}$ & $\begin{array}{c}\text { FRA62 } \\
\leq 1938\end{array}$ & $\begin{array}{c}\text { FRA63 } \\
1939-1941\end{array}$ & $\begin{array}{c}\text { FRA64 } \\
1942-1947\end{array}$ & $\begin{array}{c}\text { MAF } \\
\geq 1948\end{array}$ \\
\hline $\begin{array}{l}\text { Full Retirement Age (FRA) } \\
\text { Price of Early Claiming }\end{array}$ & 62 & 63 & 64 & 64 \\
\hline
\end{tabular}

Notes: The table shows the changes to OASI benefits due to the different reform steps. FRA is the age a woman receives a full pension, the full retirement age. The price for early claiming refers to the reduction in pension benefits per year of early claiming. For instance, FRA63 cohorts could claim early at age 62 with a $3.4 \%$ lower pension.

Table 2: Percent Claiming Early: Data versus Simulations

\begin{tabular}{|c|c|c|c|c|c|c|c|}
\hline & \multirow[t]{3}{*}{ Data } & \multicolumn{6}{|c|}{ Simulation: Maximize social security wealth } \\
\hline & & \multicolumn{3}{|c|}{ Average survival rates } & \multicolumn{3}{|c|}{ Heterogenous survival rates } \\
\hline & & $\beta=0.98$ & $\beta=0.99$ & $\beta=1$ & $\beta=0.98$ & $\beta=0.99$ & $\beta=1$ \\
\hline FRA63 & 22.1 & $\begin{array}{l}70.9 \\
{[+48.8]}\end{array}$ & $\begin{array}{l}47.7 \\
{[+25.6]}\end{array}$ & $\begin{array}{l}35.6 \\
{[+13.5]}\end{array}$ & $\begin{array}{l}70.5 \\
{[+48.4]}\end{array}$ & $\begin{array}{l}47.0 \\
{[+24.9]}\end{array}$ & $\begin{array}{l}35.1 \\
{[+13.0]}\end{array}$ \\
\hline FRA64 & 29.8 & $\begin{array}{l}75.5 \\
{[+45.7]}\end{array}$ & $\begin{array}{l}52.3 \\
{[+22.5]}\end{array}$ & $\begin{array}{l}39.4 \\
{[+9.6]}\end{array}$ & $\begin{array}{l}75.2 \\
{[+45.4]}\end{array}$ & $\begin{array}{l}51.5 \\
{[+21.7]}\end{array}$ & $\begin{array}{l}38.7 \\
{[+8.9]}\end{array}$ \\
\hline MAF & 13.3 & $\begin{array}{l}18.2 \\
{[+4.9]}\end{array}$ & $\begin{array}{l}14.2 \\
{[+0.9]}\end{array}$ & $\begin{array}{l}12.5 \\
{[-0.8]}\end{array}$ & $\begin{array}{l}18.2 \\
{[+4.9]}\end{array}$ & $\begin{array}{l}14.3 \\
{[+0.9]}\end{array}$ & $\begin{array}{l}12.5 \\
{[-0.9]}\end{array}$ \\
\hline
\end{tabular}

Notes: The table presents the percent of women who claim early in the SSSD for the different reform steps (first column) and the percent of women who should claim early to maximize social security wealth for different discount factors $(\beta)$ when everybody faces the same survival rates (columns 3-5) and when we let survival rates vary by income and marital status (columns 6-8). 
Table 3: Summary Statistics

\begin{tabular}{|c|c|c|c|}
\hline & FRA63 & FRA64 & MAF \\
\hline \multicolumn{4}{|l|}{ A. Outcome variables } \\
\hline Claiming Age (years) & $\begin{array}{l}61.63 \\
(2.42)\end{array}$ & $\begin{array}{l}62.29 \\
(2.76)\end{array}$ & $\begin{array}{l}62.82 \\
(2.84)\end{array}$ \\
\hline Retirement Age (years) & $\begin{array}{l}60.26 \\
(3.89)\end{array}$ & $\begin{array}{l}61.01 \\
(4.01)\end{array}$ & $\begin{array}{l}61.64 \\
(3.97)\end{array}$ \\
\hline OASI pension (CHF per year) & $\begin{array}{l}19,076 \\
(7,061)\end{array}$ & $\begin{array}{l}19,522 \\
(6,746)\end{array}$ & $\begin{array}{l}19,586 \\
(6,700)\end{array}$ \\
\hline $\mathrm{SSW}(\mathrm{CHF})$ & $\begin{array}{l}362,357 \\
(133,988)\end{array}$ & $\begin{array}{l}355,297 \\
(121,967)\end{array}$ & $\begin{array}{l}347,571 \\
(117,376)\end{array}$ \\
\hline \multicolumn{4}{|l|}{ B. Characteristics } \\
\hline$\%$ Foreign & 21.35 & 17.70 & 16.42 \\
\hline$\%$ Married & 62.74 & 63.04 & 62.29 \\
\hline \% Supplementary pension spouse & 30.66 & 20.70 & 7.85 \\
\hline Supplementary pension amount (CHF per year) & $\begin{array}{l}2,070 \\
(3,451)\end{array}$ & $\begin{array}{l}1,278 \\
(2,865)\end{array}$ & $\begin{array}{l}364 \\
(1,591)\end{array}$ \\
\hline Average indexed earnings (CHF per year) & $\begin{array}{l}50,592 \\
(30,607)\end{array}$ & $\begin{array}{l}53,213 \\
(32,341)\end{array}$ & $\begin{array}{l}54,868 \\
(29,124)\end{array}$ \\
\hline Earnings at age 55 (CHF per year) & $\begin{array}{l}34,553 \\
(34,259)\end{array}$ & $\begin{array}{l}37,021 \\
(53,859)\end{array}$ & $\begin{array}{l}41,132 \\
(39,673)\end{array}$ \\
\hline \% German-speaking region & 70.55 & 69.97 & 69.17 \\
\hline$\%$ Self-employed & 8.59 & 10.35 & 12.18 \\
\hline$\%$ Public sector & 18.74 & 17.33 & 16.56 \\
\hline Months employed ages 50-55 & $\begin{array}{l}49.89 \\
(17.29)\end{array}$ & $\begin{array}{l}50.54 \\
(17.25)\end{array}$ & $\begin{array}{l}50.43 \\
(16.96)\end{array}$ \\
\hline Months unemployed ages 50-55 & $\begin{array}{l}0.61 \\
(2.93)\end{array}$ & $\begin{array}{l}1.32 \\
(5.02)\end{array}$ & $\begin{array}{l}1.13 \\
(4.46)\end{array}$ \\
\hline No. observations & 36,564 & 42,357 & 50,344 \\
\hline
\end{tabular}

Notes: The table reports summary statistics of key outcome variables (panel A) and background characteristics (panel B) for the three samples we use to measure the impacts of the reform steps FRA63, FRA64, and MAF. The FRA63 sample includes women born 30 weeks around the cutoff separating the 1938 and 1939 birth cohorts, the FRA64 sample includes women born 30 weeks around the cutoff separating the 1941 and 1942 birth cohorts, and the MAF sample includes women born 30 weeks around the cutoff separating the 1947 and 1948 birth cohorts. 
Table 4: Effects on Pension Benefits, Pension Claiming, and Retirement

\begin{tabular}{|c|c|c|c|c|c|c|}
\hline & \multicolumn{2}{|c|}{ FRA 63} & \multicolumn{2}{|c|}{ FRA 64} & \multicolumn{2}{|c|}{ MAF } \\
\hline & $\begin{array}{l}\text { local } \\
(1)\end{array}$ & $\begin{array}{l}\text { global } \\
(2)\end{array}$ & $\begin{array}{l}\text { local } \\
(3)\end{array}$ & $\begin{array}{l}\text { global } \\
(4)\end{array}$ & $\begin{array}{l}\text { local } \\
(5)\end{array}$ & $\begin{array}{l}\text { global } \\
(6)\end{array}$ \\
\hline \multicolumn{7}{|l|}{ A. Claiming age (years) } \\
\hline Full sample & $\begin{array}{l}0.723^{\star \star \star} \\
(0.086)\end{array}$ & $\begin{array}{l}0.699^{\star \star \star} \\
(0.055)\end{array}$ & $\begin{array}{l}0.690^{\star \star \star} \\
(0.096)\end{array}$ & $\begin{array}{l}0.644^{\star \star \star} \\
(0.060)\end{array}$ & $\begin{array}{l}0.370^{\star \star \star} \\
(0.090)\end{array}$ & $\begin{array}{l}0.404^{\star \star \star} \\
(0.057)\end{array}$ \\
\hline Single/age balanced & $\begin{array}{l}0.667^{\star \star \star} \\
(0.129)\end{array}$ & $\begin{array}{l}0.678^{\star \star \star} \\
(0.083)\end{array}$ & $\begin{array}{l}0.710^{\star \star \star} \\
(0.139)\end{array}$ & $\begin{array}{l}0.720^{\star \star \star} \\
(0.086)\end{array}$ & $\begin{array}{l}0.480^{\star \star \star} \\
(0.128)\end{array}$ & $\begin{array}{l}0.518^{\star \star \star} \\
(0.080)\end{array}$ \\
\hline Exit by age 62 & $\begin{array}{l}0.710^{\star \star \star} \\
(0.149)\end{array}$ & $\begin{array}{l}0.624^{\star \star \star} \\
(0.094)\end{array}$ & $\begin{array}{l}0.613^{\star \star \star} \\
(0.182)\end{array}$ & $\begin{array}{l}0.532^{\star \star \star} \\
(0.115)\end{array}$ & $\begin{array}{l}0.410^{\star \star} \\
(0.194)\end{array}$ & $\begin{array}{l}0.487^{\star \star \star} \\
(0.124)\end{array}$ \\
\hline \multicolumn{7}{|l|}{ B. Effects on benefits } \\
\hline Annual pension benefits & $\begin{array}{l}-348 \\
(254)\end{array}$ & $\begin{array}{l}-195 \\
(161)\end{array}$ & $\begin{array}{l}-552^{\star \star} \\
(235)\end{array}$ & $\begin{array}{l}-494^{\star \star \star} \\
(148)\end{array}$ & $\begin{array}{l}181 \\
(210)\end{array}$ & $\begin{array}{l}41 \\
(131)\end{array}$ \\
\hline SSW & $\begin{array}{l}-21,276^{\star \star \star} \\
(4,809)\end{array}$ & $\begin{array}{l}-18,322^{\star \star \star} \\
(3,052)\end{array}$ & $\begin{array}{l}-25,162^{\star \star \star} \\
(4,245)\end{array}$ & $\begin{array}{l}-23,735^{\star \star \star} \\
(2,673)\end{array}$ & $\begin{array}{l}-3,389 \\
(3,684)\end{array}$ & $\begin{array}{l}-5,608^{\star \star} \\
(2,304)\end{array}$ \\
\hline \multicolumn{7}{|l|}{ C. Retirement age (years) } \\
\hline Full sample & $\begin{array}{l}0.649^{\star \star \star} \\
(0.140)\end{array}$ & $\begin{array}{l}0.593^{\star \star \star} \\
(0.090)\end{array}$ & $\begin{array}{l}0.413^{\star \star \star} \\
(0.136)\end{array}$ & $\begin{array}{l}0.450^{\star \star \star} \\
(0.086)\end{array}$ & $\begin{array}{l}-0.018 \\
(0.124)\end{array}$ & $\begin{array}{l}-0.017 \\
(0.078)\end{array}$ \\
\hline Single/age balanced & $\begin{array}{l}0.502^{\star \star \star} \\
(0.188)\end{array}$ & $\begin{array}{l}0.530^{\star \star \star} \\
(0.121)\end{array}$ & $\begin{array}{l}0.465^{\star \star} \\
(0.182)\end{array}$ & $\begin{array}{l}0.544^{\star \star \star} \\
(0.115)\end{array}$ & $\begin{array}{c}-0.010 \\
(0.167)\end{array}$ & $\begin{array}{l}0.084 \\
(0.105)\end{array}$ \\
\hline
\end{tabular}

Notes: The table presents RD-estimates on the impact of the different reform steps on the claiming age (panel A), pension benefits (panel b), and the retirement age (panel C). The local (global) specification uses a bandwidth of 12 (30) weeks and includes a linear trend of the running variable on either side of the cutoff. Observations are weighted using a triangular kernel. Single/age balanced includes women who are single or whose husband at most two years older. ***Significant at the $1 \%$ level. **Significant at the $5 \%$ level. *Significant at the $10 \%$ level. 
Table 5: Lifetime Marginal Propensities to Earn Out of Unearned Income

\begin{tabular}{|c|c|c|c|c|c|c|}
\hline & \multicolumn{2}{|c|}{ FRA63 } & \multicolumn{2}{|c|}{ FRA64 } & \multicolumn{2}{|c|}{ MAF } \\
\hline & Coeff. & S.E. & Coeff. & S.E. & Coeff. & S.E. \\
\hline Full sample & $-0.566^{\star \star \star}$ & $(0.121)$ & $-0.385^{\star \star \star}$ & $(0.076)$ & -0.340 & $(0.319)$ \\
\hline Swiss & $-0.542^{\star \star \star}$ & $(0.098)$ & $-0.486^{\star \star \star}$ & $(0.091)$ & -0.405 & $(0.583)$ \\
\hline Foreign & $-0.368^{\star}$ & $(0.210)$ & -0.120 & $(0.109)$ & -0.536 & $(0.532)$ \\
\hline Single & $-0.519^{\star \star \star}$ & $(0.196)$ & $-0.387^{\star \star \star}$ & $(0.133)$ & -0.252 & $(0.369)$ \\
\hline Married & $-0.613^{\star \star \star}$ & $(0.145)$ & $-0.372^{\star \star \star}$ & $(0.087)$ & -0.456 & $(0.552)$ \\
\hline Self-employed & -0.686 & $(0.541)$ & -0.435 & $(1.809)$ & -1.057 & $(1.900)$ \\
\hline Not self-employed & $-0.565^{\star \star \star}$ & $(0.124)$ & $-0.370^{\star \star \star}$ & $(0.069)$ & -0.227 & $(0.293)$ \\
\hline Public sector & $-0.393^{\star \star}$ & $(0.200)$ & -0.126 & $(0.086)$ & -1.231 & $(12.56)$ \\
\hline Private sector & $-0.623^{\star \star \star}$ & $(0.146)$ & $-0.434^{\star \star \star}$ & $(0.091)$ & -0.323 & $(0.299)$ \\
\hline Low AIE & -0.587 & $(0.388)$ & $-0.413^{\star \star}$ & $(0.185)$ & -0.256 & $(0.256)$ \\
\hline High AIE & $-0.597^{\star \star \star}$ & $(0.103)$ & $-0.448^{\star \star \star}$ & $(0.085)$ & -0.479 & $(0.547)$ \\
\hline
\end{tabular}

Notes: The table presents RD-estimates on the impact of the different reform steps on the lifetime marginal propensity to earn out of unearned income, which is equal to the RD-estimate on the effect on lifetime earnings divided by the RD-estimate on lifetime pension wealth. The specification uses a bandwidth of 30 weeks and includes a linear trend of the running variable on either side of the cutoff. Observations are weighted using a triangular kernel. ${ }^{* * *}$ Significant at the $1 \%$ level. ${ }^{* *}$ Significant at the $5 \%$ level. *Significant at the $10 \%$ level.

Table 6: Categorizing Actives and Passives by Compliance

\begin{tabular}{llll}
\hline & \multicolumn{1}{c}{ FRA63 } & \multicolumn{1}{c}{ FRA64 } & \multicolumn{1}{c}{ MAF } \\
\hline Compliers & $\begin{array}{l}\text { All Passives } \\
\text { Some Actives }\end{array}$ & $\begin{array}{l}\text { All Passives } \\
\text { Some Actives }\end{array}$ & $\begin{array}{l}\text { No Passives } \\
\text { Some Actives }\end{array}$ \\
Non-Compliers & $\begin{array}{l}\text { No Passives } \\
\text { Some Actives }\end{array}$ & $\begin{array}{l}\text { No Passives } \\
\text { Some Actives }\end{array}$ & $\begin{array}{l}\text { All Passives } \\
\text { Some Actives }\end{array}$ \\
\hline
\end{tabular}

Notes: The table shows for each reform step whether compliers and non-compliers are passive and/or active decision makers. Passive decision makers claim benefits at the FRA independent of financial consequences. Active decision makers respond to economic incentives when choosing their claiming age. Compliers (non-compliers) are decision makers who (do not) change their claiming decision because of the reform step. 
Table 7: Shares and Bounds

\begin{tabular}{llll}
\hline & $\begin{array}{lll}\text { FRA63 } \\
(1)\end{array}$ & $\begin{array}{l}\text { FRA64 } \\
(2)\end{array}$ & $\begin{array}{l}\text { MAF } \\
(3)\end{array}$ \\
\hline Share compliers & $\begin{array}{l}0.754^{\star \star \star} \\
(0.008)\end{array}$ & $\begin{array}{l}0.686^{\star \star \star} \\
(0.008)\end{array}$ & $\begin{array}{l}0.221^{\star \star \star} \\
(0.009)\end{array}$ \\
& & & \\
Share non-compliers & $0.246^{\star \star \star}$ & $0.314^{\star \star \star}$ & $0.779^{\star \star \star}$ \\
& $(0.008)$ & $(0.008)$ & $(0.009)$ \\
& & & \\
Lower bound passives & & $0.465^{\star \star \star}$ & \\
& & $(<0.001)$ & \\
Upper bound passives & & 3 & $0.686^{\star \star \star}$ \\
& & \multicolumn{3}{c}{$(<0.001)$} \\
\hline
\end{tabular}

Notes: The table presents RD-estimates on the impact of the different steps on compliers (=changing their claiming decision) and non-compliers (=changing their claiming decision). The lower bound is equal to the minimum of compliers in FRA63, compliers in FRA64, and non-compliers in MAF. The upper bound is equal to one minus compliers in MAF minus non-compliers in FRA64. The specification uses a bandwidth of 30 weeks and includes a linear trend of the running variable on either side of the cutoff. Observations are weighted using a triangular kernel. ${ }^{* * *}$ Significant at the $1 \%$ level. ${ }^{* *}$ Significant at the $5 \%$ level. ${ }^{*}$ Significant at the $10 \%$ level. 
Table 8: Effects on Individual Lifetime Income and Fiscal Expenditures

\begin{tabular}{|c|c|c|c|c|c|c|}
\hline & \multicolumn{2}{|c|}{ FRA 63} & \multicolumn{2}{|c|}{ FRA 64} & \multicolumn{2}{|c|}{ MAF } \\
\hline & $\begin{array}{l}\text { local } \\
(1)\end{array}$ & $\begin{array}{l}\text { global } \\
(2)\end{array}$ & $\begin{array}{l}\text { local } \\
(3)\end{array}$ & $\begin{array}{l}\text { global } \\
(4)\end{array}$ & $\begin{array}{l}\text { local } \\
(5)\end{array}$ & $\begin{array}{l}\text { global } \\
(6)\end{array}$ \\
\hline \multicolumn{7}{|l|}{ A. Individual lifetime income } \\
\hline $\begin{array}{l}\text { SSW total }(\mathrm{CHF}) \\
\text { (A) }\end{array}$ & $\begin{array}{l}-24,228^{\star \star \star} \\
(4.011)\end{array}$ & $\begin{array}{l}-21,478^{\star \star \star} \\
(2,563)\end{array}$ & $\begin{array}{l}-27,632^{\star \star \star} \\
(3,635)\end{array}$ & $\begin{array}{l}-26,009^{\star \star \star} \\
(2,283)\end{array}$ & $\begin{array}{l}-4,261 \\
(3.109)\end{array}$ & $\begin{array}{l}-6,422^{\star \star \star} \\
(1,936)\end{array}$ \\
\hline SSW behavioral (CHF) & $-10,928^{\star \star \star}$ & $-8,243^{\star \star \star}$ & $-14,525^{\star \star \star}$ & $-12,884^{\star \star \star}$ & 2,993 & 896 \\
\hline (B) & $(3,946)$ & $(2,520)$ & $(3,576)$ & $(2,244)$ & $(3,098)$ & $(1,929)$ \\
\hline Earnings $(\mathrm{CHF})$ & $11,713^{\star \star \star}$ & $11,668^{\star \star \star}$ & $10,770^{\star \star \star}$ & $10,833^{\star \star \star}$ & $5,001^{\star \star}$ & 2,147 \\
\hline (C) & $(2,004)$ & $(1,272)$ & $(2,541)$ & $(1,590)$ & $(2,497)$ & $(1,581)$ \\
\hline UI income (CHF) & $110^{\star \star \star}$ & $122^{\star \star \star}$ & $632^{\star \star \star}$ & $353^{\star \star \star}$ & -14 & 155 \\
\hline (D) & $(31)$ & $(20)$ & $(220)$ & $(134)$ & $(236)$ & $(147)$ \\
\hline Total lifetime income $(\mathrm{CHF})$ & $-12,527^{\star \star \star}$ & $-9,550^{\star \star \star}$ & $-15,852^{\star \star \star}$ & $-14,663^{\star \star \star}$ & 946 & $-3,923$ \\
\hline$(\mathrm{E}=\mathrm{A}+\mathrm{C}+\mathrm{D})$ & $(4,786)$ & $(3,043)$ & $(4,810)$ & $(3,026)$ & $(4,376)$ & $(2,745)$ \\
\hline \multicolumn{7}{|l|}{ B. Fiscal expenditures } \\
\hline Total fiscal costs (CHF) & $-22,203^{\star \star \star}$ & $-21,121^{\star \star \star}$ & $-28,310^{\star \star \star}$ & $-26,898^{\star \star \star}$ & $-5,086^{\star}$ & $-6,620^{\star \star \star}$ \\
\hline$\left(\mathrm{F}=\mathrm{A}+\mathrm{D}-(\mathrm{C}+\mathrm{D})^{*}\right.$ payroll tax $)$ & $(5,156)$ & $(2,957)$ & $(3,608)$ & $(2,278)$ & $(3,074)$ & $(1,912)$ \\
\hline $\begin{array}{l}\text { Fiscal multiplier }(\mathrm{CHF}) \\
(\mathrm{G}=\mathrm{F} /(\mathrm{A}-\mathrm{B})\end{array}$ & 1.67 & 1.60 & 2.16 & 2.05 & 0.70 & 0.90 \\
\hline
\end{tabular}

Notes: The table presents RD-estimates on the impact of the different reform steps on individual incomes (panel A) and fiscal expenditures (panel B). The local (global) specification uses a bandwidth of 12 (30) weeks and includes a linear trend of the running variable on either side of the cutoff. Observations are weighted using a triangular kernel. *** Significant at the $1 \%$ level. **Significant at the $5 \%$ level. *Significant at the $10 \%$ level. 


\section{Online Appendix of:}

\section{The Impact of Social Security on Pension Claiming and Retirement: Active vs. Passive Decisions \\ Rafael Lalive, Arvind Magesan, and Stefan Staubli}

\section{A Survival Rates and Social Security Wealth}

\section{A.1 Calculating Survival Rates}

Survival rates are a key input when calculating the social security wealth (SSW). This section describes how we predict survival rates using the Swiss Social Security Database (SSSD). We calculate these rates for the average woman as well as for the average single woman in each AIE-quintile and the average married woman in each AIE-quintile. We closely follow Chetty et al. (2016) who predict survival rates for different demographic groups in the United States.

From the SSSD, we extract all women born between 1935 and 1938 and, based on whether they are single or married and their AIE-quintile, assign them to one of ten subgroups. Since we can observe women up to age 76 , we use the empirical mortality rates to predict survival rates until age 76 . Between age 77 and age 86, we predict survival rates using a Gompertz extrapolation, based on a regression of log mortality $m_{a}$ on a linear trend in age $a$ :

$$
\log m_{a}=\alpha+\beta a g e_{a}+\varepsilon_{a}
$$

We run separate regressions for the full sample and for each of the ten subgroups defined above. Beyond age 87, we predict survival rates using mortality rates for the average women from the Swiss Federal Statistical Office.

Figure A.1 shows the predicted survival rates for the average woman in our sample together with the survival rates for women from the Swiss Federal Statistical Office. Our predicted survival rates closely align with the survival rates from the Statistical Office. If at all, our survival rates are slightly above the official rates, implying that our estimated SSW gain from delaying claiming is too high. The SSW for early claiming would be higher using the survival rates from the Statistical Office.

Figure A.2 shows the predicted survival rates for each of the ten subgroups defined by marital status and AIE-quintile. The figure shows substantial heterogeneity in survival rates. For each AIE-quintile, we observe that survival rates are higher for married women (dashed lines) relative to single women (solid lines). Moreover, we observe that women with a higher AIE tend to live longer than women with a lower AIE, consistent with evidence showing that life expectancy is highly correlated with income (Chetty et al. 2016).

\section{A.2 Alterative Ways of Calculating Social Security Wealth}

In this section, we present results for alternative ways to calculate social security wealth (SSW). Figure A.3 shows the results graphically and Table reports the corresponding numbers. Our conclusions remain 
Figure A.1: Comparison of Estimated and Official Survival Curves for Women

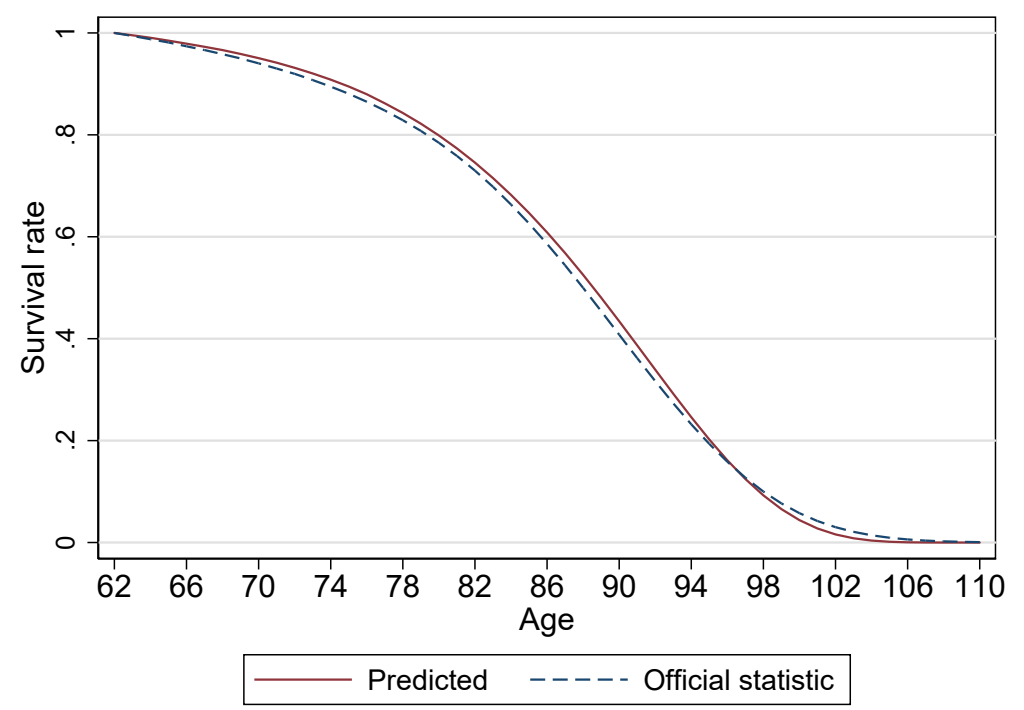

Notes: The figure shows predicted female survival rates using the SSSD and female survival rates from the Swiss Federal Statistical Office. For the prediction, we use female birth cohorts born between 1935 and 1938. Until the age 76, we predict survival rates using empirical mortality rates in the data. Between age 77 and age 86, we predict survival rates using a Gompertz extrapolation, based on a regression of log mortality on a linear trend in age. Beyond age 87, we predict survival rates using mortality rates from the Swiss Federal Statistical Office.

Figure A.2: Estimated Survival Curves for Women by Marital Status and Income

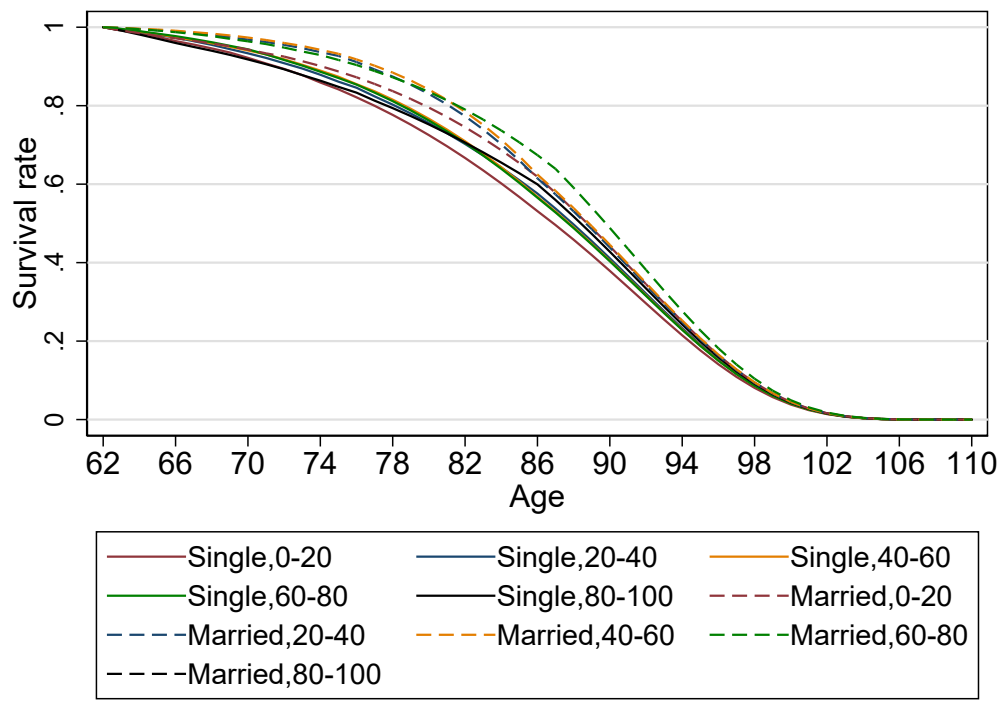

Notes: The figure shows predicted female survival rates using the SSSD data for ten subgroups defined by marital status and AIE-quintile. For the prediction, we use female birth cohorts born between 1935 and 1938. Until age 67, we predict survival rates for each subgroup using empirical mortality rates in the data. Between age 77 and age 86, we predict survival rates for each subgroup using a Gompertz extrapolation, based on a regression of log mortality on a linear trend in age. Beyond age 87, we predict survival rates for each subgroup using mortality rates from the Swiss Federal Statistical Office.

always the same: FRA63 and FRA64 are actuarially unfair, incentivizing women to claim early, while 
Figure A.3: How the Reform Affects Social Security Wealth

(a) Before-tax SSW with Accrual

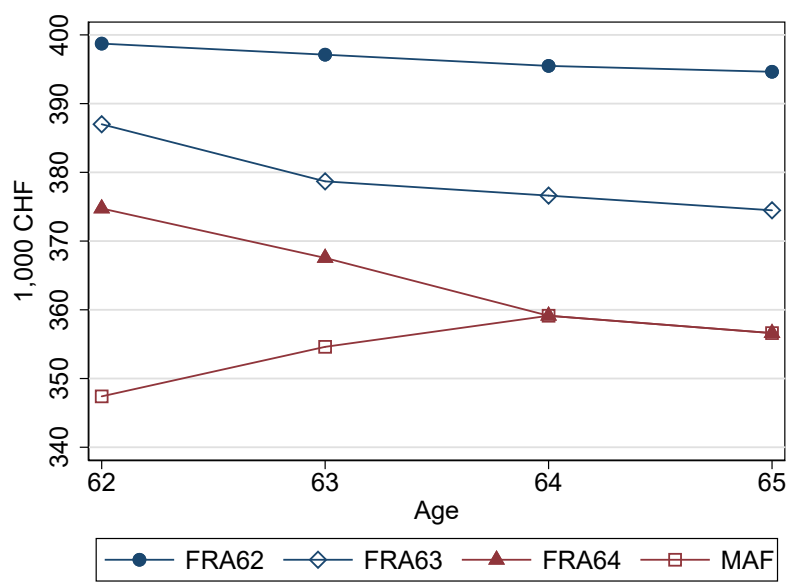

(c) After-tax SSW, Work until FRA

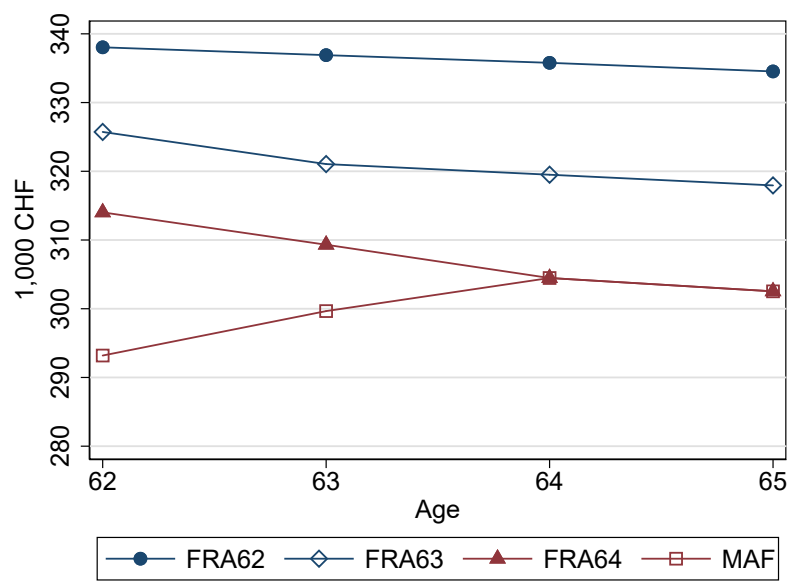

(b) After-tax SSW

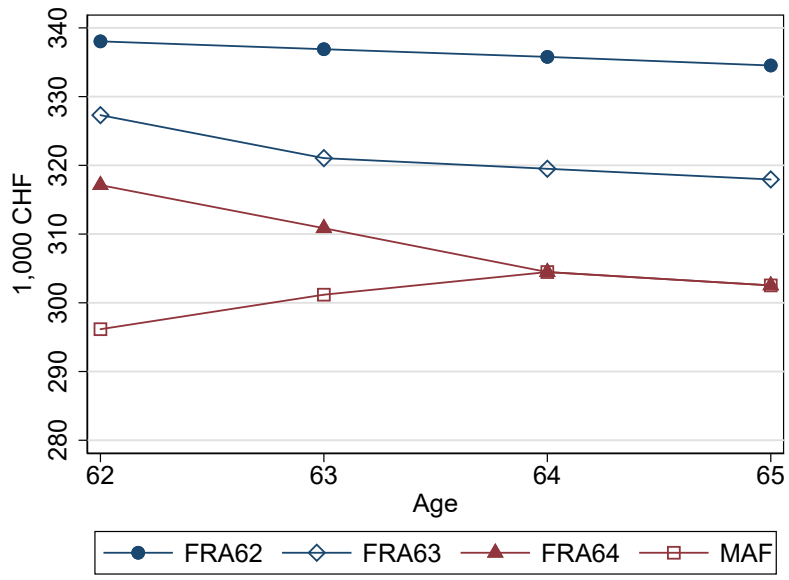

(d) After-tax SSW with Accrual, Work until FRA

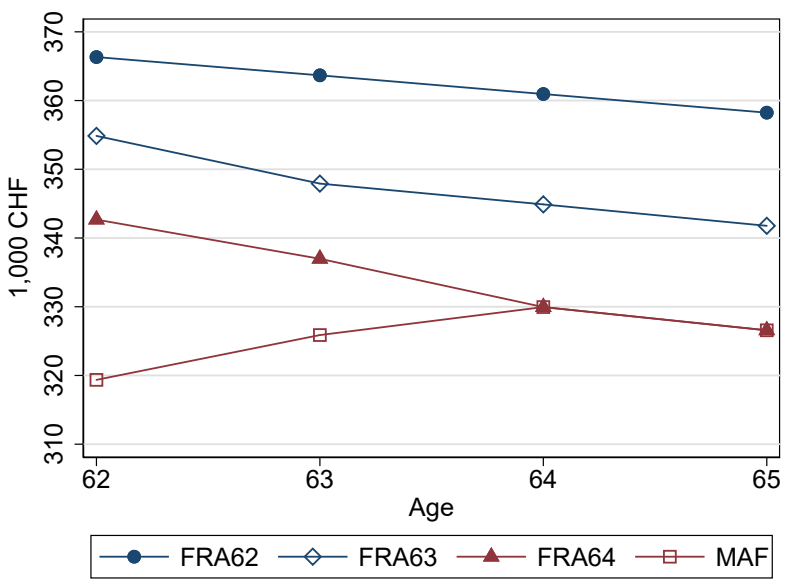

Notes: The figure shows the social security wealth (SSW) as a function of the claiming age and pension regime under different assumptions about income taxes, work behavior, and calculation of benefits. Figure (a) shows the SSW before (income) taxes taking into account the effect of additional earnings on OASI benefits (the accrual), figure (b) shows the SSW after taxes, figure (c) shows the SSW after taxes assuming people continue to work until the FRA, and figure (d) shows the SSW after taxes and with the accrual assuming people continue to work until the FRA.

MAF is more than actuarially fair, incentivizing women to delay claiming to the FRA.

The baseline SSW in Figure 1(b) is before income taxes and ignores the effect of working on OASI benefits through changes in the AIE (the pension accrual). Figure A.3 (a) shows the SSW with the pension accrual, assuming that women continue to work until the FRA. If a woman has already retired before the FRA, we take her earnings in the last job before retirement to calculate the accrual. The figure shows that for all reform steps claiming early becomes less attractive relative to the baseline case. Since older women are often past their peak earning years, continuing to work reduces their AIE and hence their OASI benefits.

Figure A.3(b) shows the SSW after income taxes. We observe that the SSW after taxes is actuarially more unfair than the SSW before taxes. Since the tax schedule is progressive, the gain in OASI benefits 
from delaying is taxed at a higher rate, making it less attractive to delay claiming.

Figure A.3(c) shows the SSW after tax if women would continue to work until the FRA. We observe that the SSW at the early claiming ages is lower relative to the case when women do not work until the FRA (A.3b). This finding is intuitive: Since Switzerland taxes OASI pension and earnings together, women who claim early and continue to work enter a higher tax bracket. But even with this additional tax burden, we see that FRA63 and FRA64 incentivize early claiming. The incentive for early claiming becomes stronger if we additionally account for the pension accrual (Figure A.3(d)).

Table A.1: Change in Social Security Wealth at Different Ages

\begin{tabular}{lllll}
\hline & FRA62 & FRA63 & FRA64 & MAF \\
\hline A. SSW63 - SSW62 & & & & \\
Before tax & -320 & $-5,970$ & $-5,343$ & 7,771 \\
Before tax with accrual & $-1,608$ & $-8,307$ & $-7,197$ & 7,209 \\
After tax & $-1,141$ & $-6,253$ & $-6,265$ & 5,022 \\
After tax, work until FRA & $-1,141$ & $-4,675$ & $-4,710$ & 6,469 \\
After tax with accrual, work until FRA & $-2,657$ & $-6,943$ & $-5,699$ & 6,521 \\
& & & & \\
B. SSW64 $-S S W 63$ & & & & \\
Before tax & -423 & -810 & $-6,152$ & 5,708 \\
Before tax with accrual & $-1,634$ & $-2,075$ & $-8,412$ & 4,524 \\
After tax & $-1,118$ & $-1,549$ & $-6,382$ & 3,291 \\
After tax, work until FRA & $-1,118$ & $-1,549$ & $-4,841$ & 4,814 \\
After tax with accrual, work until FRA & $-2,719$ & $-3,025$ & $-7,028$ & 4,070 \\
& & & & \\
B. SSW65 $-S S W 64$ & & & & \\
Before tax & 263 & -945 & $-1,285$ & $-1,285$ \\
Before tax with accrual & -853 & $-2,137$ & $-2,527$ & $-2,527$ \\
After tax & $-1,250$ & $-1,558$ & $-1,943$ & $-1,943$ \\
After tax, work until FRA & $-1,250$ & $-1,558$ & $-1,943$ & $-1,943$ \\
After tax with accrual, work until FRA & $-2,713$ & $-3,114$ & $-3,318$ & $-3,381$ \\
\hline
\end{tabular}

Notes: The table shows the difference in social security wealth (SSW) between two adjacent claiming ages underlying Figure A.3 "Before tax" calculates the SSW before (income) taxes, "before tax with accrual" is before (income) taxes and accounts for the effect of additional earnings on OASI benefits (the accrual), "after tax" is the SSW after taxes, "after tax, work until FRA" is the SSW after taxes assuming people continue to work until the FRA, and "after tax with accrual, work until FRA" is the SSW after tax, accounting for the accrual and assuming people continue to work until the FRA. We assume a discount factor $\beta$ of 0.98 and average death hazard.

\section{B Validity of Empirical Design and Robustness}

This section presents evidence supporting the validity of the RD design, explores the sensitivity of the estimates to the functional form, and studies whether the abolishment of the supplementary pension affect the robustness of our estimates.

Density Test. Figure B.4 shows that the number of women born per weeks is smooth around the cutoff dates. Table B.2 shows the corresponding RD estimates at the cohort cutoffs when the outcome is the 
Figure B.4: Number of Women per Week of Birth

(a) FRA63

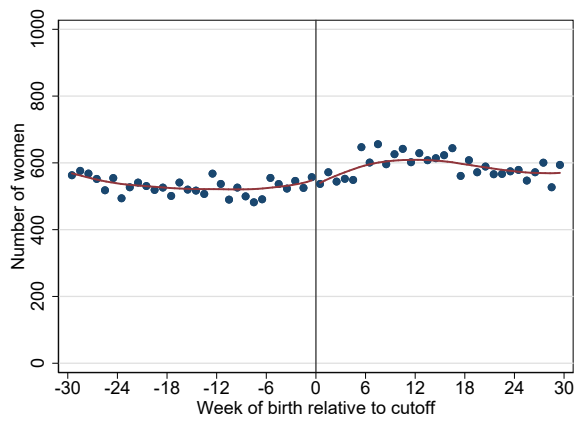

(b) FRA64

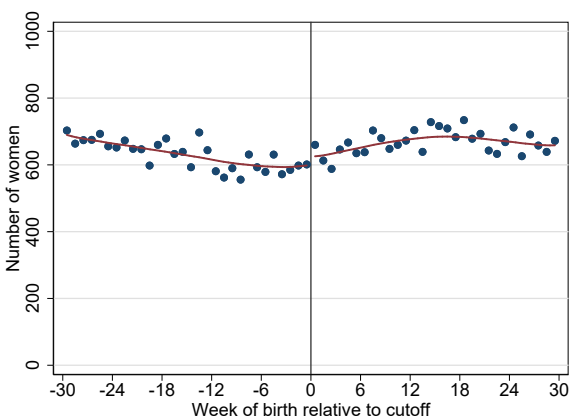

(c) MAF

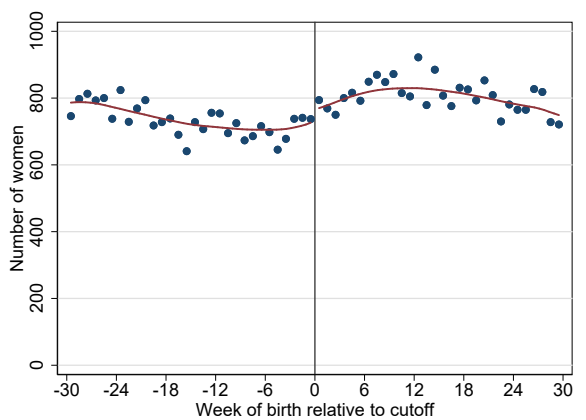

Notes: The figures show the mean number of women per week of birth around the cutoff separating the 1939 and 1938 birth cohorts (FRA63), the 1941 and 1942 birth cohorts (FRA64), and the 1947 and 1948 birth cohorts (MAF). The solid red line plots the best local linear fit to the actual data above and below the reform cutoff.

number of observations per week of birth (following McCrary, 2008). The point estimates are small and statistically insignificant for bandwidths of 12 weeks and the optimal bandwidth using the Calonico et al. (2014) procedure (CCT), independent of whether we include a linear or a quadratic trend on either side of the cutoff. The point estimates are statistically significant for the linear specification with a bandwidth of 30 weeks. Figure B.4 shows that the number of births is seasonal; the linear specification does not capture this seasonality when the bandwidth is large.

Table B.2: Number of Women per WOB

\begin{tabular}{|c|c|c|c|c|c|c|}
\hline & \multicolumn{3}{|c|}{ linear } & \multicolumn{3}{|c|}{ quadratic } \\
\hline & local & $\mathrm{CCT}$ & global & local & $\mathrm{CCT}$ & global \\
\hline \multicolumn{7}{|l|}{ A. FRA63 } \\
\hline Number of individuals & $\begin{array}{l}-17 \\
(14)\end{array}$ & $\begin{array}{l}-19 \\
(17)\end{array}$ & $\begin{array}{l}52^{\star \star \star} \\
(18)\end{array}$ & $\begin{array}{l}-23 \\
(20)\end{array}$ & $\begin{array}{l}-23 \\
(20)\end{array}$ & $\begin{array}{l}-9 \\
(15)\end{array}$ \\
\hline Bandwidth (weeks) & 12 & 8 & 36 & 12 & 12 & 36 \\
\hline \multicolumn{7}{|l|}{ B. FRA64 } \\
\hline Number of individuals & $\begin{array}{l}25 \\
(23)\end{array}$ & $\begin{array}{l}30 \\
(27)\end{array}$ & $\begin{array}{l}58^{\star \star \star} \\
(15)\end{array}$ & $\begin{array}{l}39 \\
(30)\end{array}$ & $\begin{array}{l}27 \\
(30)\end{array}$ & $\begin{array}{l}23 \\
(23)\end{array}$ \\
\hline Bandwidth (weeks) & 12 & 9 & 36 & 12 & 14 & 36 \\
\hline \multicolumn{7}{|l|}{ C. $M A F$} \\
\hline Number of individuals & $\begin{array}{l}33 \\
(21)\end{array}$ & $\begin{array}{l}20 \\
(21)\end{array}$ & $\begin{array}{l}112^{\star \star \star} \\
(21)\end{array}$ & $\begin{array}{l}7 \\
(28)\end{array}$ & $\begin{array}{l}9 \\
(26)\end{array}$ & $\begin{array}{l}39^{\star} \\
(22)\end{array}$ \\
\hline
\end{tabular}

Notes: The table presents RD estimates corresponding to equation (), where the dependent variable is the number of women per week-of-birth (WOB). The linear (quadratic) specification includes a linear (quadratic) trend of the running variable (WOB) on either side of the cutoff. The local and global specifications use a bandwidth of 12 and 30 weeks. The CCT specification uses the optimal bandwidth using the Calonico et al. (2014) procedure. Observations are weighted using a triangular kernel. ***Significant at the $1 \%$ level. **Significant at the $5 \%$ level. ${ }^{*}$ Significant at the $10 \%$ level. 
Smoothness of Predetermined Characteristics. We next explore whether predetermined characteristics change discontinuously at the cohort boundary; evidence for significant discontinuities would cause doubt that the assignment of women around the cutoff is random. Table B.3 shows separate RD estimates for a rich set of characteristics. We find little evidence for manipulation around the cohort cutoffs. When using a bandwidth of 12 weeks around the cutoffs, we find that point estimates are always statistically insignificant and small. When using a bandwidth of 30 weeks, we find that 5 out of 33 point estimates are statistically significant at the $10 \%$-level.

Table B.3: Selection on Observable Characteristics

\begin{tabular}{|c|c|c|c|c|c|c|}
\hline & \multicolumn{2}{|c|}{ FRA 63} & \multicolumn{2}{|c|}{ FRA 64} & \multicolumn{2}{|c|}{ MAF } \\
\hline & $\begin{array}{l}\text { local } \\
(1)\end{array}$ & $\begin{array}{l}\text { global } \\
(2)\end{array}$ & $\begin{array}{l}\text { local } \\
(3)\end{array}$ & $\begin{array}{l}\text { global } \\
(4)\end{array}$ & $\begin{array}{l}\text { local } \\
(5)\end{array}$ & $\begin{array}{l}\text { global } \\
(6)\end{array}$ \\
\hline$\%$ Foreign & $\begin{array}{l}0.7 \\
(1.5)\end{array}$ & $\begin{array}{l}-1.2 \\
(1.0)\end{array}$ & $\begin{array}{l}1.6 \\
(1.3)\end{array}$ & $\begin{array}{l}0.9 \\
(0.8)\end{array}$ & $\begin{array}{l}1.5 \\
(1.2)\end{array}$ & $\begin{array}{l}0.7 \\
(0.7)\end{array}$ \\
\hline$\%$ German-speaking region & $\begin{array}{l}0.3 \\
(1.5)\end{array}$ & $\begin{array}{l}-0.8 \\
(1.0)\end{array}$ & $\begin{array}{l}-2 \\
(1.4)\end{array}$ & $\begin{array}{l}0.5 \\
(0.9)\end{array}$ & $\begin{array}{l}1.8 \\
(1.3)\end{array}$ & $\begin{array}{l}1.5^{\star} \\
(0.8)\end{array}$ \\
\hline$\%$ Married & $\begin{array}{l}2 \\
(1.7)\end{array}$ & $\begin{array}{l}1.2 \\
(1.1)\end{array}$ & $\begin{array}{l}-2.4 \\
(1.7)\end{array}$ & $\begin{array}{l}-1.4 \\
(1.1)\end{array}$ & $\begin{array}{l}0.5 \\
(1.5)\end{array}$ & $\begin{array}{l}-0.1 \\
(1)\end{array}$ \\
\hline \% Husband born 1933 & $\begin{array}{l}0.7 \\
(0.8)\end{array}$ & $\begin{array}{l}0.1 \\
(0.5)\end{array}$ & $\begin{array}{l}-0.8 \\
(0.5)\end{array}$ & $\begin{array}{l}-0.2 \\
(0.3)\end{array}$ & $\begin{array}{l}0.2 \\
(0.2)\end{array}$ & $\begin{array}{l}0.2 \\
(0.1)\end{array}$ \\
\hline \% Husband born 1938 & $\begin{array}{l}-0.7 \\
(1.0)\end{array}$ & $\begin{array}{l}-0.7 \\
(0.6)\end{array}$ & $\begin{array}{l}0.4 \\
(0.9)\end{array}$ & $\begin{array}{l}-0.4 \\
(0.6)\end{array}$ & $\begin{array}{l}-0.5 \\
(0.4)\end{array}$ & $\begin{array}{l}-0.1 \\
(0.2)\end{array}$ \\
\hline$\%$ Self-employed & $\begin{array}{l}-0.1 \\
(1.0)\end{array}$ & $\begin{array}{l}-0.5 \\
(0.6)\end{array}$ & $\begin{array}{l}-0.1 \\
(1.0)\end{array}$ & $\begin{array}{l}1.2^{\star} \\
(0.7)\end{array}$ & $\begin{array}{l}0.5 \\
(1.0)\end{array}$ & $\begin{array}{l}0.8 \\
(0.6)\end{array}$ \\
\hline$\%$ Public sector & $\begin{array}{l}1.2 \\
(1.4)\end{array}$ & $\begin{array}{l}0.6 \\
(0.9)\end{array}$ & $\begin{array}{l}-2.1 \\
(1.3)\end{array}$ & $\begin{array}{c}-1.4^{\star} \\
(0.8)\end{array}$ & $\begin{array}{l}-1.5 \\
(1.1)\end{array}$ & $\begin{array}{l}0.0 \\
(0.7)\end{array}$ \\
\hline Months employed until age 55 & $\begin{array}{l}-0.85 \\
(0.62)\end{array}$ & $\begin{array}{l}-0.52 \\
(0.39)\end{array}$ & $\begin{array}{l}-0.60 \\
(0.61)\end{array}$ & $\begin{array}{l}-0.30 \\
(0.38)\end{array}$ & $\begin{array}{l}-0.19 \\
(0.53)\end{array}$ & $\begin{array}{l}-0.28 \\
(0.33)\end{array}$ \\
\hline Months unemployed until age 55 & $\begin{array}{l}0.04 \\
(0.11)\end{array}$ & $\begin{array}{l}0.02 \\
(0.07)\end{array}$ & $\begin{array}{l}-0.04 \\
(0.18)\end{array}$ & $\begin{array}{l}-0.11 \\
(0.11)\end{array}$ & $\begin{array}{l}-0.05 \\
(0.15)\end{array}$ & $\begin{array}{l}-0.04 \\
(0.09)\end{array}$ \\
\hline $\begin{array}{l}\text { Average annual indexed earnings } \\
\text { (2016 CHF) }\end{array}$ & $\begin{array}{l}-529 \\
(1,111)\end{array}$ & $\begin{array}{l}-68 \\
(687)\end{array}$ & $\begin{array}{l}-1,524 \\
(1,110)\end{array}$ & $\begin{array}{l}-1,226^{\star} \\
(693)\end{array}$ & $\begin{array}{l}-605 \\
(910)\end{array}$ & $\begin{array}{l}-256 \\
(577)\end{array}$ \\
\hline $\begin{array}{l}\text { Annual earnings at age } 55 \\
(2016 \mathrm{CHF})\end{array}$ & $\begin{array}{l}94 \\
(1,222)\end{array}$ & $\begin{array}{l}32 \\
(767)\end{array}$ & $\begin{array}{l}-673 \\
(1,194)\end{array}$ & $\begin{array}{l}-1,401^{\star} \\
(809)\end{array}$ & $\begin{array}{l}1,743 \\
(1,193)\end{array}$ & $\begin{array}{l}1,048 \\
(757)\end{array}$ \\
\hline Obs & 14,494 & 36,564 & 16,131 & 42,357 & 19,868 & 50,344 \\
\hline
\end{tabular}

Notes: The table presents RD estimates corresponding to equation (), where the dependent variable are different predetermined characteristics. The local (global) specification uses a bandwidth of 12 (30) weeks and includes a linear trend of the running variable on either side of the cutoff. Observations are weighted using a triangular kernel. ${ }^{* * *}$ Significant at the $1 \%$ level. **Significant at the $5 \%$ level. *Significant at the $10 \%$ level.

Sensitivity of Estimates to Functional Form. We also test the sensitivity of our main estimates in Table 4 by including a quadratic trend on either side of the cohort cutoff instead of a linear trend (Table B.4). We find that the RD estimates for the quadratic specification are similar to the linear specification. If at all, the point estimates appear slightly larger, but we cannot reject the null hypothesis that they are 
statistically the same as in the linear specification.

Table B.4: Main Estimates with a Quadratic Trend

\begin{tabular}{|c|c|c|c|c|c|c|}
\hline & \multicolumn{2}{|c|}{ FRA 63} & \multicolumn{2}{|c|}{ FRA 64} & \multicolumn{2}{|c|}{ MAF } \\
\hline & $\begin{array}{l}\text { local } \\
(1)\end{array}$ & $\begin{array}{l}\text { global } \\
(2)\end{array}$ & $\begin{array}{l}\text { local } \\
(3)\end{array}$ & $\begin{array}{l}\text { global } \\
(4)\end{array}$ & $\begin{array}{l}\text { local } \\
(5)\end{array}$ & $\begin{array}{l}\text { global } \\
(6)\end{array}$ \\
\hline \multicolumn{7}{|l|}{ A. Claiming age (years) } \\
\hline Full sample & $\begin{array}{l}0.771^{\star \star \star} \\
(0.127)\end{array}$ & $\begin{array}{l}0.718^{\star \star \star} \\
(0.079)\end{array}$ & $\begin{array}{l}0.717^{\star \star \star} \\
(0.141)\end{array}$ & $\begin{array}{l}0.686^{\star \star \star} \\
(0.088)\end{array}$ & $\begin{array}{l}0.413^{\star \star \star} \\
(0.131)\end{array}$ & $\begin{array}{l}0.356^{\star \star \star} \\
(0.083)\end{array}$ \\
\hline Single/age balanced & $\begin{array}{l}0.717^{\star \star \star} \\
(0.191)\end{array}$ & $\begin{array}{l}0.698^{\star \star \star} \\
(0.119)\end{array}$ & $\begin{array}{l}0.659^{\star \star \star} \\
(0.204)\end{array}$ & $\begin{array}{l}0.737^{\star \star \star} \\
(0.127)\end{array}$ & $\begin{array}{l}0.553^{\star \star \star} \\
(0.186)\end{array}$ & $\begin{array}{l}0.435^{\star \star \star} \\
(0.118)\end{array}$ \\
\hline Exit by age 62 & $\begin{array}{l}0.769^{\star \star \star} \\
(0.221)\end{array}$ & $\begin{array}{l}0.686^{\star \star \star} \\
(0.137)\end{array}$ & $\begin{array}{l}0.638^{\star \star} \\
(0.267)\end{array}$ & $\begin{array}{l}0.604^{\star \star \star} \\
(0.167)\end{array}$ & $\begin{array}{l}0.481^{\star} \\
(0.28)\end{array}$ & $\begin{array}{l}0.407^{\star \star} \\
(0.18)\end{array}$ \\
\hline \multicolumn{7}{|l|}{ B. Effects on benefits } \\
\hline Annual pension benefits & $\begin{array}{l}-553 \\
(373)\end{array}$ & $\begin{array}{l}-311 \\
(235)\end{array}$ & $\begin{array}{l}-334 \\
(342)\end{array}$ & $\begin{array}{l}-621^{\star \star \star} \\
(216)\end{array}$ & $\begin{array}{l}96 \\
(312)\end{array}$ & $\begin{array}{l}107 \\
(193)\end{array}$ \\
\hline SSW & $\begin{array}{l}-25168^{\star \star \star} \\
(7057)\end{array}$ & $\begin{array}{l}-20642^{\star \star \star} \\
(4445)\end{array}$ & $\begin{array}{l}-21986^{\star \star \star} \\
(6161)\end{array}$ & $\begin{array}{l}-26165^{\star \star \star} \\
(3908)\end{array}$ & $\begin{array}{l}-4990 \\
(5477)\end{array}$ & $\begin{array}{l}-4732 \\
(3390)\end{array}$ \\
\hline \multicolumn{7}{|l|}{ C. Retirement age (years) } \\
\hline Full sample & $\begin{array}{l}0.748^{\star \star \star} \\
(0.204)\end{array}$ & $\begin{array}{l}0.648^{\star \star \star} \\
(0.130)\end{array}$ & $\begin{array}{l}0.511^{\star \star \star} \\
(0.197)\end{array}$ & $\begin{array}{l}0.430^{\star \star \star} \\
(0.125)\end{array}$ & $\begin{array}{c}-0.171 \\
(0.182)\end{array}$ & $\begin{array}{l}-0.022 \\
(0.115)\end{array}$ \\
\hline Single/age balanced & $\begin{array}{l}0.746^{\star \star \star} \\
(0.272)\end{array}$ & $\begin{array}{l}0.484^{\star \star \star} \\
(0.175)\end{array}$ & $\begin{array}{l}0.576^{\star \star} \\
(0.264)\end{array}$ & $\begin{array}{l}0.543^{\star \star \star} \\
(0.167)\end{array}$ & $\begin{array}{c}-0.143 \\
(0.243)\end{array}$ & $\begin{array}{l}-0.032 \\
(0.154)\end{array}$ \\
\hline
\end{tabular}

Notes: The table presents RD estimates on the impact of the different reform steps on pension benefits (panel A), the claiming age (panel B), and the retirement age (panel C). The local (global) specification uses a bandwidth of 12 (30) weeks and includes a quadratic trend of the running variable on either side of the cutoff. Observations are weighted using a triangular kernel. Single/age balanced includes women who are single or whose husband at most two years older. ***Significant at the $1 \%$ level. **Significant at the $5 \%$ level. *Significant at the $10 \%$ level.

Addressing the Abolishment of Supplementary Pensions. The 1997 reform also abolished the supplementary pension for retired husbands whose wives were born in 1942 or after. This change could affect our analysis of the FRA64 reform step, because the cohort cutoff for both changes is January 1, 1942. Figure B.5(a) shows that the percent of women in our sample who receive a supplementary pension drops from 30 to 10 percentage points at the cohort cutoff. The percent does not drop to zero, because women born in 1942 or after still qualify for supplementary benefits if the husband draws a disability pension.

Our strategy to isolate the impact of FRA64 is to focus on women who are single or whose husband is at most 2 years older. This age restriction guarantees that married women become eligible for OASI benefits before the husband reaches his FRA of 65. Figure B.5(b) shows that for this sample of women there is no jump in supplementary benefit receipt at the cohort cutoff. Yet, we still observe clear jumps in the claiming age (Figure B.5c) and the retirement age (Figure B.5 d).

Table 4 in the paper reports the corresponding $\mathrm{RD}$ estimates for this sample of women. The point estimates are always similar to the full sample; we can never reject the null hypothesis that the point 
estimates are the same for the full sample and the sample of women who are single or whose husband is at most two years older. From this analysis, we conclude that the claiming and retirement responses capture primarily the impact of FRA64, while the abolishment of supplementary pensions appears to have a minimal impact.

Figure B.5: Sensitivity of FRA64 Estimates

(a) Full Sample

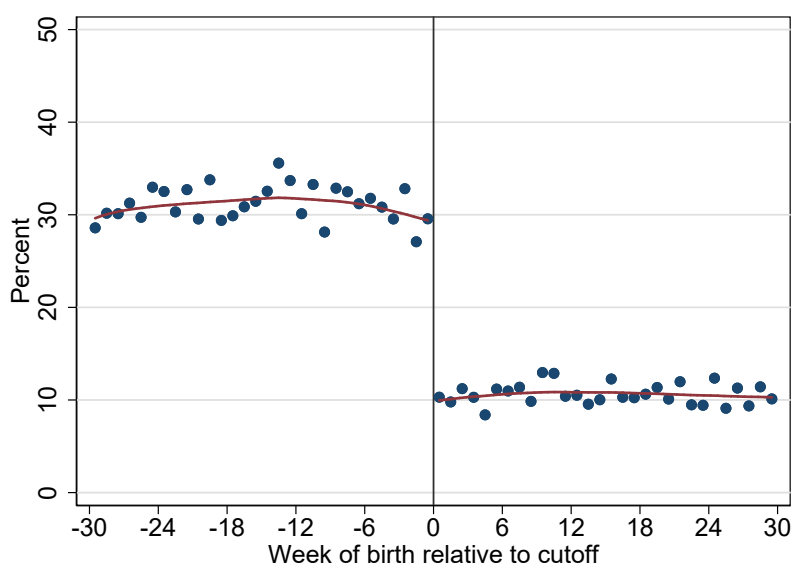

(b) Single or Age Balanced

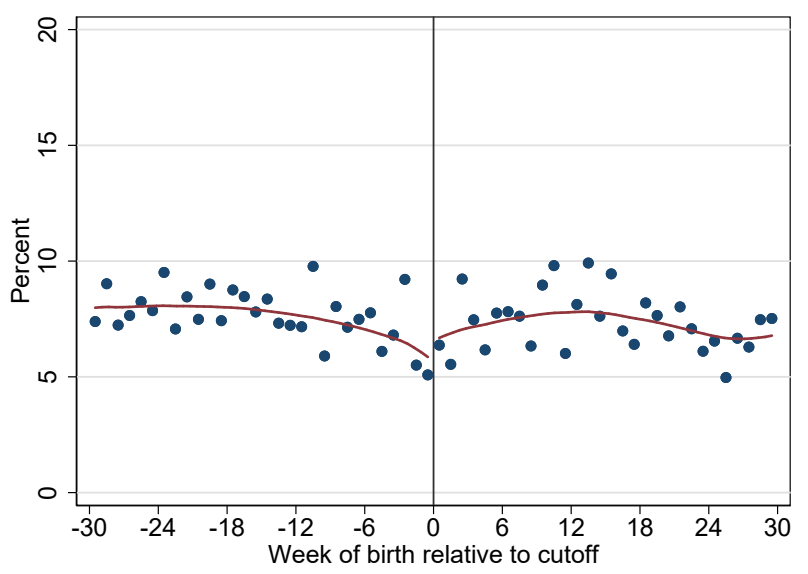

B. Retirement and Claiming Age for Single or Age Balanced Sample

(c) Claiming Age

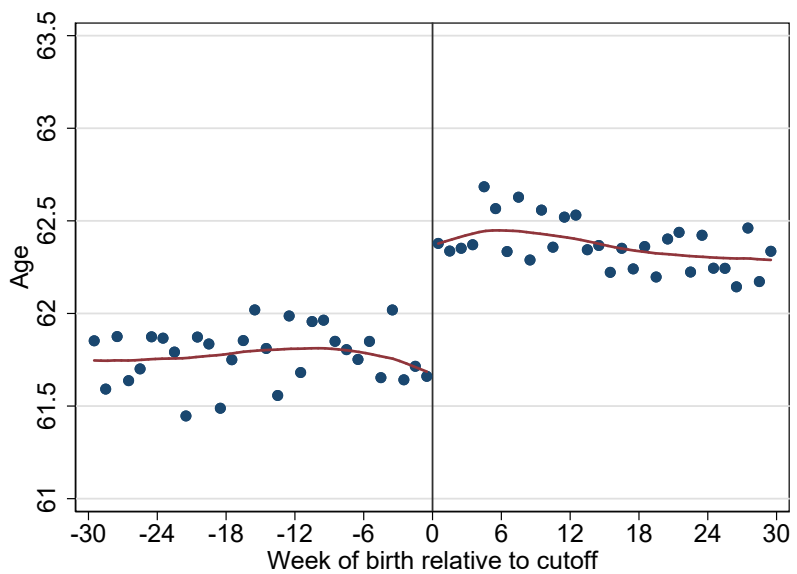

(d) Retirement Age

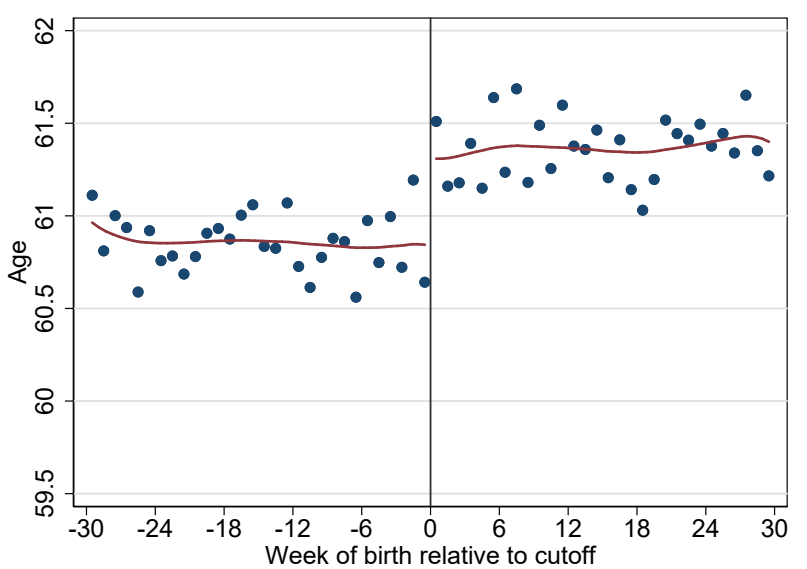

Notes: Women born in 1942 were not eligible anymore for spousal supplementary pensions whereas those born in 1941 were still eligible (figure (a) in Panel A). To see whether the effects are sensitive to the abolishment of supplementary pensions, we focus on women who are single or whose husband is at most two years older (age balanced). These women are not affected by the policy change (figure (b) in panel A). Note that women are still eligible for a spousal supplementary pension if their husband is receiving a disability pension. Claiming and retirement for single women or women living in age-balanced couples respond similar to FRA64 as the entire sample (figures in panel B). 
(a) FRA63

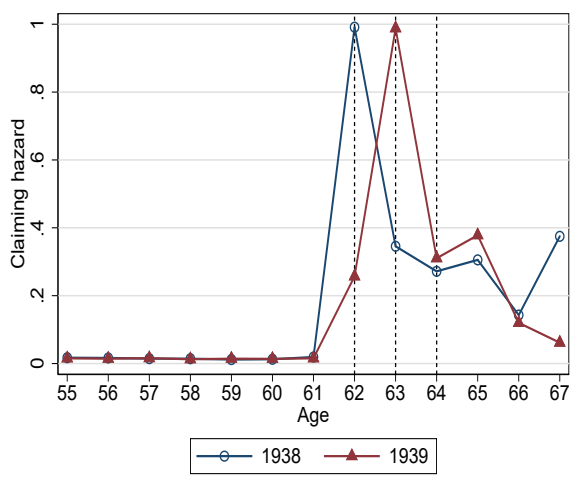

(b) FRA64

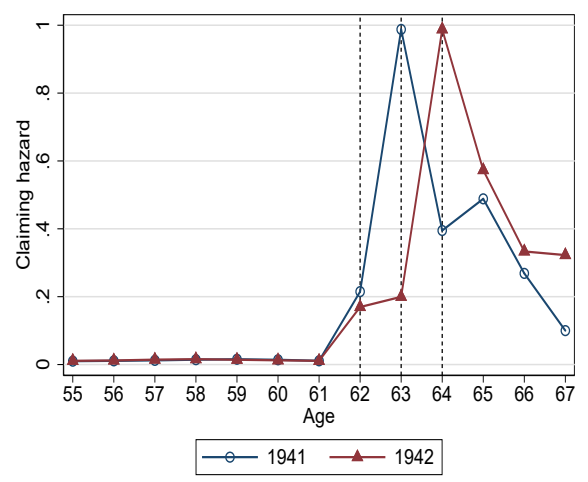

(c) MAF

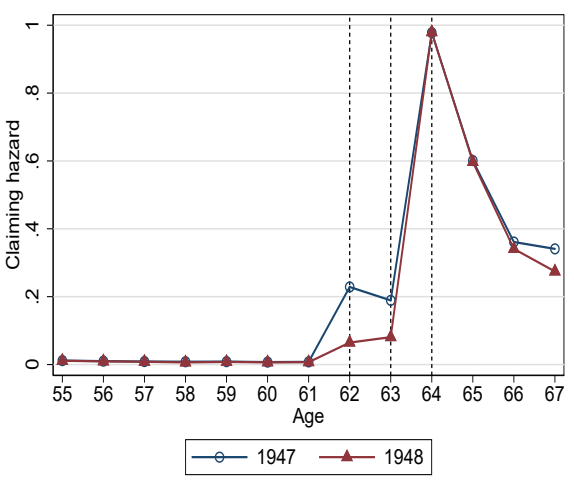

Notes: The figures show the claiming hazard for an old age or disability pension. Figure (a) shows the effect of increasing the FRA from 62 to 63 years (FRA63), figure (b) shows the effect of increasing the FRA from 63 to 64 years (FRA64), and figure (c) shows the effect of doubling the early claiming penalty (MAF). Blue circles refers to the first cohort affected by the reform. Red triangles refers to last cohort not affected by the reform.

\section{Further Evidence on the Effects of the 1997 Reform}

In this section, we provide evidence on the effect of the 1997 reform on women's claiming and retirement hazards, husbands' claiming and retirement behavior, mortality, women's claiming behavior of occupational pensions, and the marginal propensity to earn out of unearned income.

Claiming and Retirement Hazards. The reform induced increases in the average age of claiming and retirement. Here we provide descriptive evidence on how these changes came about. We present claiming and retirement hazards for women born up to 30 weeks before and after each reform step.29 Hazards are useful since they provide information on the proportion of women starting to claim at an age, or retiring at an age, relative to women who have not done so until that age.

Figure C.6.(a) reports effects of FRA63 on the hazard probability of disability or old age pension claiming. Women born in 1938 (blue circles) are eligible for a full old age pension at 62 years, with no possibility to draw an early retirement pension before. The claiming hazard is slightly positive before age 61 , reflecting disability pension claiming, which is possible before age 62 . The hazard probability peaks at close to 1 at age 62 , so women almost perfectly comply with the full retirement age. Interestingly, few women take-up the possibility to claim later than the FRA in spite of the actuarial fair adjustment for delaying claiming. Raising the FRA to age 63 (red triangles) reduces the claiming hazard at age 62 substantially, from nearly $100 \%$ to just over $20 \%$. The hazard is again nearly 1 at the new FRA of age 63. Raising the FRA to 63 years delays pension claiming substantially, but a sizeable proportion of women draw their pension also at the early retirement age of 62 .

In Figure C.6(b), we contrast the claiming hazards for the cohorts around the FRA64 cutoff. Individuals born in 1941 (blue circles) receive full benefits if they claim at the FRA of 63, while individuals born in

\footnotetext{
${ }^{29}$ This comparison provides a raw measure of the effects of the reform on claiming and retirement decisions but may be confounded by trends or cohort composition effects.
} 
1942 (red triangles) receive full benefits if they claim at the FRA of 64 . The comparison is similar to that of the FRA63 cutoff. The hazard is near 1 for both cohorts at their respective FRA's. Interestingly, the hazards are also almost identical at roughly $20 \%$ in the year before the respective FRAs, and the hazards at 62 (two years before the FRA for the 1942 cohort) are also similar across the cohorts. There is some early claiming in both cohorts, but less than would be consistent with maximization of social security wealth.

In Figure C.6.(c), we contrast the hazards for the cohorts around the MAF cutoff. Here, individuals born in 1947 (blue) and 1948 (red) both receive full benefits if they claim at the common FRA of 64, but the penalty for claiming before 64 is much higher for the 1948 cohort. Again, the hazards for both groups are close to 1 at the FRA. The early claiming hazard for the 1948 cohort is about half of the early claiming hazard of the 1947 cohort, suggesting that the increased penalties for early claiming were effective.

In Figures C.6(a) and C.6(b) we see that the claiming hazards move in lockstep with an increase in the FRA even though, for the average women in the treatment One explanation, why the claiming hazards move in lockstep with an increase in the FRA even though claiming before the FRA maximizes pension wealth, is that women who work and claim before the FRA may enter a higher tax bracket. We can check whether this is the case by excluding women who work as of age 62 . The remaining individuals do not have to worry about the tax implications of claiming early because they do not have labour earnings that can be taxed.

Figure C.7 presents the claiming profile for women who have exited the labor market by age 62 . We see that the hazards move in lockstep with an increase in the FRA, similar to the overall population of women. We therefore conclude that the strong claiming response is not driven by the tax implications associated with claiming early while working.

Figure C.7: Pension Claiming Hazard, Women Who Left the Labor Market

(a) FRA63

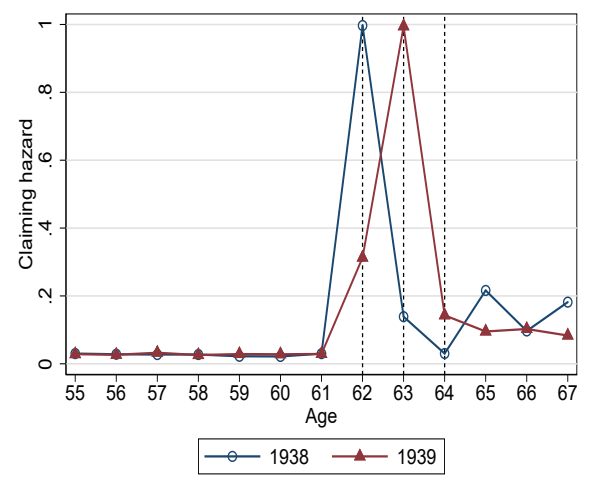

(b) FRA64

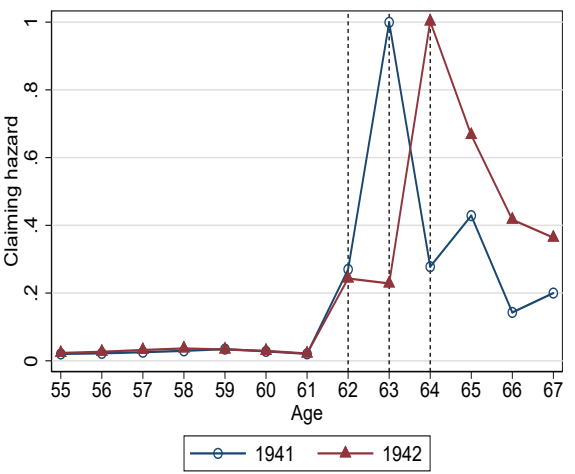

(c) MAF

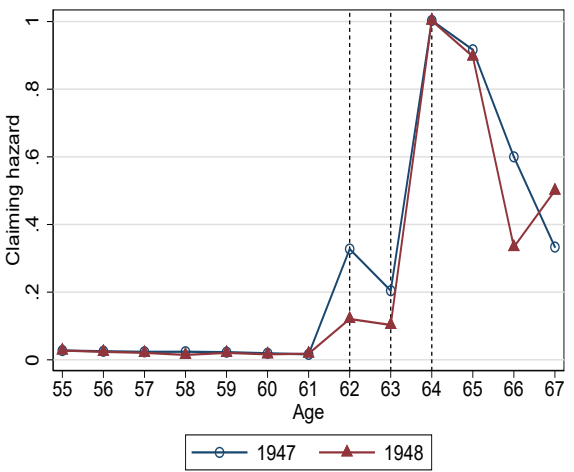

Notes: The figures show the claiming hazard for an old age or disability pension by age for women who left the labor market before age 62. Figure (a) shows the effect of increasing the FRA from 62 to 63 years (FRA63), figure (b) shows the effect of increasing the FRA from 63 to 64 years (FRA64), and figure (c) shows the effect of doubling the early claiming penalty (MAF). Blue circles refers to the first cohort affected by the reform. Red triangles refers to last cohort not affected by the reform.

Figure C.8(a) shows how the reform affected the retirement hazards for the cohorts in FRA63. Increasing the FRA significantly delays retirement, as the hazards at the respective FRAs are approximately equal, at just under 0.8. Interestingly, the reform also decreases the hazard at age 61, a year before the old 
Figure C.8: Effects on Retirement Hazard

(a) FRA63

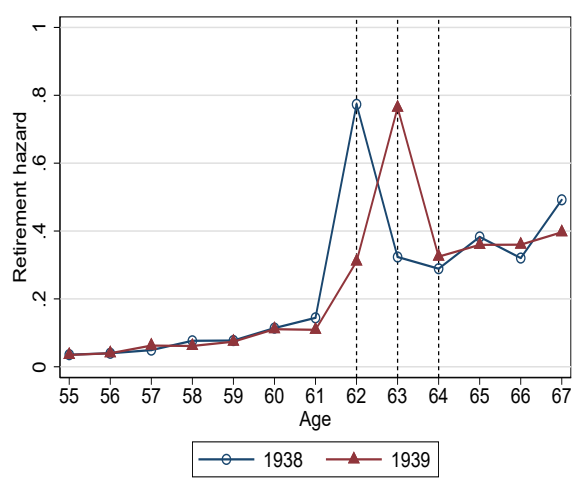

(b) FRA64

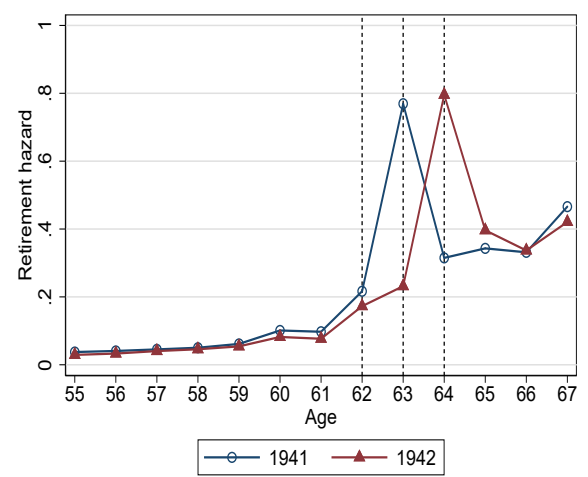

(c) MAF

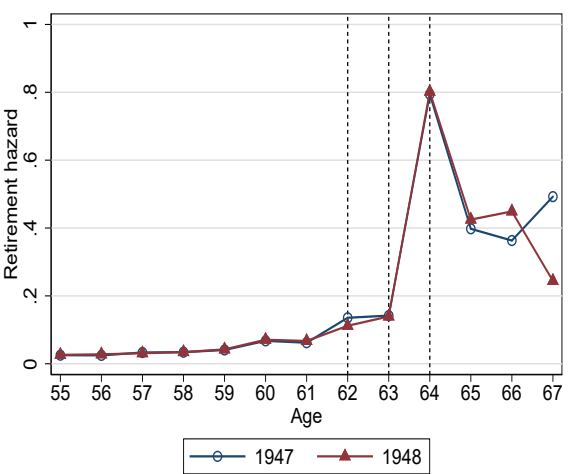

Notes: The figures show the retirement hazard by age. Figure (a) shows the effect of increasing the FRA from 62 to 63 years (FRA63), figure (b) shows the effect of increasing the FRA from 63 to 64 years (FRA64), and figure (c) shows the effect of doubling the early claiming penalty (MAF). Blue circles refers to the first cohort affected by the reform. Red triangles refers to last cohort not affected by the reform.

FRA, and a small sub-group of women born in 1939 continue to leave the labor force upon reaching the old FRA of 62 years. FRA63 increases labor supply substantially, and the increase is concentrated around age 62 and 63 .

Forward-looking individuals might adjust labor supply already in advance of an increase in the full pension age. Although FRA63 was announced only four years before coming into effect, leaving little time to adjust, FRA64, announced 8 years before coming into force, might leave enough time for anticipatory behavior. In Figure C.8(b) we compare the retirement hazards for the cohorts around the FRA64 cutoff, and we see that the patterns are roughly the same as in the case of FRA63, although the hazards in Figure C.8(b) are lower at ages 60-62, suggesting some mild anticipatory behavior.

Figure C.8(c) presents the retirement hazards of women born around the MAF cutoff. The 1947 cohort is the last cohort facing an early retirement adjustment of 3.4\%. The 1948 cohort is the first cohort facing the double adjustment. Labor supply patterns are similar between the two groups, consistent with the RD-estimates showing that MAF has no significant effect on the retirement age.

Husband's Retirement and Claiming Response. It is plausible that the reform encourages husbands to work longer if they want to retire together with their wives. Since our data contain spousal identifiers, we can estimate the reform's effect on husbands' retirement and claiming decision. We find no evidence that husbands change their decision when to retire or when to claim their OASI pension.

Figure C.9 shows husbands' retirement and claiming age as a function of their wives' birthdate around the reform cutoffs. None of the graphs shows a visible jump in the husband's retirement age (Figures C.9ac) or the claiming age (Figures C.9d-f) around the wife's cohort cutoff. The corresponding RD estimates are also insignificant, as Table C.5 shows.

Husbands in our data are on average three years older than their wives and may simply not respond, because they reach age 65 (where most men retire and claim) before wives reach their FRA. We can test 
Figure C.9: Husbands' Retirement and Claiming Age

(a) FRA63

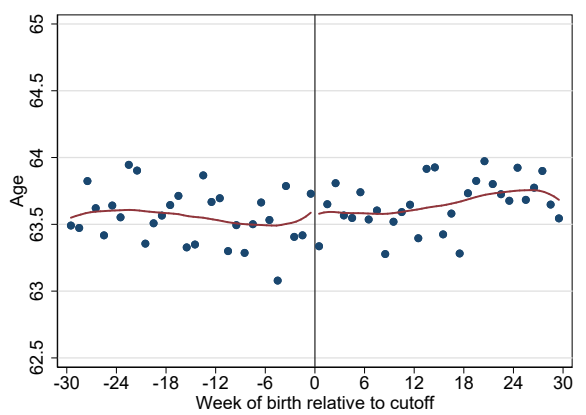

(d) FRA63

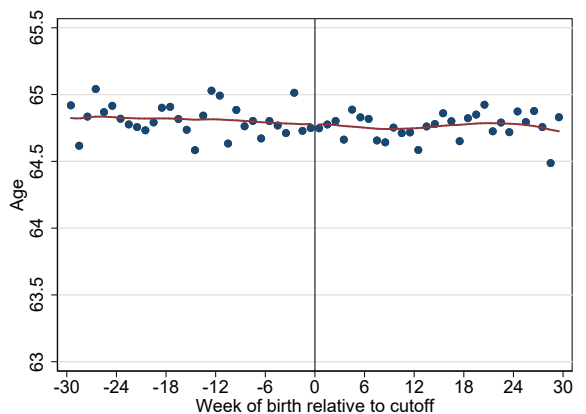

A. Husbands' Retirement Age

(b) FRA64

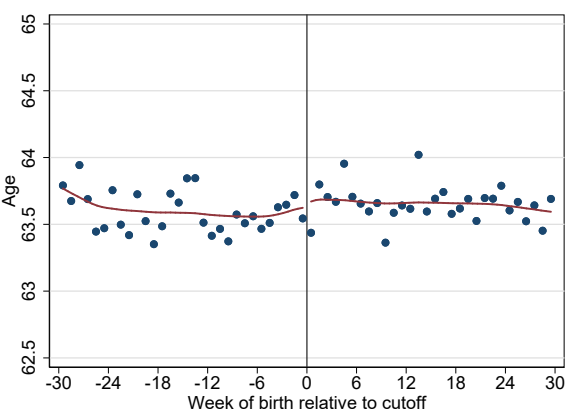

B. Husbands' Claiming Age

(e) FRA64

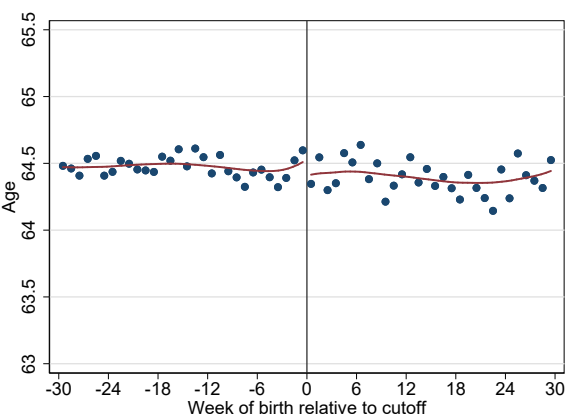

(c) MAF

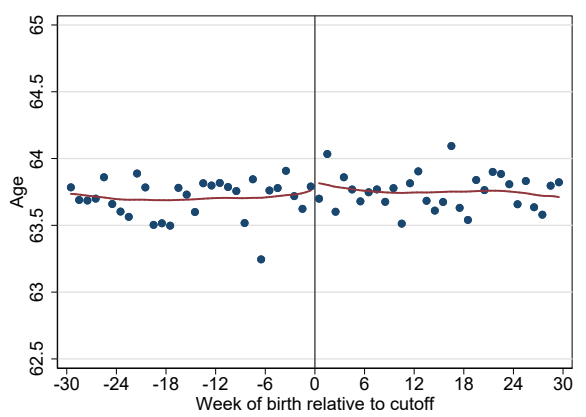

(f) MAF

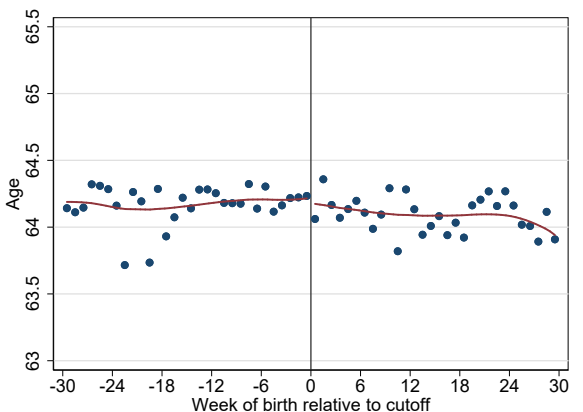

Notes: This figure reports the average age when husbands exit the labor force (panel A) and the average claiming age of any pension (panel B). The x-axis reports the date of birth minus the reform cutoff. The light line refers to women born just not affected by the reform, the solid line refers to women just affected by the reform.

this hypothesis by limiting our sample to wives whose husbands is less than a year older, so that the wife reaches her FRA before the husband reaches his. Even for this limited sample we find no significant change in husbands' retirement or claiming behavior.

Table C.5: Husband's Response

\begin{tabular}{|c|c|c|c|c|c|c|}
\hline & \multicolumn{2}{|c|}{ FRA63 } & \multicolumn{2}{|c|}{ FRA64 } & \multicolumn{2}{|c|}{ MAF } \\
\hline & local & global & local & global & local & global \\
\hline Claiming age (years) & $\begin{array}{l}0.005 \\
(0.089)\end{array}$ & $\begin{array}{l}-0.039 \\
(0.056)\end{array}$ & $\begin{array}{l}-0.117 \\
(0.093)\end{array}$ & $\begin{array}{l}-0.004 \\
(0.060)\end{array}$ & $\begin{array}{l}-0.051 \\
(0.103)\end{array}$ & $\begin{array}{l}-0.088 \\
(0.066)\end{array}$ \\
\hline Retirement age (years) & $\begin{array}{c}-0.047 \\
(0.149)\end{array}$ & $\begin{array}{l}0.013 \\
(0.095)\end{array}$ & $\begin{array}{l}0.031 \\
(0.146)\end{array}$ & $\begin{array}{l}0.110 \\
(0.092)\end{array}$ & $\begin{array}{l}0.021 \\
(0.133)\end{array}$ & $\begin{array}{l}0.031 \\
(0.084)\end{array}$ \\
\hline No. observations & 7,755 & 19,398 & 8,630 & 22,733 & 10,361 & 26,053 \\
\hline
\end{tabular}

Notes: The table presents RD-estimates on the impact of the different reform steps on husband's claiming and retirement age. The local (global) specification uses a bandwidth of 12 (30) weeks and includes a linear trend of the running variable on either side of the cutoff. Observations are weighted using a triangular kernel. ${ }^{* * *}$ Significant at the $1 \%$ level. ${ }^{* *}$ Significant at the $5 \%$ level. *Significant at the $10 \%$ level. 
Mortality. A large literature studies whether retiring early shortens your life or prolongs it. The 1997 reform offers a clean setting to tackle this question. Since our data end in 2016, we can track cohorts for six years (for MAF) to fifteen years (for FRA63) after they reached age 62. We define two outcomes related to mortality. The first is an indicator for whether a woman dies before the last age, we observe her in the data: age 77 for FRA63, age 74 for FRA64, and age 68 for MAF. The second is the age at death (in year-months). We set the age at death to the last age if a woman is still alive at that age.

Figure C.10: Probability to Die and Age at Death

(a) FRA63

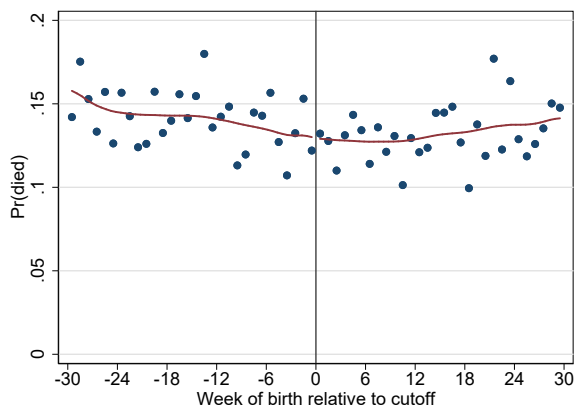

(d) FRA63

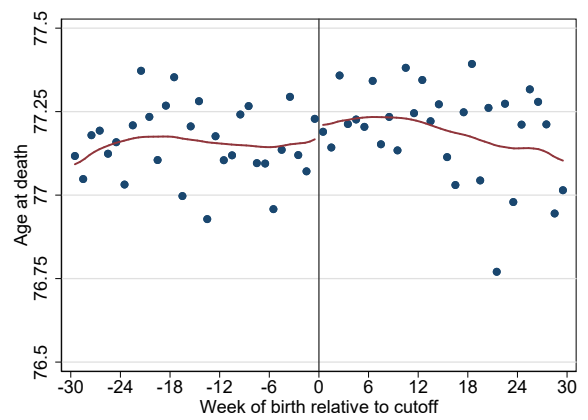

A. Probability to Die

(b) FRA64

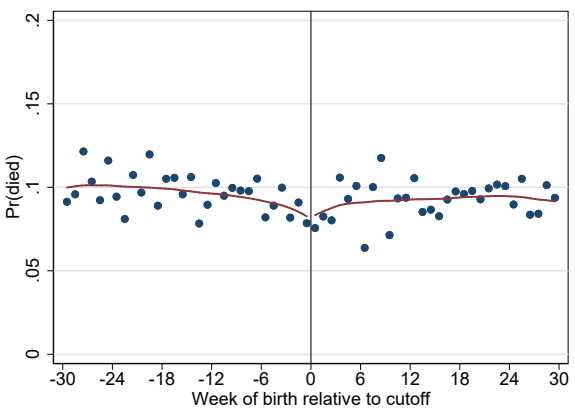

B. Age at Death

(e) FRA64

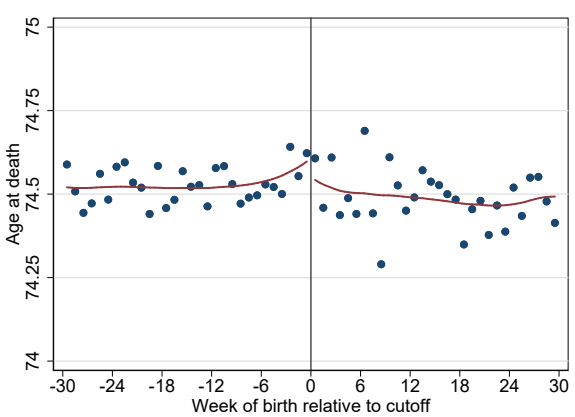

(c) MAF

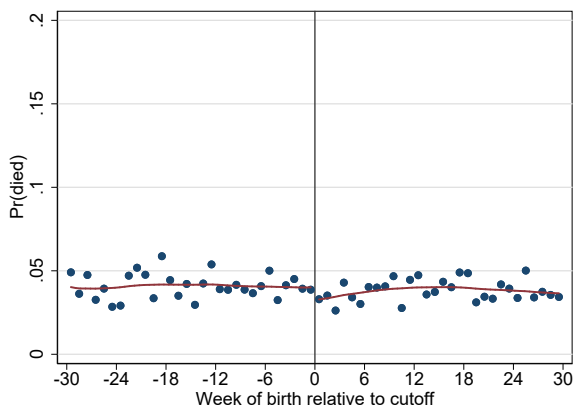

(f) $\mathrm{MAF}$

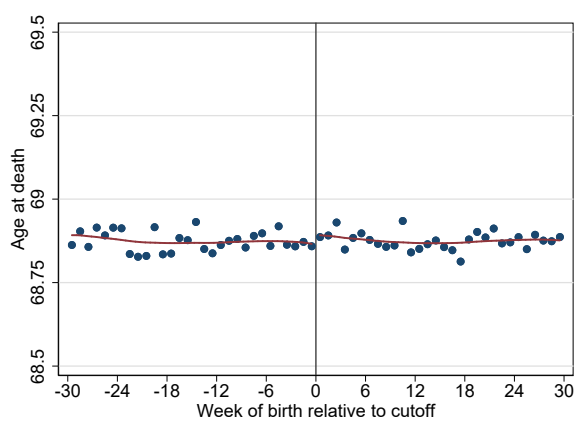

Notes: Notes: The figure show the claiming hazard for an old age or disability pension by age for women who left the labor market before age 62. Figure (a) shows the effect of increasing the FRA from 62 to 63 years (FRA63), figure (b) shows the effect of increasing the FRA from 63 to 64 years (FRA64), and figure (c) shows the effect of doubling the early claiming penalty (MAF). Blue circles refers to the first cohort affected by the reform. Red triangles refers to last cohort not affected by the reform.

In Figure C.10 we observe no clear discontinuity at the cohort boundaries for neither of the mortality outcomes. The RD estimates confirm the absence of any mortality effect (Table C.10). Out of twelve estimates, only one is statistically significant at the 10\%-level: the age at death for FRA63 increases by 0.1 years, but the effect disappears if we narrow the bandwidth around the cutoff. The absence of a significant effect on mortality is consistent with recent evidence by Kuhn et al. (2020) and Fitzpatrick and Moore (2018). They also focus on mortality as an outcome and find that retirement increase mortality among men but has no effect on women. 
Table C.6: Effects on Probability to Die and Age at Death

\begin{tabular}{|c|c|c|c|c|c|c|}
\hline & \multicolumn{2}{|c|}{ FRA63 } & \multicolumn{2}{|c|}{ FRA64 } & \multicolumn{2}{|c|}{ MAF } \\
\hline & local & global & local & global & local & global \\
\hline Died by last age & $\begin{array}{l}0.002 \\
(0.013)\end{array}$ & $\begin{array}{l}-0.004 \\
(0.008)\end{array}$ & $\begin{array}{l}0.001 \\
(0.010)\end{array}$ & $\begin{array}{l}0.001 \\
(0.006)\end{array}$ & $\begin{array}{l}-0.007 \\
(0.006)\end{array}$ & $\begin{array}{l}-0.005 \\
(0.004)\end{array}$ \\
\hline Age at death & $\begin{array}{l}0.030 \\
(0.100)\end{array}$ & $\begin{array}{l}0.105^{\star} \\
(0.064)\end{array}$ & $\begin{array}{l}-0.059 \\
(0.061)\end{array}$ & $\begin{array}{l}-0.034 \\
(0.040)\end{array}$ & $\begin{array}{l}0.029 \\
(0.023)\end{array}$ & $\begin{array}{l}0.012 \\
(0.014)\end{array}$ \\
\hline Obs & 13,556 & 34,183 & 15,413 & 40,438 & 19,041 & 48,250 \\
\hline
\end{tabular}

Notes: The table presents RD-estimates on the impact of the different reform steps on whether a woman died before the last age, we observe her in the data (age 77 for FRA63, age 74 for FRA64, and age 68 for MAF) and the age at death (censored above at age 77 for FRA63, age 74 for FRA64, and age 68 for FRA). The local (global) specification uses a bandwidth of 12 (30) weeks and includes a linear trend of the running variable on either side of the cutoff. Observations are weighted using a triangular kernel. ${ }^{* * *}$ Significant at the $1 \%$ level. ${ }^{* *}$ Significant at the $5 \%$ level. ${ }^{*}$ Significant at the $10 \%$ level.

Occupational Pensions. In addition to an OASI pension, women who have earned around 20,000 CHF or more per year also qualify for an occupational pension. In this section, we study whether the 1997 reform changed when women claim their occupational pension and how much pension benefits, they get. The 1997 reform affected only OASI pensions and had no direct effect on occupational pensions. The reform could have an indirect effect on occupational pensions if women tend to claim OASI and occupational pensions jointly, or if the delayed retirement caused by the reform increases occupational pension amounts.

Because in the social security data, we cannot observe occupational pension benefits or contributions, we use tax records from the Canton of Berne, covering about one eight of the Swiss population. We have access to tax records for the period 2001 to 2015, prohibiting us to study the effects of FRA63 and instead we focus on FRA64 and MAF. We use the same regression discontinuity design as for the main analysis. Our two outcomes of interests are the claiming age of an occupational pension and the level of an occupational pension.

Figure C.11 shows how the claiming age and the benefit level evolve around the cohort cutoffs for FRA64 and MAF. The distribution is noisier, because of the smaller sample size, but we do not see a clear discontinuity in either outcome at the cohort cutoff. Table C.7 shows that the corresponding RD estimates are statistically insignificant, although the standard errors are also large because of the small sample size.

Marginal Propensities to Earn Out of Unearned Income. Figure C.12 shows estimates of lifetime marginal propensities to earn out of unearned income. We obtain these estimates by dividing the change in lifetime earnings at the cohort cutoff by the corresponding change in pension wealth (both estimated using the RD design). The estimated propensities to earn tend to be larger (in absolute value) for FRA63 compared to FRA63 and MAF, but we cannot reject the null hypothesis that they are equal. We also find that different subgroups of the population respond in the same way to each reform step. 
Figure C.11: Effects on Occupational Pension

(a) FRA64

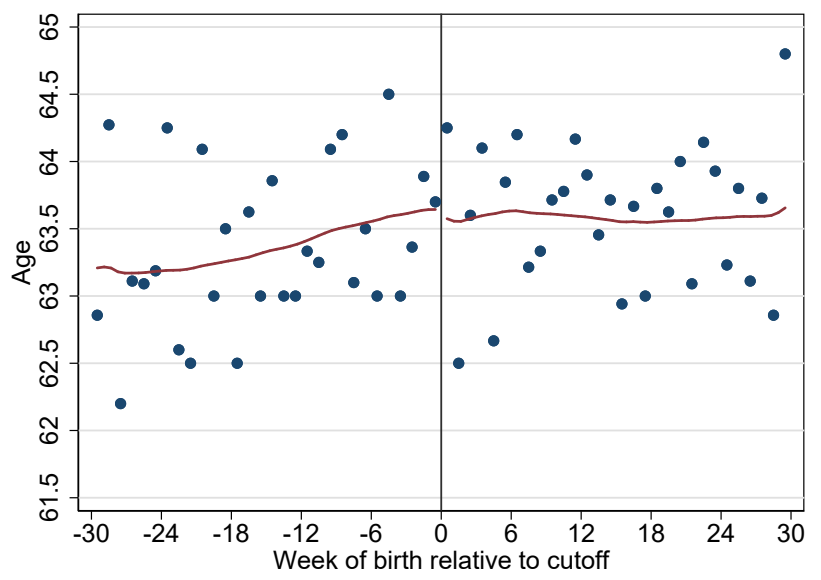

(b) MAF

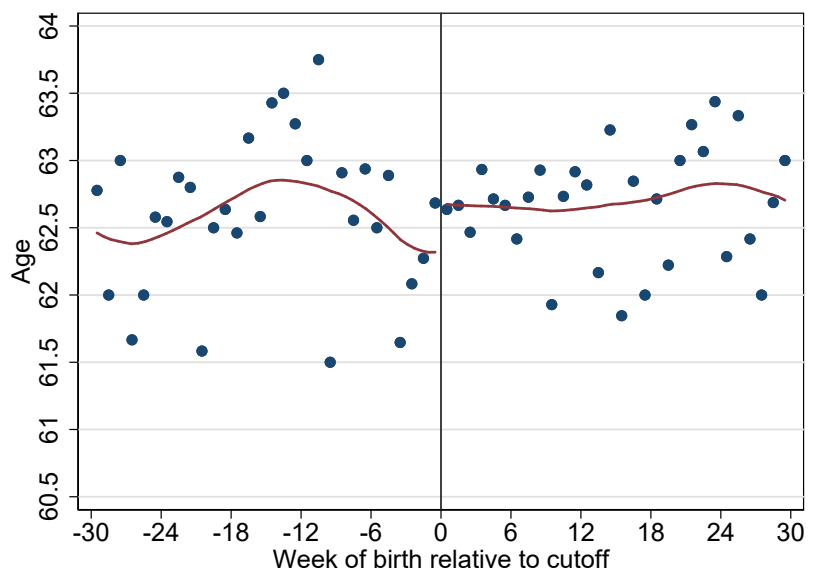

(c) FRA64

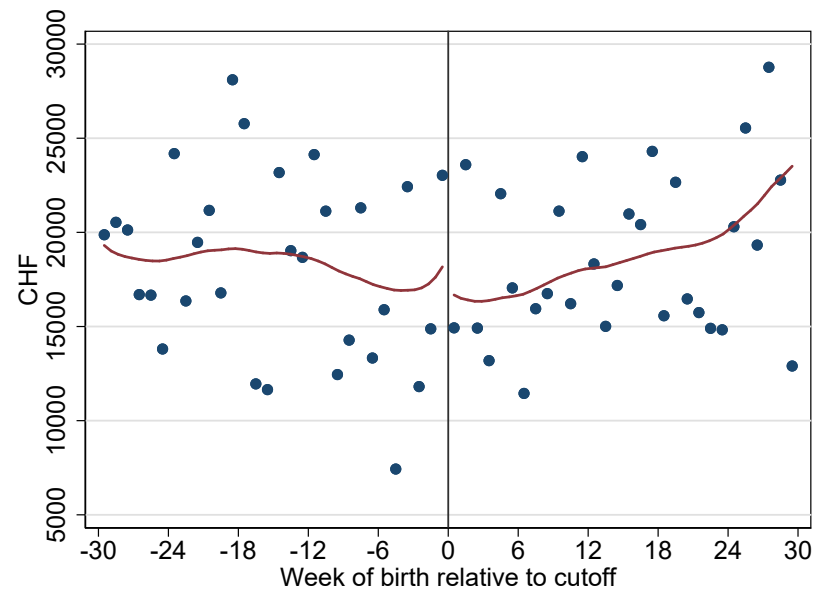

(d) MAF

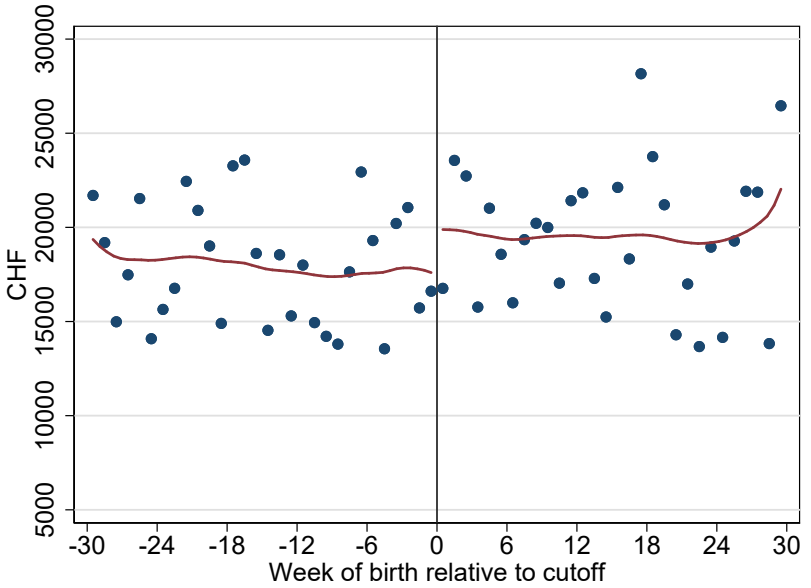

Notes: The figure shows the claiming age of occupational pensions (panel A) and the annual level of occupational pensions in Swiss Francs (panel B) around the cutoff separating the 1939 and 1938 birth cohorts (FRA63), the 1941 and 1942 birth cohorts (FRA64), and the 1947 and 1948 birth cohorts (MAF). The solid red line plots the best local linear fit to the actual data above and below the reform cutoff.

\section{Point Estimation of $\pi$}

While $\pi$ is the only parameter of interest in the structural model, we must estimate a scale parameter, $\sigma_{\epsilon}$, in order to recover the choice probabilities $P_{t}$. The reason is that, for a given $\pi$ and discount factor and mortality probabilities, the researcher can get different choice probabilities for different choices of units for $b_{t}$ (CHF or 100s of CHF or 1000s of CHF etc.). So instead of leaving this choice at the discretion of the researcher, we let the data select the appropriate units by estimating the scale parameter $\sigma_{\epsilon}$.

As such, we use an EM algorithm to estimate $\pi, \sigma_{\epsilon}$ given the model proposed in section 5 of the paper. We provide details here (see, e.g., Arcidiacono and Jones (2003) Section 2). Let $\mathbf{y}_{i}=\left(\mathbf{a}_{i}, \mathbf{x}_{i}\right)$, where $a_{i}$ is the claiming age of individual $i$ and $\mathbf{x}_{i}$ are the state variables. The unconditional (on type) contribution 
Table C.7: Effects on Occupational Pension Claiming Age and Benefit Level

\begin{tabular}{llllll}
\hline & \multicolumn{2}{c}{ FRA64 } & & \multicolumn{2}{c}{ MAF } \\
\cline { 2 - 3 } \cline { 5 - 6 } \cline { 5 - 6 } Claiming age (years) & -0.071 & -0.052 & & 0.370 & 0.090 \\
& $(0.601)$ & $(0.351)$ & & $(0.485)$ & $(0.304)$ \\
& & & & & \\
Annual amount (CHF) & $-3,108$ & $-1,087$ & & $-1,848$ & 1,072 \\
& $(2,996)$ & $(1,876)$ & & $(3,001)$ & $(2,046)$ \\
No. observations & 221 & 553 & & 310 & 771 \\
Bandwidth (weeks) & 12 & 30 & & 12 & 30 \\
\hline
\end{tabular}

The table presents RD-estimates on the impact of the different reform steps on the claiming age of occupational pensions and the annual amount of occupational pensions in Swiss Francs. The local (global) specification uses a bandwidth of 12 (30) weeks and includes a linear trend of the running variable on either side of the cutoff. Observations are weighted using a triangular kernel. ${ }^{* * *}$ Significant at the $1 \%$ level. **Significant at the $5 \%$ level. *Significant at the $10 \%$ level.

Figure C.12: Marginal Propensities to Earn Out of Unearned Income

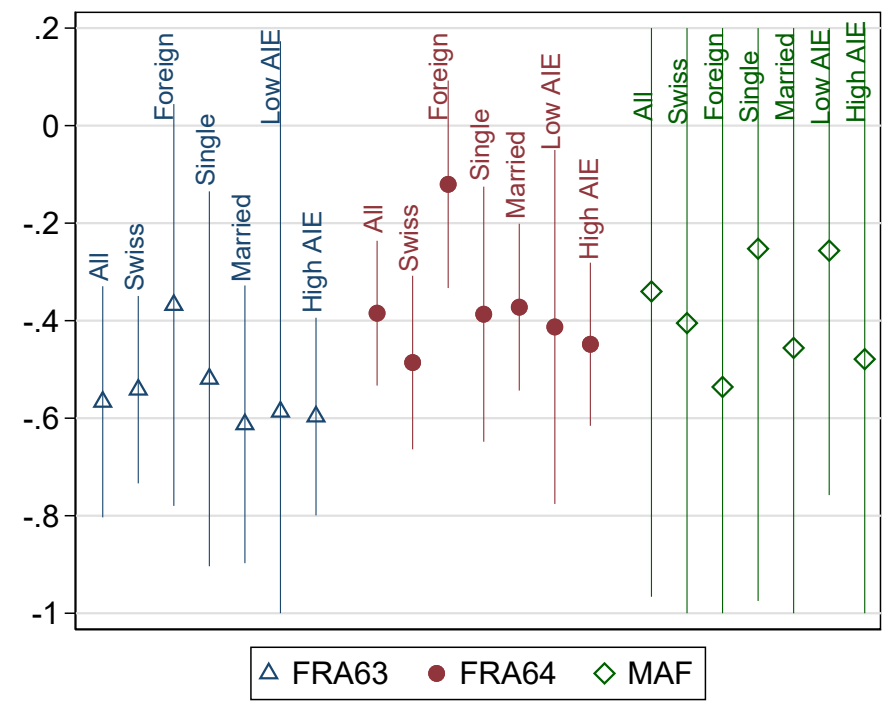

Notes: The figure shows RD-estimates on the impact of the different reform steps on the lifetime marginal propensity to earn out of unearned income, which is equal to the RD-estimate on the effect on lifetime earnings divided by the RD-estimate on lifetime pension wealth. The length of the vertical lines around the point estimate denotes the $95 \%$ confidence interval (capped below at -1 and above at 0.2 ). The specification uses a bandwidth of 30 weeks and includes a linear trend of the running variable on either side of the cutoff. Observations are weighted using a triangular kernel. ***Significant at the $1 \%$ level. **Significant at the $5 \%$ level. *Significant at the $10 \%$ level.

of individual $i$ to the likelihood is given by:

$$
g\left(\mathbf{y}_{i} ; \sigma_{\epsilon}, \pi\right)=\pi f_{\pi}\left(\mathbf{y}_{i} ; \sigma_{\varepsilon}\right)+(1-\pi) f_{1-\pi}\left(\mathbf{y}_{i} ; \sigma_{\varepsilon}\right)
$$

where $f_{\pi}\left(\mathbf{y}_{i} ; \sigma_{\varepsilon}\right)$ is the likelihood of observing $\mathbf{y}_{i}$ given individual $i$ is passive and $f_{1-\pi}\left(\mathbf{y}_{i} ; \sigma_{\varepsilon}\right)$ is the same for an active individual. Note that $f_{\pi}\left(\mathbf{y}_{i} ; \sigma_{\varepsilon}\right)$ is either 0 or 1 - it is one if $a_{i}=F R A_{i}$ and is zero if $a_{i} \neq F R A_{i}$ 
Using Bayes' rule, we have:

$$
\operatorname{Pr}\left(\mathbf{1}_{i}^{\pi}=1 \mid \mathbf{y}_{i} ; \sigma_{\varepsilon}, \pi\right)=\frac{\pi f_{\pi}\left(\mathbf{y}_{i} ; \sigma_{\varepsilon}\right)}{g\left(\mathbf{y}_{i} ; \sigma_{\epsilon}, \pi\right)}
$$

One approach to recovering $\pi$ would be to directly maximize the log likelihood $\ell\left(\sigma_{\varepsilon}, \pi\right)=$ $\sum_{i} \ln \left(g\left(\mathbf{y}_{i} ; \sigma_{\epsilon}, \pi\right)\right)$ with respect to both $\left(\sigma_{\epsilon}, \pi\right)$. This can be computationally challenging however. The standard alternative is to use an EM algorithm that works in the following way. The ML estimate of $\pi$ satisfies:

$$
\left.\hat{\pi}=\frac{1}{N} \sum_{i} \operatorname{Pr}\left(\mathbf{1}_{(}^{\pi} i\right)=1 \mid \mathbf{y}_{i} ; \hat{\sigma}_{\varepsilon}, \hat{\pi}\right)
$$

Note that $\hat{\pi}$ is on both sides of this equation. It can also be shown that the MLE of $\sigma_{\varepsilon}$ satisfies:

$$
\begin{aligned}
\hat{\sigma}_{\varepsilon} & =\arg \max _{\hat{\sigma}} \sum_{i} \operatorname{Pr}\left(\mathbf{1}_{\pi}(i)=1 \mid \mathbf{y}_{i} ; \hat{\sigma}_{\varepsilon}, \hat{\pi}\right) \ln \left(f_{\pi}\left(\mathbf{y}_{i} ; \sigma_{\varepsilon}\right)\right) \\
& +\quad\left(1-\operatorname{Pr}\left(\mathbf{1}_{\pi}(i)=1 \mid \mathbf{y}_{i} ; \hat{\sigma}_{\varepsilon}, \hat{\pi}\right)\right) \ln \left(f_{1-\pi}\left(\mathbf{y}_{i} ; \sigma_{\varepsilon}\right)\right)
\end{aligned}
$$

These two equations suggest an iterative procedure that is computationally cheap to implement. Suppose we begin with a guess of $\sigma_{\varepsilon}$, say $\sigma_{\varepsilon}^{(0)}$. Using this guess, we can use equation D.4 to obtain a guess of $\pi$, say $\pi^{(0)}$ (D.4 defines a fixed point mapping in $\pi$, as the RHS is continuous function of $\pi$ and defined on the convex and compact subset of the real line that $\pi$ lives in, so we iterate in this mapping until we get $\pi^{(0)}$ such that $\pi^{(0)}=\frac{1}{N} \sum \operatorname{Pr}\left(\mathbf{1}_{\pi}(i)=1 \mid \mathbf{y}_{i} ; \sigma_{\varepsilon}^{(0)}, \pi^{(0)}\right)$. Then with $\left(\sigma_{\varepsilon}^{(0)}, \pi^{(0)}\right)$ in hand we have $\operatorname{Pr}\left(\mathbf{1}_{i}^{\pi}=1 \mid \mathbf{y}_{i} ; \sigma_{\varepsilon}^{(0)}, \pi^{(0)}\right)$ and can plug this into equation D.5, and obtain a new estimate of $\sigma_{\varepsilon}$, say $\sigma_{\varepsilon}^{(1)}$. We continue in this fashion until convergence - until $\sigma_{\varepsilon}^{(k)} \simeq \sigma_{\varepsilon}^{(k-1)}$.

\section{E Survey Evidence on Claiming and Retirement}

To better understand women's rational for retirement and claiming, we complement the evidence from the administrative data with survey evidence from the Survey of Health Aging and Retirement in Europe (SHARE) and an original survey as part of the LINK Internet Panel, a representative internet panel of the Swiss population with 115,000 respondents.

SHARE Survey. SHARE is a bi-annual, cross-national panel of about 140,000 individuals aged 50 or older in 27 countries, including Switzerland. SHARE has seven survey waves and the first wave was collected in 2003/2004.

While SHARE does not ask about the reasons underlying the claiming decision, the main purpose of our original survey, it contains detailed information on the reasons underlying the retirement decision. Figure E.13 shows the importance of each reason, pooling women from all survey waves. By far the most important reason for retirement is becoming eligible for an OASI pension. Over $60 \%$ of women list OASI eligibility as the reason for retirement. Less than $10 \%$ of women list one of the other reasons as the reason for retirement. The figure provides additional evidence that mandatory retirement is not a key driver of retirement, as firm early retirement programs and layoffs account only for a small share of retirements. 
Figure E.13: Reasons for Retirement

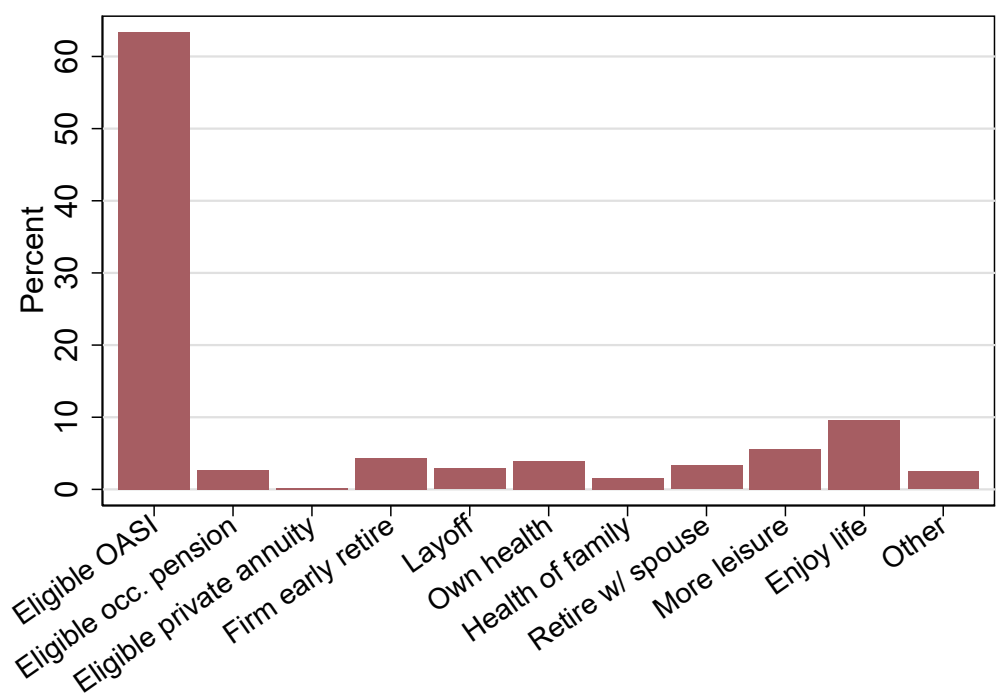

Notes: The figure lists different reasons for why women retire from work using data from SHARE Switzerland. The height of the bar measures the percent of women who said that they retired from work for the listed reason. "Eligible OASI": Became eligible for OASI pension, "Eligible occ. pension": Became eligible for private occupational pension, "Eligible private annuity": Became eligible for private pension, "Firm early retire": Was offered an early retirement option, "Layoff": Made redundant, "Own health": Own ill health, "Health of family": Ill health of relative or friend, "Retire w/ spouse": To retire at same time as spouse or partner, "More leisure": To spend more time with family, "Enjoy life": To enjoy life.

Original Survey. To learn how women gather information about the OASI pension and how they decide when to claim, we fielded an original survey within the LINK Internet Panel. Our survey was sent to 5,000 women aged 60 to 65 and respondents were paid 4 Swiss Francs to complete the survey. Of the 5,000 contacted women, 2,916 women opened the survey and 1,223 women completed it, resulting in a response rate of $25 \%$. Table E.8 reports estimates when regressing an indicator for completing the survey on a set of characteristics we can measure for all women who opened the survey. The results show that women from the French-speaking region and women with missing or low wealth were less likely to complete the survey. On the other hand, women who are renting a house, women with higher education, and women who are slightly older were more likely to complete the survey.

Of the 1,223 women who completed the survey, 389 women were receiving an OASI pension and 834 were expecting to receive an OASI pension in the future. We asked both groups of women when they claimed their OASI pension, or when they were expecting to claim their pension if they were not receiving one at the time of completing the survey. Figure E.14 shows that the claiming age distribution for women who have and have not claimed already is nearly identical. About $85 \%$ of women indicate that they have claimed or are planning to claim at age 64. Age 64 is the FRA for women in our sample, because they are all born after 1947 and thus face the same incentives as the women in the MAF cohort of our study. Women who have not claimed yet are more likely to claim at age 65 than those who have already claimed, but the difference is small (about 5\%).

We also asked women how important the OASI pension is or will be (for women who have not claimed yet), for the total retirement income, ranging from "not important" to "very important". Figure E.15 
Table E.8: Analysis of Probability to Complete the Survey

\begin{tabular}{ll}
\hline French-speaking region & $-.060^{* * *}$ \\
& $(.019)$ \\
Wealth missing & $-.070^{* * *}$ \\
& $(.023)$ \\
Wealth below median & $-.059^{* * *}$ \\
& $(.022)$ \\
Housing: rent & $.117^{* * *}$ \\
& $(.018)$ \\
Middle education & $.100^{* * *}$ \\
& $(.032)$ \\
High education & $.089^{* * *}$ \\
& $(.034)$ \\
Age 61 & .028 \\
& $(.029)$ \\
Age 62 & $.078^{* *}$ \\
& $(.030)$ \\
Age 63 & $.105^{* * *}$ \\
& $(.031)$ \\
Age 64 & $.106^{* * *}$ \\
& $(.031)$ \\
Age 65 & $.086^{* * *}$ \\
Constant & $(.031)$ \\
& $.280^{* * *}$ \\
No. observations & $(.042)$ \\
& 2,916 \\
& .037
\end{tabular}

Notes: The table shows which characteristics correlate with the probability to complete the survey. The dependent variable is an indicator, which is 1 if a woman completed the survey and 0 otherwise. The estimates for the indicators "middle education" and "high education" are relative to the reference category "low education." The reference category for the age dummies is "Age 60." ***Significant at the $1 \%$ level. **Significant at the $5 \%$ level. *Significant at the $10 \%$ level.

shows the percent distribution across the different importance categories, splitting the sample into women who claimed/plan to claim early, at the FRA, and after the FRA. Independent of when women claim, we find that the OASI pension is very important for 55 to $60 \%$ of women, important for $30 \%$ of women, and fairly important for $10 \%$ of women. Only few women, less than $2 \%$, respond that the OASI pension is not important. Overall these results underscore the importance of the OASI pension for retirement income.

Figure E.16 shows the percent of women who say that they can or could afford to retire early. This question is intended to capture whether liquidity constraints play a significant role in the timing of when to claim OASI. Figure E.16(a) distinguishes between women who claim/plan to claim before the FRA, at the FRA, and after the FRA, while Figure E.16(b) distinguishes between women with financial wealth below and above the median. As Figure E.16(a) shows, women who claim after the FRA are less likely to afford early claiming compared to women who claim at or before the FRA. Figure E.16(b) shows that financial wealth is highly correlated with whether a woman can afford early claiming. Only $30 \%$ of low-wealth women can afford early claiming, while almost $70 \%$ of high-wealth women can. 
Figure E.14: Claiming Age Distribution

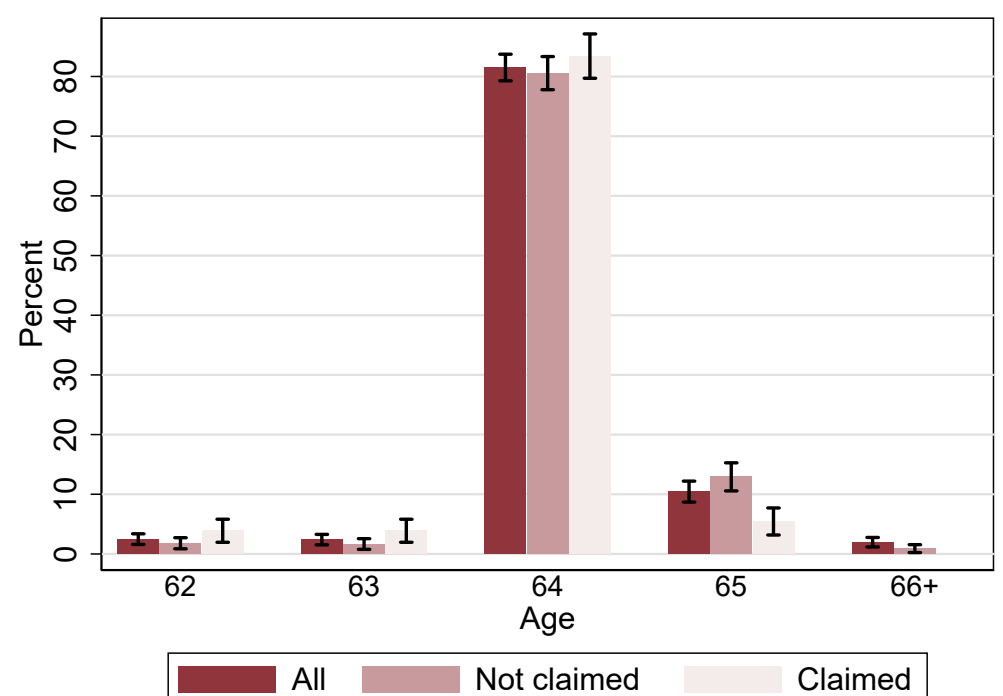

Notes: The figure shows the distribution of claiming ages, distinguishing between women who have claimed an OASI pension already ("claimed") and women who still have to claim ("not claimed"). The length of the vertical lines at the end of the bar denotes the $95 \%$ confidence interval.

Figure E.15: Importance of OASI Pension for Total Retirement Income

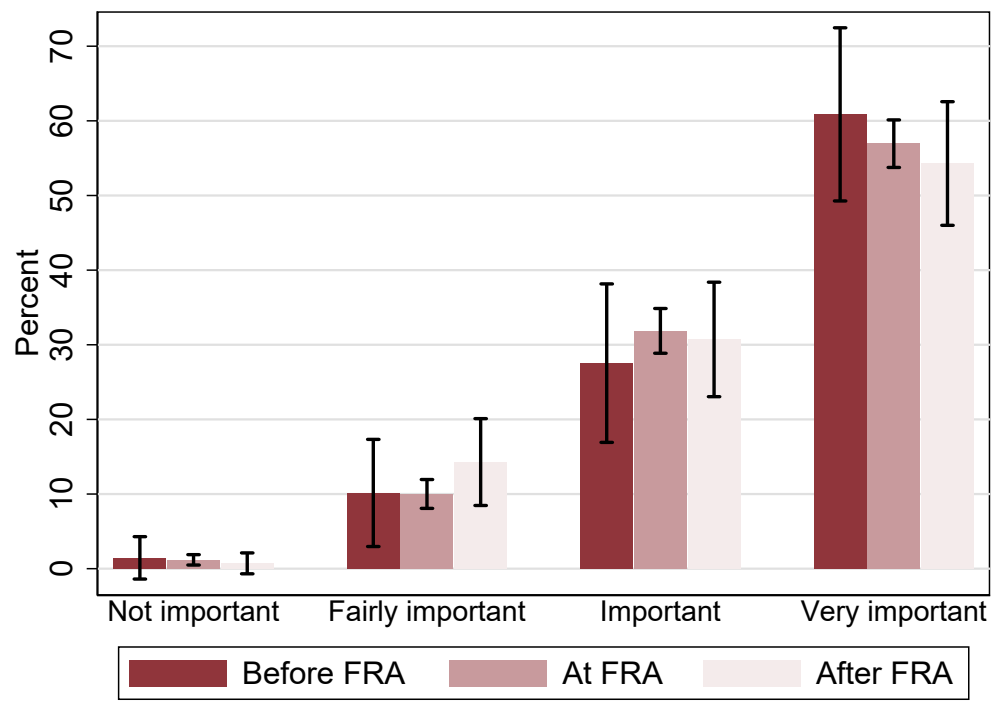

Notes: The figure shows how important the OASI pension is for the total retirement income for women who claimed/plan to claim early, claimed/plan to claim at the FRA, and delayed/plan to delay claiming.

To better understand women's level of information about OASI pensions, we asked how they gathered information to decide when to claim their OASI pension. They had to chose at least one and up to three of the following options: sought advice from a financial advisor, sought advice from an employee at the OASI office, sought advice from friends or family, searched online or attended a workshop (for example at the workplace), thought about it myself, or did not think about it. Figure E.17 shows the percent of women who selected an option, distinguishing between women who, at the time of the interview, have and have 
(a) By Claiming Age

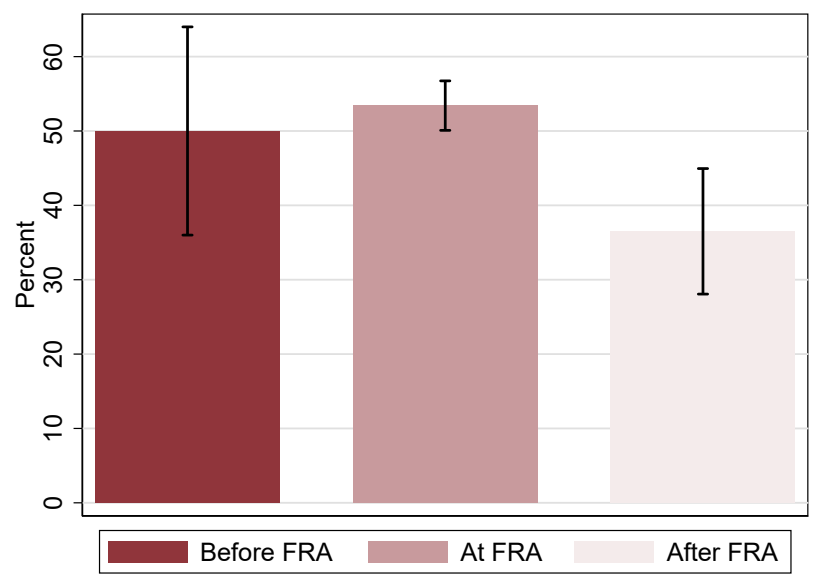

(b) By Financial Wealth

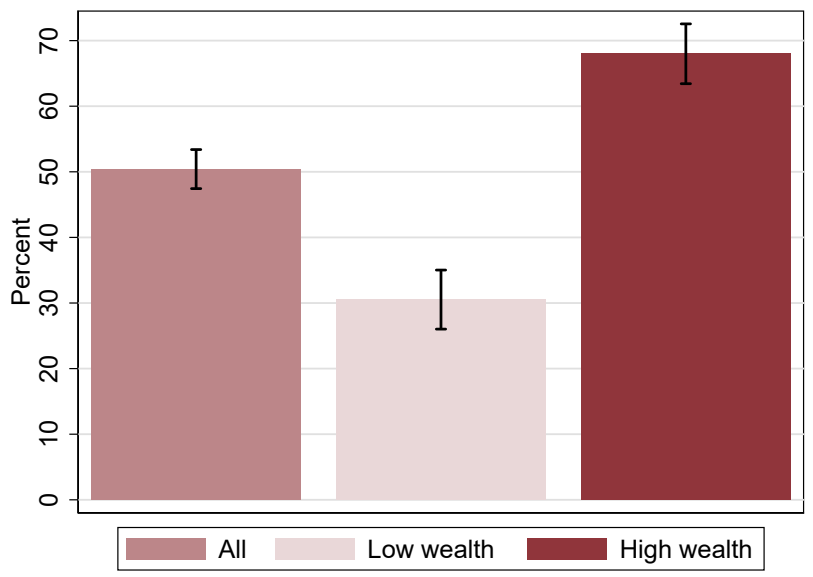

Notes: The figure shows the percent of women who say that they can or could afford to retire early. Figure (a) distinguishes between women who claim/plan to claim before the FRA, at the FRA, and after the FRA. Figure (b) distinguishes between women with financial wealth below and above the median. The length of the vertical lines at the end of the bar denotes the $95 \%$ confidence interval.

not claimed an OASI pension. The importance of different sources is similar across the two groups with one exception. Women who have claimed already, compared to women who still have to claim, are more likely to have sought advice from the OASI office and less likely to have not thought about the claiming decision.

\section{F The Introduction of Early Claiming for Men}

Another element of the 1997 reform was the introduction of early claiming for men at age 63 and age 64, while keeping the FRA fixed at age 65. Specifically, men born after 1932 could claim OASI benefits already at age 64 . We call this reform step ERA64. Men born after 1937 could claim as early as age 63. We call this reform step ERA63. The price for early claiming was set to $6.8 \%$ of full benefits per year of early claiming; the same price women born after 1947 have to pay. While our study focuses on women, because we can estimate how many are passive given the variation in both the FRA and the early claiming price, estimating how the introduction of early claiming affects men's claiming and retirement behavior is interesting on its own.

Figure F.18 shows the pension adjustment factors (PAF) and the social security wealth (SSW) for men when claiming at different ages. The male SSW is significantly lower than the female SSW for two reasons: Men tend to die earlier and they only qualify for a full OASI pension at age 65, while women do so at age 64 or earlier, depending on their date of birth. The blue circles give the PAF and SSW for men born in different years. The reform does not shift the PAF or SSW profile but extends the claiming choice set to include age 64 and age 63 .

The SSW profile shows that the introduction of early claiming is actuarially unfair: men who claim early will lose SSW. The optimal claiming age that maximizes pension wealth is the FRA, before and 
Figure E.17: Evidence on Gathering Information, Comparing Women Who Have and Have Not Claimed

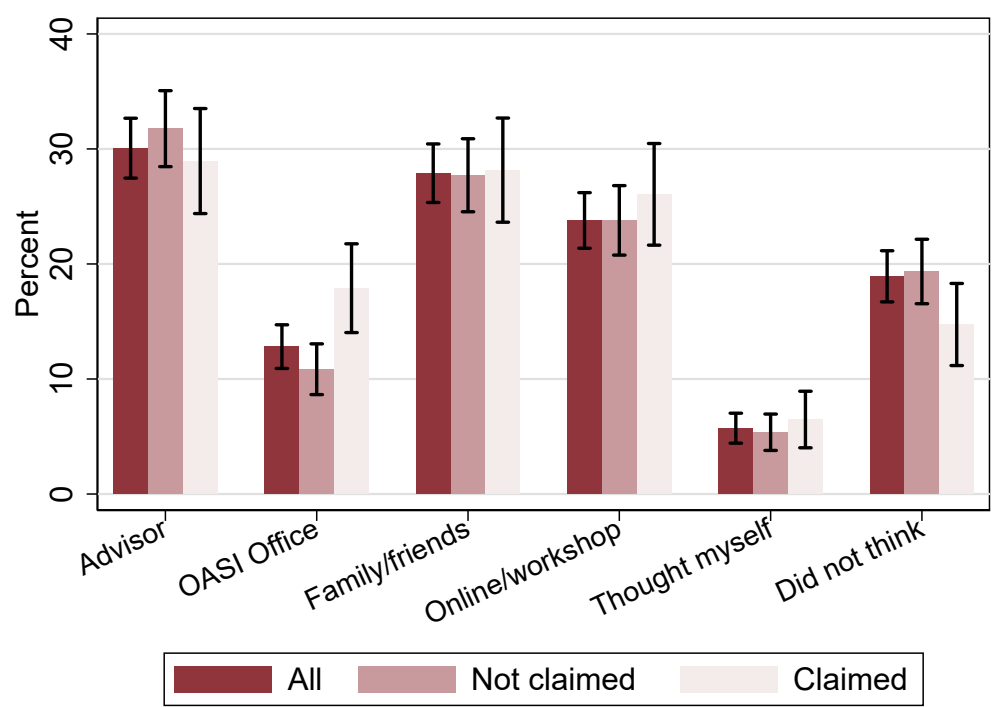

Notes: The figure shows how women gathered information to make their claiming decision, distinguishing between women who have and have not claimed already. The height of the bar is the percent of women who choose an option. The options are "sought advice from a financial advisor (advisor)", "sought advice from an employee at the OASI office (OASI office)", "sought advice from friends or family (family/friends)", "searched online or attended a workshop (online/workshop)", "thought about it myself (thought myself), or "did not think about it (did not think)." The length of the vertical lines at the end of the bar denotes the $95 \%$ confidence interval.

Figure F.18: Pension Adjustment Factors and Social Security Wealth at Different Claiming Ages, Men

(a) PAF

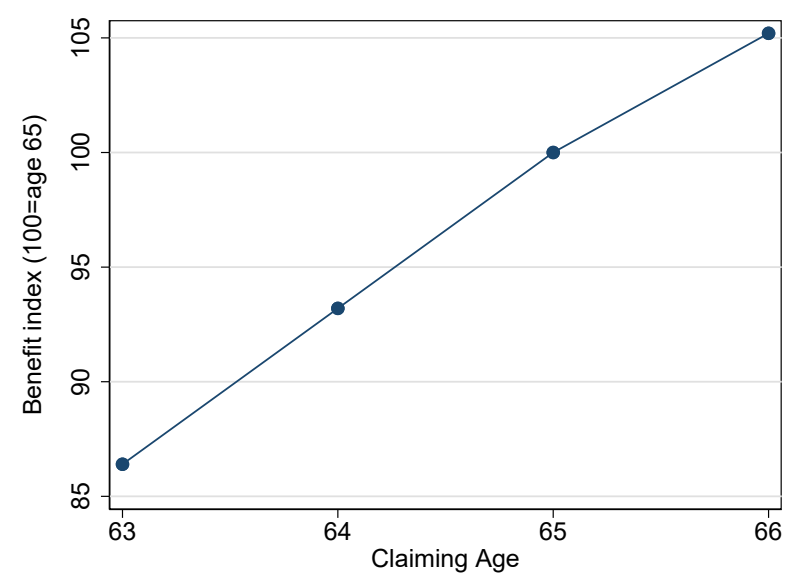

(b) SSW

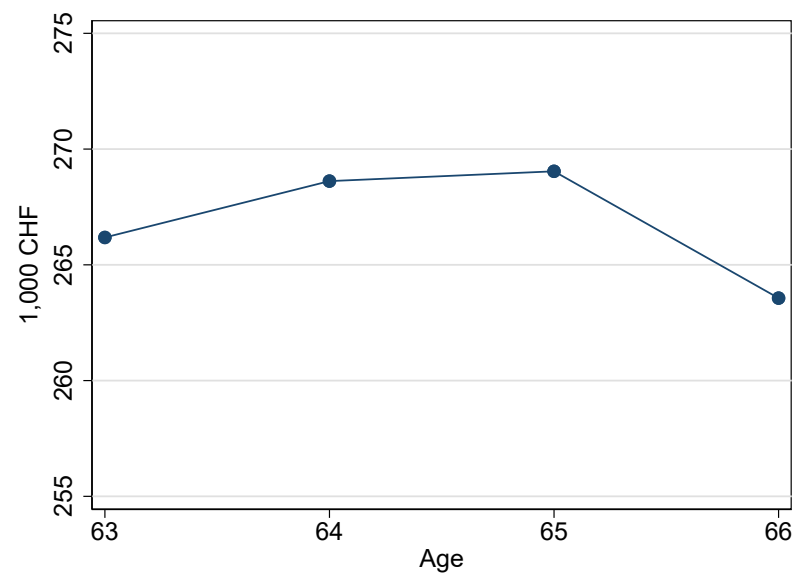

Notes: Graph (a) shows how the Swiss social security system adjusts men's old age pensions as a function of the claiming age. Base pension amount, 100, is the pension for a man claiming a pension at the FRA of 65. Graph (b) shows the discounted social security wealth as a function of the claiming age. We assume a discount factor $\beta$ of 0.98 and average death hazard.

after the reform. Men who are eligible for early claiming should therefore not change the claiming date, and consequently they also should not change the retirement date. Moreover, claiming early is an active decision: Men who want to claim early have to inform the local OASI agency at least one day before they 
reach the respective early claiming age.

We estimate the effect of the introduction of early claiming using an analogous regression discontinuity design as for women. For each reform step, we contrast the first birth cohort of men who is eligible for early claiming to the last birth cohort who is not and estimate the change in an outcome variable at the cohort boundary. We include a linear trend on either side of the cutoff and present estimates for two different bandwidths, a "local" one (20 weeks) and a "global" one (50 weeks). These bandwidths are about one and a half times larger than the bandwidths for women. The reason is that, while we observe full population of women in Switzerland, for men we only observe a $25 \%$ random sample, resulting in a smaller sample size and less precise estimates.

Figure F.19 illustrates the claiming age and the retirement age around the cohort cutoffs. We observe no change in the claiming age at the cohort cutoff for ERA63 (Figure F.19a) or ERA64 (Figure F.19b). The corresponding RD estimates, shown in the first row of Table 4 , point in the same direction: They are small and statistically insignificant for both reform steps. As Figures F.19 (c) and F.19(d) show, the retirement age also displays no visible jump at the cohort boundaries and the corresponding RD estimates are statistically insignificant (second row of Table 4 ).

The introduction of early claiming for men could potentially influence our estimates for women, for example if couples prefer to retire together. This concern is unfounded given that men do not change their claiming or retirement behavior. Moreover, as we have shown in Table B.3, the percent of women whose husband is eligible for early claiming does not change significantly at the female cohort cutoffs.

Table F.9: Effects on Pension Claiming and Retirement Age, Men

\begin{tabular}{cllllll}
\hline & \multicolumn{2}{c}{ ERA64 } & & \multicolumn{2}{c}{ ERA63 } \\
\cline { 2 - 3 } \cline { 5 - 6 } \cline { 5 - 6 } & local & global & & local & global \\
\hline Claiming age (years) & -0.028 & 0.038 & & 0.034 & 0.025 \\
& $(0.140)$ & $(0.088)$ & & $(0.144)$ & $(0.091)$ \\
Retirement age (years) & -0.141 & -0.016 & & 0.065 & 0.071 \\
& $(0.137)$ & $(0.087)$ & & $(0.144)$ & $(0.091)$ \\
No. observations & 10,792 & 27,192 & & 12,753 & 31,780 \\
Bandwidth (weeks) & 20 & 50 & & 20 & 50 \\
\hline
\end{tabular}

Notes: The table presents RD-estimates on the impact of the different reform steps on the claiming age and the retirement age. The local (global) specification uses a bandwidth of 20 (50) weeks and includes a linear trend of the running variable on either side of the cutoff. Observations are weighted using a triangular kernel. ${ }^{* * *}$ Significant at the $1 \%$ level. $* *$ Significant at the $5 \%$ level. ${ }^{*}$ Significant at the $10 \%$ level. 
Figure F.19: Claiming and Retirement Age, Men

(a) ERA64

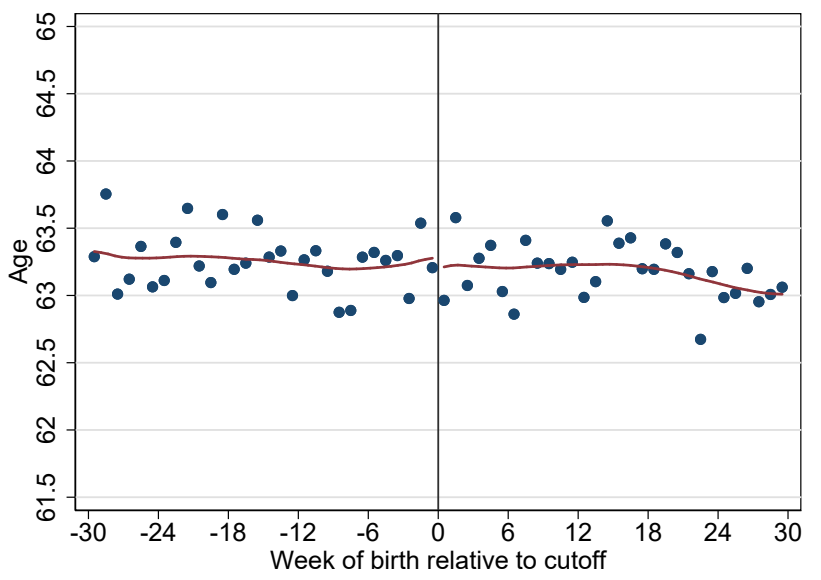

(b) ERA63

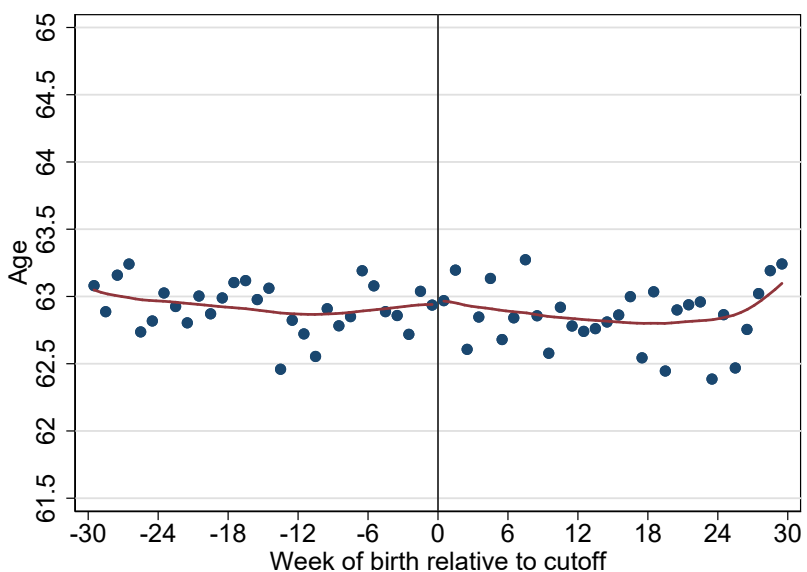

(c) ERA64

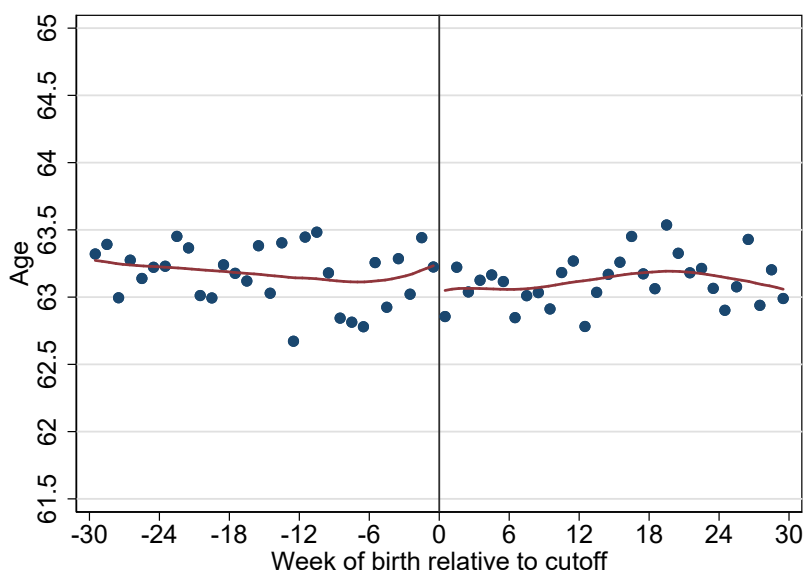

B. Retirement Age

(d) ERA63

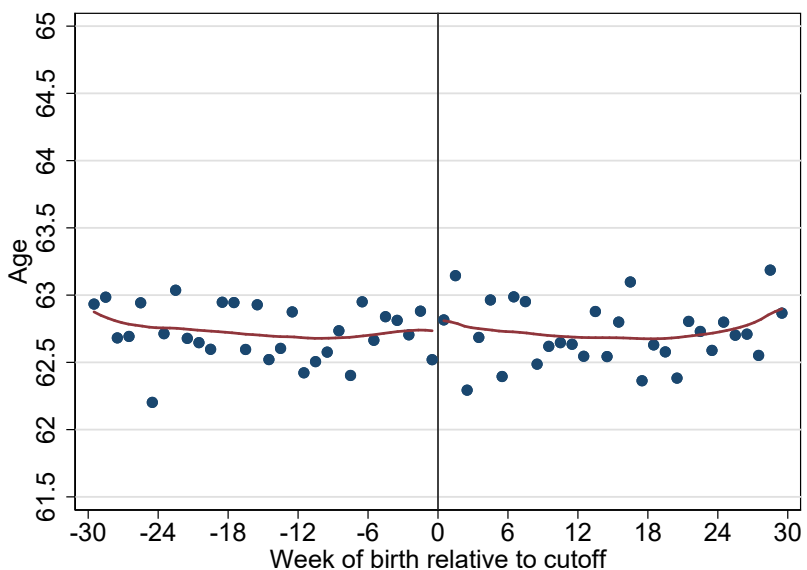

Notes: The figures show the claiming age (panel A) and the retirement age (panel B) around the cutoff separating the 1932 and 1933 birth cohorts (ERA64) and the 1937 and 1938 birth cohorts (ERA63). The solid red line plots the best local linear fit to the actual data above and below the reform cutoff. 